\title{
Brook trout bioenergetics and the use of bioelectrical impedance analysis for proximate composition
}

\author{
Marlin Keith Cox II \\ West Virginia University
}

Follow this and additional works at: https://researchrepository.wvu.edu/etd

\section{Recommended Citation}

Cox, Marlin Keith II, "Brook trout bioenergetics and the use of bioelectrical impedance analysis for proximate composition" (2004). Graduate Theses, Dissertations, and Problem Reports. 2067.

https://researchrepository.wvu.edu/etd/2067

This Dissertation is protected by copyright and/or related rights. It has been brought to you by the The Research Repository @ WVU with permission from the rights-holder(s). You are free to use this Dissertation in any way that is permitted by the copyright and related rights legislation that applies to your use. For other uses you must obtain permission from the rights-holder(s) directly, unless additional rights are indicated by a Creative Commons license in the record and/ or on the work itself. This Dissertation has been accepted for inclusion in WVU Graduate Theses, Dissertations, and Problem Reports collection by an authorized administrator of The Research Repository @ WVU.

For more information, please contact researchrepository@mail.wvu.edu. 
Brook Trout Bioenergetics and the Use of Bioelectrical Impedance Analysis for Proximate Composition

Marlin Keith Cox II

Dissertation submitted to the Davis College of Agriculture, Forestry and Consumer Sciences at West Virginia University, in partial fulfillment of the requirements

for the degree of

Doctor of Philosophy

In

Forest Resource Science

Kyle J. Hartman Ph.D.

Kenneth Blemings Ph.D.

Stuart Welsh Ph.D.

Brett Kenney Ph.D.

Patricia Mazik Ph.D.

Division of Forestry

Morgantown, West Virginia

2004

Key words: bioenergetics, brook trout, bioelectrical impedance analysis, BIA, proximate composition 


\section{ABSTRACT \\ Brook trout (Salvelinus fontinalis) Bioenergetics and the Use of Bioelectrical Impedance Analysis for Proximate Composition}

\section{Marlin K. Cox II}

Three aspects of a bioenergetics model were examined for brook trout (Salvelinus fontinalis) in the laboratory: 1) refinement of the metabolism parameter estimations, 2) calculation of activity rates and 3) subsequent validation of the brook trout model. An integral part of bioenergetics modeling is the initial inputs of predator and prey energy density from body composition estimations. We present bioelectrical impedance analysis (BIA) as a means of rapidly estimating body composition in fish and then adjusted variables that may affect these predictions. We also used this tool and applied it to a compensatory growth study. Brook trout (Salvelinus fontinalis) were randomly split into 3 groups $(\mathrm{N}=8)$ with each group having a different feeding regime (starved, compensatory or ad libitum). Changes in weight, gross growth efficiency, and body composition were measured repeatedly on individual fish using standard laboratory measures as well as bioelectrical impedance analysis (BIA) to determine if 1) compensatory growth occurred and 2 ) if the weight changes were energetic.

In 31 day bioenergetics experiments, final weights were underestimated by $4.5 \%$ $( \pm 11.06 \%, 95 \%$ confidence limits) and consumption was overestimated by $8.3 \%$ ( \pm $16.42 \%, 95 \%$ confidence limits). Bioelectrical impedance analysis models built with brook trout (Salvelinus fontinalis) were linear with strong validation group correlations $\left(\mathrm{R}^{2}>0.86\right)$ for water, protein, fat and fat-free and dry weights. Temperature affected predicted estimates of total body water, dry weight and total weight linearly, but when data was normalized by weight, the temperature term was effectively canceled out. Gutfill did not effect BIA predictions of any body composition parameter estimate while electrode placement did. Bioelectrical impedance analysis and standard compositional analysis determined that weight gains were energetic due to increases in protein, dry mass and fat, and not due to non-energetic gains (water). Furthermore, BIA found no significant differences in compositional changes between the treatment and control groups throughout the experiment. 


\section{Acknowledgements}

I would like to thank Dominion Energy for processing for analyzing caloric data. I would also like to acknowledge the WVDNR Bowden State Fish Hatchery, S. Welsh, R. Whitmore, K. Blemings, G. Seidel, and R.J. Liedtke, for laboratory analysis, equipment, advice and comments on earlier versions of this dissertation. All animal care and use was conducted in accordance with West Virginia University Animal Care and Use protocols. 
Chapter 1. Introduction ..................................................................................... 1

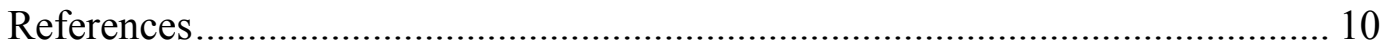

Table 1. Model equations, functions and parameters for a bioenergetics model brook trout (Salvelinus fontinalis). ........................................................ 13

Chapter 2. Refinement and testing of a brook trout bioenergetics model.............. 17

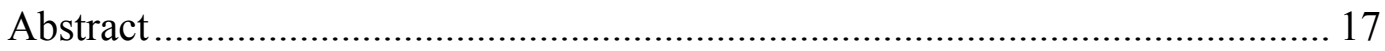

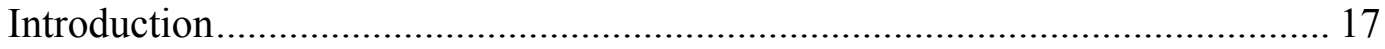

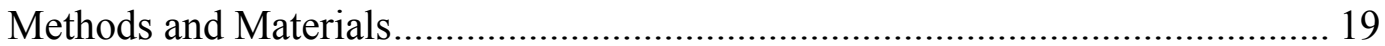

Respiration equation development with temperature and size dependence.. 20

Energy density, activity and validation..................................................... 21

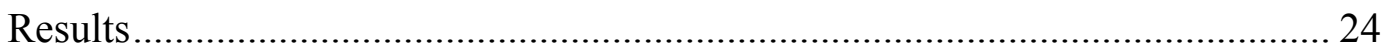

Respiration equation development with temperature and size dependence.. 24

Energy density, activity and validation....................................................... 24

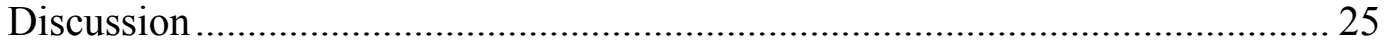

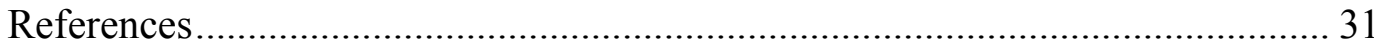

Table 2. Model equations, functions and parameters describing the brook trout model. Models for each parameter (consumption, metabolism, egestion, and excretion) are listed as well the values for each internal variable

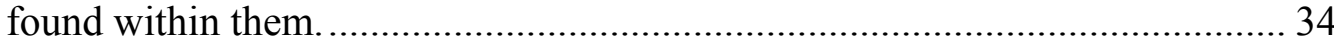

Table 3. Values of the new bioenergetics model developed in Hartman and Sweka (2001) and of the refined respiration data. ...................................... 38

Table 4. Actual and predicted total end weights (g) fitted from consumption and actual and predicted total consumption (g) fitted from end weights over a 31 day experiment calculated from individual fish in the validation group. Models were run through Fish Bioenergetics 3.1 and predicted values were compared with observed values.

Figure 1. West Virginia University cold water re-circulating tanks used for consumption and metabolism experiments. 40

Figure 2. Size dependence (A) and temperature dependence (B) of specific metabolism of brook trout at temperatures between 6 and $24^{\circ} \mathrm{C}$. In A, all data are from $20.2^{\circ} \mathrm{C}$. In $\mathrm{B}$, all data have been normalized to a $1 \mathrm{~g}$ fish by using the slope found in A. The solid line represents the fit best fit line of the model to the metabolism data. .............................................................................. 41

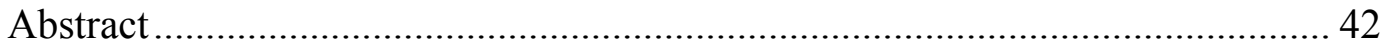

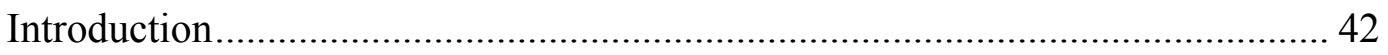

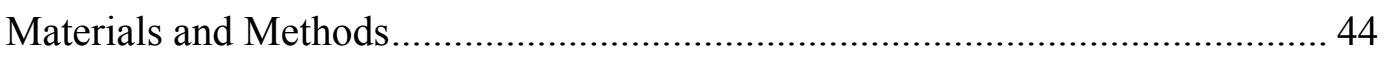

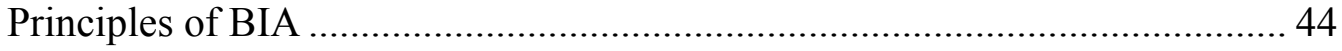




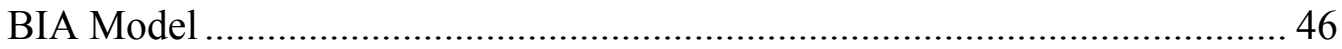

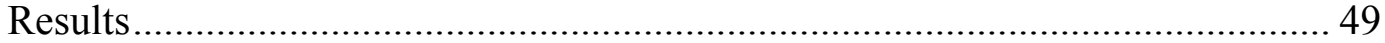

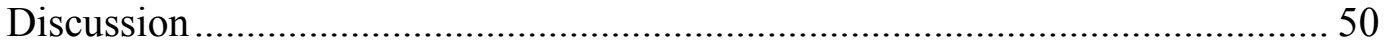

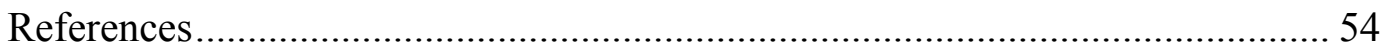

Table 5. Relationships between proximate body composition components and impedance equations for brook trout (Salvelinus fontinalis) in

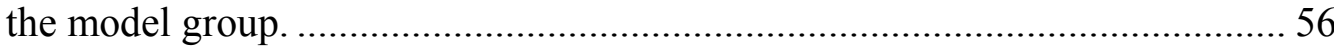

Table 6. Correlation of coefficient scores $\left(\mathrm{R}^{2}\right)$ of predicted and actual parameter values including total body water (TBW), dry weight (DW), and total weight for various warm water species (drum, gizzard shad, longear sunfish, logperch, Moxostoma. spp., rockbass, sauger, and smallmouth bass) using the brook trout BIA model.

Table 7. The number of negative responses (e.g. not swimming or feeding, bruising, bleeding, loss of color) of individual brook trout that underwent bioelectrical impedance analysis (BIA) compared to those that received no BIA analysis (control).

Figure 3. Regression analysis of predicted and actual values for the brook trout validation group $(\mathrm{n}=20)$ including total body water $(\mathrm{TBW})$, dry weight (DW), fat free mass (FFM), total body protein (TBP), total body ash (TBA), and total body fat (TBF).

Figure 4. Regression analysis of predicted and actual values for the warm water species validation group $(\mathrm{n}=81)$. Predicted values of dry weight (DW), total body water (TBW) and weight were calculated using the existing brook trout model...

Chapter 4. Field applicability of bioelectrical impedance analysis to the

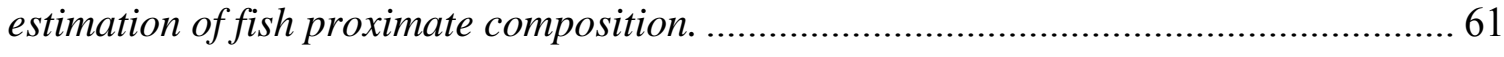

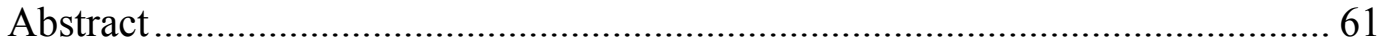

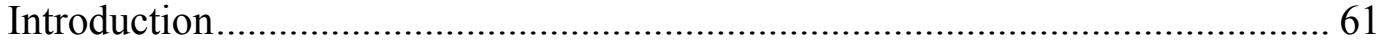

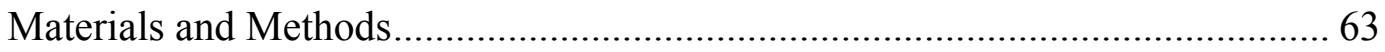

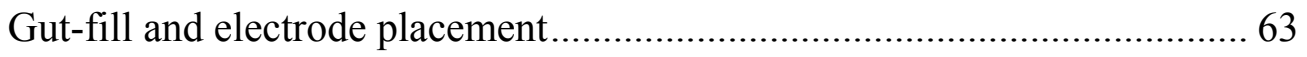

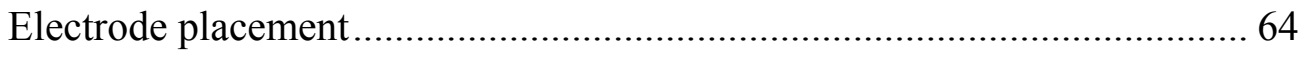

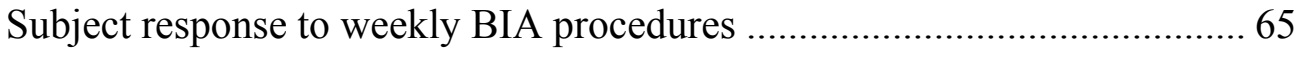

Repeated procedures and temperature ....................................................... 66

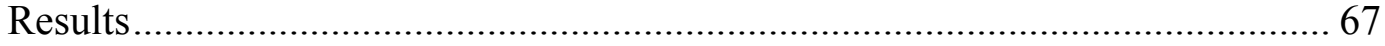

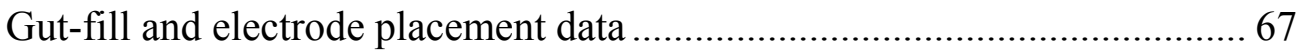

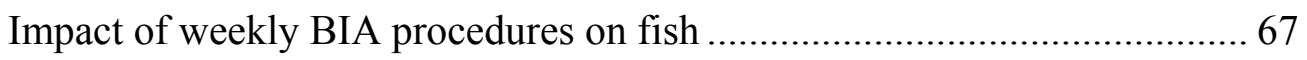

Temperature and hourly repeated procedures............................................... 67 


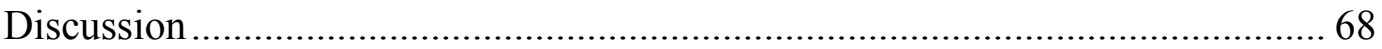

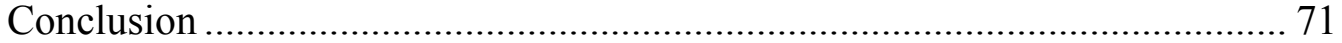

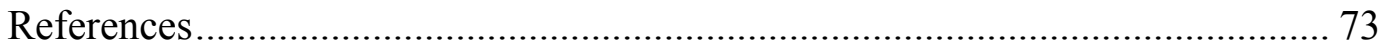

Table 8. Impedance equations developed in Chapter 3 to estimate proximate body composition in brook trout. ..................................................... 75

Table 9. Impedance equations developed in Chapter 3 to estimate proximate body composition in brook trout.

Table 10. Regression scores (correlation of coefficients) of actual and predicted values for all body composition parameters (predicted weight (WGT), total body water (TBW), dry weight (DW), fat-free mass (FFM), total body protein (TBP), total body ash (TBA) and total body fat (TBF) to compare methods from the original model (Chapter 3 ) with dorsal measurements from the validation group (A), the original model (Chapter 3) with ventral measurements from the validation group (B), and a new independent model for each parameter using ventral measures from the model group (C).

Table 11. Number of negative responses (e.g. not swimming or feeding, bruising, bleeding, loss of color) of fish receiving BIA measurements (BIA)

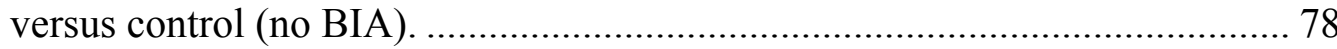

Table 12. Mean proportions ( \pm SE) of body composition compartments for each of four consecutive hourly measurements and p-values for tests within and between groups (control and treatment) for all small brook trout. 79

Table 13. Mean proportions ( \pm SE) of body composition compartments for each of four consecutive hourly measurements and p-values for tests within and between groups (control and treatment) for all large trout. 80

Figure 5. Schematic of whole and half length electrode placement locations used for evaluating BIA estimates of brook trout proximate analysis.

Figure 6. Estimated proximate composition proportions of brook trout for full and half length electrode placement with full or empty guts used in evaluating electrode placement and stomach fullness effects on estimates of proximate analysis. Different letters within a compartment indicate significant differences between total body ash (TBA), total body protein (TBP), total body fat (TBF), dry weight (DW) and total body water (TBW) (alpha $=0.05$, data was rank sum transformed prior to significance testing).

Figure 7. Linear influence of temperature upon the total weight, water weight and water proportion of brook trout at four temperatures...................... 83

Chapter 5. Compensatory growth and compositional change in brook trout

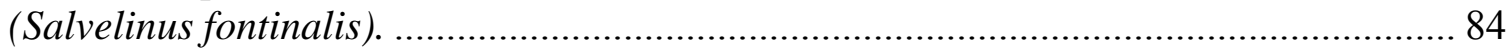

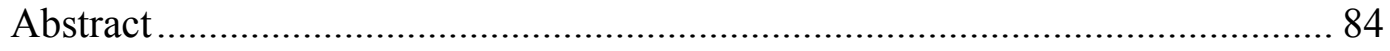

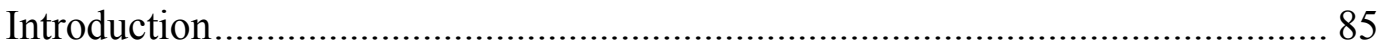




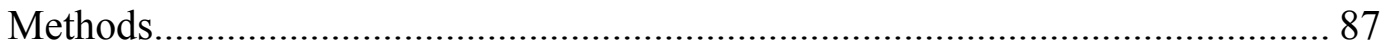

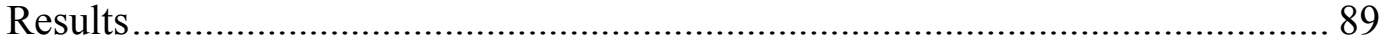

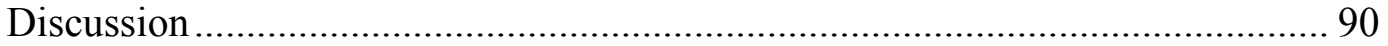

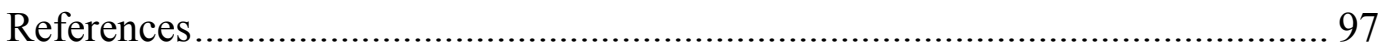

Figure 8. West Virginia University cold water re-circulating tanks used in the compensatory growth experiment........................................................ 102

Figure 9. Weekly length and weight measurements of the starved $(\mathbf{\Lambda})$, treatment $(\bullet)$ and control $(\bullet)$ groups of brook trout over 57 days $(\mathrm{N}=8$ fish per group).

Figure 10. Mean predicted and observed energy densities obtained from calculations from bioelectrical impedance analysis (BIA) predictions and laboratory results of dry weight (DW). Dry weights (observed and predicted) were then used to estimate energy densities following methods in (Hartman and Brandt 1995b).

Figure 11. Weekly body composition measurements from bioelectrical impedance analysis (BIA) starved $(\mathbf{\Lambda})$, treatment $(\bullet)$ and control $(\bullet)$ groups of brook trout over 57 days $(\mathrm{N}=8$ fish per group

Figure 12. Daily specific consumption rates (food consumed (g)/ weight fish (g) / day) of the treatment $(\bullet)$ and control $(\bullet)$ groups for the duration of the experiment $(\mathrm{N}=8$ fish per group)......................................... 106

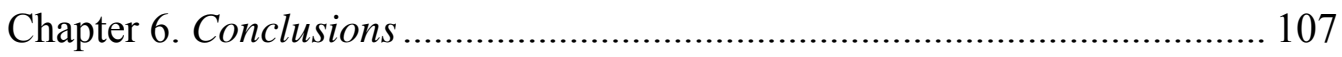

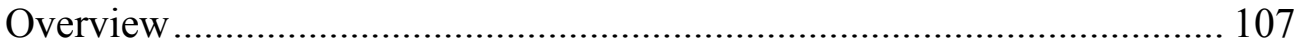

Bioenergetic model validation .................................................................... 107

Bioelectrical Impedance Analysis (BIA) …………………………….... 110

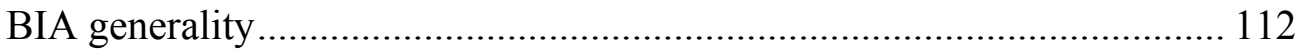

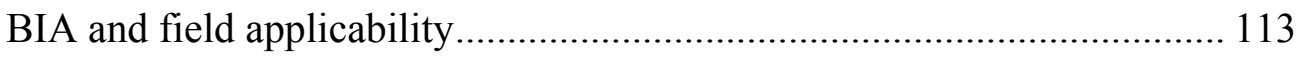

BIA and compensatory growth .............................................................. 114

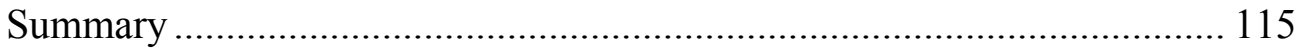

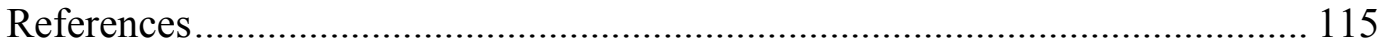




\section{Chapter 1. Introduction}

One of the fundamental processes in biological systems is the acquisition of energy and the subsequent conversions of it into maintenance, growth and reproduction (Jobling 1995). The acquired energy is first converted through a variety of transductions before it is in a usable form. These primary transductions include forming complex macromolecules from simple precursors to build electrical and chemical gradients (Lehninger et al. 1993). Once in a usable form, energy is used by organisms for producing a number of things including motion, heat and even light. Antoine Lavoisier (1743-1894) (who was also beheaded in the French Revolution) was one of the first biologists to realize that animals must somehow convert chemical fuels into heat. His experiments showed that respiration is similar to the slow combustion of carbon and hydrogen, and compared it to the reaction of a candle burning. His quote "in general, respiration is nothing but a slow combustion of carbon and hydrogen, which is entirely similar to that which occurs in a lighted lamp or candle, and that, from this point of view, animals that respire are true combustible bodies that burn and consume themselves", is one of the first explanations of bioenergetics (Lehninger et al. 1993). Presently, through biochemistry, physics and physiological biology, we have been able to grasp the mechanisms behind the transductions involved in the energy transfers within biological systems. Energy in biological systems must follow the same inherent natural laws as physical energy, and that includes the first law of thermodynamics.

The first law of thermodynamics generally states that the sum of all changes in energy must equal zero; there is no creation, destruction or net change in energy.

The equation for the first law of thermodynamics is, 


\section{(1) $\quad q+w+\ldots-U=0$}

where, $\mathrm{U}$ is total internal energy, $\mathrm{q}$ is heat flow, and $\mathrm{w}$ is work flow. Heat and work are not the only measurable forms of energy, and all others are represented by the “..." in the equation. Energy is not created or destroyed, but can be transferred. Because energy can be theoretically traced from the smallest energy particles to the largest universe wide event, any model or equation defining the transfer of energy should be able to account for all energy transfers (the sum of all parts must equal zero). Bioenergetics is the study of these energy transfers through pathways and mechanisms within and among biotic systems.

With the advent of microcomputers and models of organisms, in particular fish, bioenergetics has proliferated (Brandt and Hartman 1993). Ney (1993) found that the number of physiological parameters in bioenergetics equations can be large $(30+)$ with each having errors associated with it. To reduce error, physiological estimates within each model should be made with species specific measures that may also contain certain parameters that may have size and temperature dependence functions within them (Kitchell et al. 1977). Once all the parameters have been defined in a model, parameter estimations can be predicted. Although Ney (1993) found that it is possible to have numerous parameters, the number of parameters varies with species and is not necessarily large. An example is Winberg's (1956) bioenergetics equation that was developed for fish. The standard bioenergetics equation found there is

(2) $G=C-R-(F+U)-S D A$,

where $(\mathrm{C})$ is consumption, $(\mathrm{R})$ is respiration, $(\mathrm{F})$ is egestion, $(\mathrm{U})$ is excretion, (SDA) is specific dynamic action and $(\mathrm{G})$ is growth. 
Consumption $(\mathrm{C})$ is useful in identifying how much fish can eat and when used with other parameters can estimate potential growth (Table 1). In most poikilotherms, C is affected by water temperature and organism size and therefore has a temperature and size dependence function associated with it. Consumption varies allometrically with a weight specific exponent of -0.2 to -0.3 , and temperature effects on $\mathrm{C}$ are characterized by positive relationships until a threshold level is reached; at this point, $\mathrm{C}$ declines towards the upper lethal temperature for that species (Table 1, Hartman and Hayward, in press). Some factors that influence $\mathrm{C}$ include dissolved oxygen levels, energy content of the fish and its food, food type, the density of the fish, past feeding or condition history, and fish health. Laboratory measurements of $\mathrm{C}$ are usually taken at several water temperatures with several different sizes of fish and these measurements are in units of $g$ food consumed $\cdot \mathrm{g}$ fish ${ }^{-1} \cdot \mathrm{day}^{-1}$. The foodstuffs consumed are then allocated towards other energy sinks such as respiration, growth, or losses.

Respiration $(\mathrm{R})$ can be defined as the sum of metabolic activities taking place in an organism and is represented as standard or routine metabolism (Table 1). Because oxygen is the final electron acceptor in aerobic metabolic pathways, total metabolic rates are represented by oxygen consumption. Regardless of type of metabolism (standard or routine), each is an estimation of the relationship between oxygen use and energy expenditure. Standard metabolic rates do not include activity related costs while routine metabolism does. Specific dynamic action (SDA) represents heat lost during metabolic processes, and can be measured by taking the difference between the routine metabolic rates of fasted and fed fish. This difference is higher in herbivores because of the higher waste that is lost per unit of energy consumed. In an SDA study, Beamish (1974) studied 
largemouth bass (Micropterus salmoides) and used swimming respirometers to measure SDA of bass $(65.5 \mathrm{~g})$ while they were forced to swim at a rate of 1.7 body lengths per second at four different feeding levels (2, 4, 6 and $8 \%$ of body weight per day). He found that SDA comprised $17.2 \%$ of the total metabolized energy. Factors that influence $\mathrm{R}$ include fish size, water temperature, and activity. As with consumption, respiration varies with temperature and should be standardized using laboratory tests for metabolic rates at various temperatures (Lucas and Armstrong 1991). Two equations are used to characterize temperature dependence. The first equation depicting metabolism is represented by an exponential relationship and uses swimming speed as a function of the activity multiplier. Three different formulations of the activity multiplier can be used. The first formulation was described with largemouth bass by Rice and Cochran (1984) and holds swimming speed constant; the second was described with bloaters and uses swimming speed as a function of mass above a cutoff temperature, and the third was described with lake trout by Stewart et al. (1983) and uses swimming speed as a function of mass and water temperature below a cutoff temperature. The second equation is temperature dependent with an activity multiplier. Several studies have shown that activity rates of organisms can be a large component of bioenergetics models that are influenced by environmental and physiological factors acting on the organism (Boisclair and Leggett 1989; Madon and Culver 1993; Boisclair and Sirois 1993).

Egestion and excretion ( $\mathrm{F}$ and $\mathrm{U}$, respectively) represent the energy released back into the environment through feces and nitrogenous wastes (Table 1). These wastes are produced by the fish and released back into the environment. Egestion and excretion may vary as a function of meal size, or as a constant proportion of meal size and water 
temperature. Sensitivity analyses conducted on bioenergetics models have indicated that these parameters are relatively insensitive to error and fluctuate little between species (Bartell et al. 1986). Quantification of egestion can be done by measuring the mass and energy differential between food consumed and feces excreted and is given in $\mathrm{g} \cdot \mathrm{g}^{-1} \cdot \mathrm{d}^{-1}$. Excretion is usually measured chemically using total ammonia nitrogen concentrations per day and follows feeding at regular time intervals (Forsberg and Summerfelt 1992).

There are three equations commonly used to describe egestion and excretion for fish (Kitchell 1977, Elliot 1976, Stewart 1983). The first assumes that egestion and excretion are constant proportions of consumption and is more appropriate when the diet is either all invertebrate or all fish. The second equation incorporates water temperature, ration level and mass, and the third includes corrections for indigestible portions of the prey and is useful when the prey items shift from highly digestible (e.g. fish) to less digestible (e.g. crustaceans).

Growth $(\mathrm{G})$ is considered the ultimate expression of well being at the individual level (Table 1) (Shine and Schwarqkopf 1992; Brandt and Hartman 1993; Elliott and Hurley 1995; Elliott and Hurley 1995). The relationships between growth and consumption are fairly straightforward; the more food a fish eats, the larger it is able to grow. Growth is dependent on prey availability as an energy source and the energetic costs the fish must go through to acquire prey. Once energy has been acquired, the costs of respiration $(\mathrm{R})$, egestion $(\mathrm{F})$, excretion $(\mathrm{U})$, and specific dynamic action (SDA) must be addressed before surplus energy consumed is available for growth (Brett and Groves 1979). Actual growth reflects changes in body composition or mass of growth components (e.g. fat and protein) relative to inert (ash) or compensating (water) 
components, however; growth in most studies has been limited by the inability to accurately measure composition of growth. Since most animals are between 60-90\% water, changes in this compartment can greatly influence estimates of growth based on total weight. Bioenergetic modeling accounts for this potential variation by using energy density values (e.g. joules per gram) for both predator and prey calculations, but many studies of growth neglect to use the more specific growth indice of energy density.

Compensatory growth is an interesting phenomenon within growth biology that is observed as higher growth rates when animals are fed ad libitum following a period of nutrient deprivation when compared to an identical animal during normal feeding (Johansen et al. 2001). By achieving higher growth rates following food deprivation, compensatory growth is important to aquaculture and ecological sciences. Generally, compensatory growth responses are measured by growth and consumption rates of the organism. These rates are calculated using the live weight of the organism. Although an increase or decrease in live weight can indicate growth or atrophy changes, it does not necessarily reflect energetic changes; a change in live weight could result from nonenergetic changes such as water weights. Energy density or more specific body composition analyses would provide a better description of weight gains, but laboratory methods to acquire either compositional or energy density values are time consuming, laborious, and require sacrificing the animal.

A variety of in vivo and in vitro methods are available for assessing proximate composition in organisms but most appear to be impractical, inconvenient or costprohibitive for field or ecological work (Lukaski 1987). Proximate analysis of compartments include total body water (TBW), dry weight (DW), fat-free mass (FFM), 
total body protein (TBP), total body ash (TBA) and total body fat (TBF). Direct measurement of individual compartments using chemical analysis requires sacrificing the organism followed by lengthy laboratory procedures (AOAC 1990). This negates the ability for repeated measures on the same individual and suppresses new knowledge of compositional changes in endangered species. Total body water is a good predictor of other body composition estimations, but in vivo methods to estimate TBW involve using radioisotope tracers such as tritium, deuterium and oxygen-18. These markers are difficult to analyze outside a specialized laboratory and are also cost prohibitive (Lukaski 1987). Fat free mass can be estimated non-sacrificially by counting intracellular potassium-40 with thallium activated sodium iodide crystal detectors, but the high cost, instrumentation and technicality diminishes its practicality (Corcoran et al. 2000).

Electrical conductivity methods are non-sacrificial and include total body electrical conductivity (TOBEC) and bioelectrical impedance analysis (BIA); these methods both rely on impedance differences between fat and fat-free tissues. Lantry et al. (1999) found that the TOBEC method accurately estimates composition for healthy individuals, but errors increase when subjects are undergoing weight or compositional changes, or when subjects with dissimilar body sizes are compared (conductivity changes with body geometry and size). Furthermore, the TOBEC unit is large and non-portable, making field use impractical. BIA is available in an inexpensive, small, portable unit that has provided accurate and reliable estimations of water mass in humans, but similar to TOBEC, complex body geometries tend to decrease the accuracy of the composition estimations. However, we hypothesize that if BIA technology is applied to organisms with a more simplified body geometry (majority of the mass located in a single volume), 
accuracy of measurements would not be lost and proximate composition estimations could accurately and non-lethally be made in lab and field. Furthermore, because of the generality of electrical resistivity laws across various mediums, models for fish should not be species specific.

The nature of electrical resistivity suggests that electrical flow follows the same inherent laws throughout various conductive medias; nevertheless, it is affected by other variables such as temperature. Bioelectrical impedance analysis under controlled conditions may accurately estimate body composition in fish, but effects of diet, temperature, and electrode placement on individual parameter estimations are unknown. Initial measurements using BIA should be conducted in the laboratory under controlled conditions to minimize error caused by other variables (e.g. temperature, fish stomach fullness, varying electrode placement etc.). To be used as an applicable biological tool, accuracy of measurements must be assessed under strict laboratory control.

A non-invasive method of accurately estimating energy density and body composition would benefit bioenergetic modeling and the study of fish condition and growth. Bioenergetic models in fisheries have been widely used, but information on energy densities of predators and prey has been limiting (Hartman and Brandt 1995). Hartman and Brandt (1995) regressed energy density and percent dry weight, and showed a strong positive relationship between the two, but this method still requires sacrificing the organism. A non-lethal means of estimating dry weight that could also estimate energy density would be a valuable tool in future bioenergetics modeling. A current method of analyzing fish condition uses the ratio of relative length to weight to determine rotundness; but rotundness does not always increase with the health of the fish. Where 
and how energy from food is stored and used may provide valuable information to characterize energetics and condition of fish. A quick reliable method for estimating proximate body composition is needed for bioenergetic modeling, and for assessing health and condition of fish. Furthermore, to establish an ideal method in fisheries biology, it should be simple to use, applicable under various conditions, non-lethal and general enough to apply to several species of fish. 


\section{References}

AOAC 1990. Official Methods of Analysis. Association of Official Analytical Chemists, Washington, DC.

Bartell, S.M., Breck, J.E., Gardner, R.H., and Brenkert, A.L. 1986. Individual parameter perturbation and error analysis of fish bioenergetics models. Can. J. Fish. Aq. Sci. 43: $160-168$.

Beamish, F.W.H. 1974. Apparent specific dynamic action of largemouth bass, Micropterus salmoides. J. Fish. Res. Board Can. 31: 1763-1769.

Boisclair, D. and Leggett, W.C. 1989. The importance of activity in bioenergetics models applied to actively foraging fishes. Can. J. Fish. Aq. Sci. 46: 1859-1867.

Boisclair, D. and Sirois, P. 1993. Testing assumptions of fish bioenergetics models by direct estimation of growth, consumption, and activity rates. Trans. Am. Fish. Soc. 122: 784-796.

Brandt, S.B. and Hartman, K.J. 1993. Innovative approaches with bioenergetics models: Future applications to fish ecology and management. Trans. Am. Fish. Soc. 122: 731-735.

Brett, J.R. and Groves, T.D.D. 1979. Physiological energetics. In Fish physiology. Edited by W.S. Hoar, D.J. Randall, and J.R. Grett. Academic Press, New York pp. 279352.

Corcoran, C., Anderson, E.J., Burrows, B., Stanley, T., Walsh, M., Poulos, A.M., and Grinspoon, S. 2000. Comparison of total body potassium with other techniques for measuring lean body mass in men and women with AIDS wasting. Am. J. 
Clin. Nutr. 72: 1053-1058.

Elliott, J.M. and Hurley, M.A. 1995. The functional relationship between body size and growth rate in fish. Funct. Ecol. 9: 625-627.

Forsberg, J.A. and Summerfelt, R.C. 1992. Effect of temperature on diel ammonia excretion of fingerling walleye. Aqua. 102: 115-126.

Hartman, K.J. and Brandt, S.B. 1995. Estimating energy density of fish. Trans. Am. Fish. Soc. 124: 347-355.

Jobling, M. 1995. Environmental Biology of Fishes. Chapman and Hall, London.

Johansen, S.S., Ekli, M., Stangnes, B., and Jobling, M. 2001. Weight gain and lipid deposition in Atlantic salmon, Salmo salar, during compensatory growth: evidence for lipostatic regulation? Aqua. Res. 32: 963-974.

Kitchell, J.F., Stewart, D.J., and Weininger, D. 1977. Applications of a bioenergetics model to yellow perch (Perca flavescens) and walleye (Stizostedion vitreum vitreum). J. Fish. Res. Brd. Can. 1922-1935.

Lantry, B.F., Stewart, D.J., Rand, P.S., and Mills, E.L. 1999. Evaluation of total-body electrical conductivity to estimate whole-body water content of yellow perch, Perca flavescens, and alewife, Alosa pseudoharengus. Fish. Bull. 97: 71-79.

Lehninger, A., D. Nelson, and M. Cox 1993. Principles of Biochemistry. Worth, New York.

Lucas, M.C. and Armstrong, J.D. 1991. Estimation of meal energy intake from heart rate records of pike, Esox lucius L. J. Fish. Biol. 38: 317-319.

Lukaski, H.C. 1987. Methods for the assessment of human body composition: traditional and new. Am. J. Clin. Nutr. 46: 537-556. 
Madon, S.P. and Culver, D.A. 1993. Bioenergetics model for larval and juvenile walleyes: an in situ approach with experimental ponds. Trans. Am. Fish. Soc. 122: $797-813$.

Ney, J.J. 1993. Bioenergetics modeling today: Growing pains on the cutting edge. Trans. Am. Fish. Soc. 122: 736-748.

Rice, J.A. and Cochran, P.A. 1984. Independent evaluation of a bioenergetics model for largemouth bass. Ecol. 65: 732-739.

Shine, R. and Schwarqkopf, L. 1992. The evolution of reproductive effort in lizards and snakes. Evol. 46: 62-75.

Stewart, D.J., Weininger, D., Rottiers, D.V., and Edsall, T.A. 1983. An energetics model for lake trout, Salvelinus namaycush : Application to the Lake Michigan population. Can. J. Fish. Aq. Sci. 40: 681-698.

Winberg, G.G. 1956. Rate of metabolism and food requirements of fishes. Fish. Res. Board Can. Trans. Series . 194:1-202. 
Table 1. Model equations, functions and parameters for a bioenergetics model brook trout (Salvelinus fontinalis).

\section{Consumption Model}

The consumption model equations for temperature dependence for cool and cold water species are defined here. Model form is,

$$
C=C_{\max } \mathrm{f}(t)
$$

where:

$\mathrm{C}$ is the specific consumption rate $\left(\mathrm{g} \cdot \mathrm{g}^{-1} \cdot \mathrm{d}^{-1}\right)$;

$p$ is the proportionality constant having values of 0 to 1.0 , used to adjust ration when fitting an observed growth curve,or is the proportion of maximum consumption. Where 1.0 is the maximum feeding rate and 0 represents no feeding (this is based on the fish size and the water temperature);

$\mathrm{C}_{\max }$ is the maximum weight specific ration $\left(\mathrm{g} \cdot \mathrm{g}^{-1} \cdot \mathrm{d}^{-1}\right)$ at the optimum temperature $\left(\mathrm{T}_{0}\right)$ and is represented by the model:

$$
C_{\max }=C A \cdot W^{C B}
$$

where:

$\mathrm{CA}$ is the intercept of the allometric mass function;

$\mathrm{CB}$ is the slope of the allometric mass function;

$\mathrm{W}$ is the fish mass $(\mathrm{g})$;

$f(T)$ is the temperature-dependent proportional function and is represented by the model: 


$$
f(T)=K_{A}\left(K_{B}\right) ;
$$

where:

$$
\begin{aligned}
& \mathrm{K}_{\mathrm{A}}=(\mathrm{CK} 1 * \mathrm{~L} 1) /(1+\mathrm{CK} 1 *(\mathrm{~L} 1-1)), \\
& \mathrm{L} 1=\mathrm{e}^{(\mathrm{G} 1(\mathrm{~T}-\mathrm{CQ}))}, \\
& \mathrm{G} 1=(1 /(\mathrm{CTO}-\mathrm{CQ})) \ln ((0.98(1-\mathrm{CK} 1)) /(\mathrm{CK} 1 * 0.02)), \\
& \mathrm{K}_{\mathrm{B}}=(\mathrm{CK} 4 * \mathrm{~L} 2) /(1+\mathrm{CK} 4 *(\mathrm{~L} 2-1)), \\
& \mathrm{L} 2=\mathrm{e}^{(\mathrm{G} 2(\mathrm{CTL}-\mathrm{T}))}, \text { and } \\
& \mathrm{G} 2=(1 /(\mathrm{CTL}-\mathrm{CTM})) \ln ((0.98(1-\mathrm{CK} 4)) /(\mathrm{CK} 4 * 0.02)) .
\end{aligned}
$$

$\mathrm{CQ}$ is the lower water temperature at which the temperature dependence is a small fraction (CK1) of the maximum consumption rate and $\mathrm{CTO}$ is the water temperature corresponding to 0.98 of the maximum consumption rate.

$\mathrm{CTM}$ is the water temperature $(>\mathrm{CTO})$ at which temperature is still 0.98 of the maximum rate and CTL is the temperature where dependence is a fraction (CK4) of the maximum.

\section{$\underline{\text { Respiration Model }}$}

The respiration model equations for temperature dependence for cool and cold water are defined here.

Model form is:

$$
\begin{gathered}
R=R A \cdot W^{R B} \cdot f(T) \cdot A C T \\
S=S D A \cdot(C-F)
\end{gathered}
$$

where:

$\mathrm{R}$ is the specific rate of respiration $\left(\mathrm{g} \cdot \mathrm{g}^{-1} \cdot \mathrm{d}^{-1}\right)$;

$\mathrm{W}$ is fish mass (g); 
RA is the intercept of the allometric mass function $\left(g \cdot \mathrm{g}^{-1} \cdot \mathrm{d}^{-1}\right)$;

$\mathrm{RB}$ is the slope of the allometric mass function;

$\mathrm{T}$ is water temperature $(\mathrm{C})$;

ACT is the activity multiplier;

$\mathrm{S}$ is the proportion of assimilated energy lost to SDA;

SDA is the specific dynamic action;

$\mathrm{C}$ is the specific consumption rate $\left(\mathrm{g} \cdot \mathrm{g}^{-1} \cdot \mathrm{d}^{-1}\right)$;

$F$ is the specific egestion rate $\left(g \cdot g^{-1} \cdot d^{-1}\right)$;

$f(T)$ is the function for temperature of the dependence function and is represented

by:

$$
f(T)=V^{X} \cdot e^{(x \cdot(1-V))}
$$

\section{$A C T I V I T Y=A C T$}

where:

$\mathrm{V}=(\mathrm{RTM}-\mathrm{T}) /(\mathrm{RTM}-\mathrm{RTO})$

$\mathrm{X}=\left(\mathrm{Z}^{2} \cdot\left(1+(1+40 / \mathrm{Y})^{0.5}\right)^{2}\right) / 400$;

$\mathrm{Z}=\mathrm{LN}(\mathrm{RQ}) \cdot(\mathrm{RTM}-\mathrm{RTO})$

$\mathrm{Y}=\mathrm{LN}(\mathrm{RQ}) \cdot(\mathrm{RTM}-\mathrm{RTO}+2)$

RTO is the optimum temperature for respiration (C);

RTM is the highest lethal water temperature (C);

RQ approximates the Q10 (the rate at which the function increases over relatively low water temperature);

RA is the number of grams of oxygen consumed by a 1 gram fish at RTO;

$\mathrm{RB}$ is the slope of the allometric mass function for standard metabolism; 
$\mathrm{ACT}$ is a constant that is multiplied by the resting metabolism; sometimes referred to as the "Winberg multiplier".

\section{$\underline{\text { Egestion and excretion models }}$}

Egestion and Excretion equations are represented here.

Model form is:

$$
\begin{gathered}
F=F A \cdot T^{F B} \cdot e^{(F G \cdot p)} \cdot C \\
U=U A \cdot T^{U B} \cdot e^{(U G \cdot p)} \cdot(C-F)
\end{gathered}
$$

where:

$\mathrm{F}$ is the egestion rate $(\mathrm{g} \cdot \mathrm{g}-1 \cdot \mathrm{d}-1)$;

$\mathrm{U}$ is the excretion rate $(\mathrm{g} \cdot \mathrm{g}-1 \cdot \mathrm{d}-1)$;

FA is the intercept of the proportion of consumed energy egested versus water temperature and ration;

UA is similarily defined as FA except for excretion;

FB is the coefficient of water temperature dependence of egestion;

FG is the coefficient for feeding level dependence (P-value) of egestion;

*UA, UB and UG can be similarly defined for excretion. 
Chapter 2. Refinement and testing of a brook trout bioenergetics model

\author{
Abstract \\ The use of bioenergetics models is becoming an important tool in fisheries \\ biology with fieldwork conducted on a multitude of species. Prior to field applications of \\ such models, bioenergetics models should be validated under controlled environments \\ both in the lab and in the field with species-specific variables. Three aspects of a \\ bioenergetics model were examined for brook trout (Salvelinus fontinalis): 1) refinement \\ of the metabolism parameter estimations, 2) calculation of activity rates and 3) \\ subsequent validation of the brook trout model. Carefully controlled laboratory \\ experiments were used to balance the energy budget with known values through the \\ activity multiplier. Brook trout metabolic rates increased with temperature and activity \\ rates were variable $($ mean $=1.91 \pm 0.717$ s.d. $)$. Thirty-one day validation experiments \\ conducted at $16^{\circ} \mathrm{C}$ showed final weights were underestimated by $4.5 \%( \pm 11.06 \%, 95 \%$ \\ confidence limits) and consumption was overestimated by $8.3 \%( \pm 16.42 \%, 95 \%$ \\ confidence limits).
}

\title{
Introduction
}

The study of bioenergetics can involve large numbers of physiological parameters $(12-30+)$ with each parameter estimate having errors associated with it (Ney 1993). To reduce error, each model should be parameterized with species-specific physiological rates including consumption, growth, respiration, egestion and excretion. Once all the parameters have been defined in a model, knowledge of these parameters can be used to solve for a single unknown parameter due to the balanced nature of the models. Certain 
parameters such as growth and consumption are size and temperature dependent, and therefore have temperature and weight functions within each parameter to compensate for changes in these variables (Kitchell et al. 1977). Because of the first law of thermodynamics, we know that the energy equation is balanced. By developing models in a laboratory setting and mimicking natural temperature variation, parameters may be defined and provide a means to accurately model fish bioenergetics.

Brook trout (Salvelinus fontinalis) occupy headwater stream systems that are susceptible to variations in flow, diet, temperature and water quality. However brook trout have been shown to out compete other species of trout especially at higher water temperatures (De Staso III and Rahel 1994), suggesting that brook trout are more tolerant of heat stress than other trout. De Staso III and Rahel (1994) found that brook trout were clearly out competing cutthroat trout (Oncorhynchus clarki) by consuming more food, being more aggressive and occupying the lead position in a dominance hierarchy. The life history of brook trout indicates that they would be a good species for bioenergetics work.

Brandt and Hartman (1993) suggested a three-tiered approach to bioenergetics model testing following the development of a bioenergetics model. First model validations of the physiological measurements should be performed in the laboratory. Secondly, model accuracy should be examined under controlled environments in the field. Lastly, accuracy of the output from bioenergetics models must be examined with other sources of error in mind. When Hartman and Sweka (2001) developed preliminary bioenergetics models for brook trout, a possible error was found within one of the parameters. Initially, metabolic parameter estimations increased with temperature as 
expected, but at a higher temperature $\left(16.5^{\circ} \mathrm{C}\right)$, metabolic rates decreased rapidly. This did not fit a standard metabolic curve rate and results from further experimentation by Sweka et al. (2004) determined that gastric evacuation rates were lower than expected and error in metabolism measures at lower temperatures may have been due to the capture of some component of specific dynamic action (SDA) due to incomplete evacuation of stomach contents. Due to this inconsistency, refinement of the respiration equation is needed. Furthermore, additional experiments are needed to estimate activity multipliers for these trout. Because initial and final energy densities estimations from the predator as well as the energy densities of the prey are necessary in order to measure energetic transfers, these measures along with parameters previously measured in Hartman and Sweka (2001) should be measured and used to validate the bioenergetics brook trout model. Model estimations of egestion, excretion, and consumption from a previously developed brook trout bioenergetics model by Hartman and Sweka (2001) did not contain errors and needed no further work.

The objective of this paper is to improve the brook trout model presented by Hartman and Sweka (2001) by 1) refining metabolism parameters within the respiration equation, 2) estimating activity (ACT) rates, and 3 ) to validate the model.

\section{Methods and Materials}

Brook trout used in the following experiments were obtained from the Bowden State fish hatchery, Bowden, West Virginia. Approximately 100 fish were maintained as stock in a living stream tank at West Virginia University for as long as six months at approximately $16^{\circ} \mathrm{C}$ and were fed standard hatchery pellets at a rate of $<3 \% \cdot$ body weight $^{-1} \cdot \mathrm{d}^{-1}$ until used in experiments. 


\section{Respiration equation development with temperature and size}

\section{dependence}

\section{Temperature}

Respiration (R) was measured at four temperatures $\left(6.3,11.3,15.5\right.$, and $\left.20.2^{\circ} \mathrm{C}\right)$ with 3 size classes of fish, small $(n=10$, mean $=10.5 \mathrm{~g} ;)$, medium $(n=6$, mean $=39.7 \mathrm{~g})$ and large $(\mathrm{n}=6$, mean $=220.8 \mathrm{~g})$. All 22 fish were acclimated to each test temperature for at least 1 week with food being withheld for $72 \mathrm{~h}$ prior to the start of the experiment to eliminate any specific dynamic action that may have resulted from foodstuffs in the gut. Prior to the start of a metabolism experiment, fish were anesthetized in a tricane methanesulfonate (MS-222) solution of $1 \mathrm{~g} \cdot 91$ water $^{-1}$, weighed to the nearest $0.01 \mathrm{~g}$ and placed in individual respiration chambers. Fish were acclimated to the uncovered chambers for $24 \mathrm{~h}$ during which time water was allowed to overflow into the container and back into large $2 \times 3 \mathrm{~m}$ tanks. Chambers for the small fish were 3.01 Fernback flasks while medium and large fish were placed into 11.851 plastic Tupperware bowls. The chambers were made to be airtight by using rubber stoppers and lids (petroleum jelly was smeared on the inside edges of the Tupperware lids to ensure that they were airtight). Water was allowed to pour over the tops of the containers where it was then gravity fed, re-chilled in a head tank and re-pumped back into the tanks (Figure 1). The Fernback flasks were covered in black plastic and the bowls were non-transparent to eliminate visual stimuli from outside the container. Experiments began by filling the container full of water, measuring the dissolved oxygen concentration in each container with a YSI model 58 meter (air calibrated at the beginning of each day) and sealing the container. Fish were allowed to respire in the container until dissolved oxygen concentrations had 
dropped by at least $1 \mathrm{mg} \cdot 1^{-1}$. The time required to achieve this decline in dissolved oxygen concentration varied with temperature, but preliminary experiments determined that time ranged from 0.5 to $3.5 \mathrm{~h}$ with time increasing at colder temperatures.

Three measurements were made for each fish during the next $24 \mathrm{~h}$, and the average of the three measurements were used. Respiration data from a fifth temperature $\left(23^{\circ} \mathrm{C}\right)$ was obtained from Hartman and Sweka (2001). These data were graphed with $\mathrm{J} \cdot \mathrm{J}^{-1} \cdot \mathrm{d}^{-1}$ as the dependent variable and temperature as the independent variable. The temperature associated with the highest respiration was then used to determine size dependence and also represents RTO (optimum temperature for respiration) in the respiration model.

\section{Size-dependence}

The respiration data measured at $20.2^{\circ} \mathrm{C}$ was used to determine size-dependence of respiration rates. All fish data in all 3 size classes were normalized to 1g. Oxygen consumption estimates were converted into energy units by using the 13,556 joules $\cdot \mathrm{g}$ $\mathrm{O}_{2}^{-1}$ as the oxycalorific equivalent (Brett 1973), and graphed as with $\mathrm{J} \cdot \mathrm{g}$ fish ${ }^{-1}$ as the dependent variable and wet weight as the independent variable. The slope and yintercept were then used as RB and RA within the respiration equation.

\section{Energy density, activity and validation}

Eighteen brook trout $(182.5 \pm 9.9 \mathrm{~mm}$, and $51.4 \pm 8.7 \mathrm{~g}$, s.d. $)$ were randomly selected and used to determine energy density and activity, and also to validate the bioenergetics model. Fish were needed to estimate initial energy density in experiments aimed at estimating activity rates and other experiments to validate the model.

\section{Energy density}


Six brook trout were randomly sub-sampled from the 18 brook trout (hereinafter referred to as the "energy density group) anesthetized with MS-222, sacrificed and dried to establish energy content from percent dry weight using the lake trout (Salvelinus namaycush) equation $\left(\mathrm{J}_{\mathrm{g}} \mathrm{g}^{-1}=-3809+(397.9 *\right.$ percent dry weight $)$ developed by Hartman and Brandt (1995). All sacrificed fish were submerged in a concentrated MS-222 solution (2.0g MS-222 · 91 water $\left.^{-1}\right)$ immediately after anesthesia until buccal pump activity ceased. Fish were then weighed to the nearest $0.01 \mathrm{~g}$ and oven dried at $80.0^{\circ} \mathrm{C}$ to a constant weight to provide the percent dry weight information needed to estimate initial energy densities using the equation from Hartman and Brandt (1995).

\section{Activity}

Six fish were randomly selected from the 12 remaining fish and fed wax worms (larvae of Galleria mellonella) at a rate of $10 \%$ body weight every two days for $21 \mathrm{~d}$ and data including changes in mass, energy content, consumption levels and thermal history were used to estimate the activity multipliers needed to balance the bioenergetics models. Experiments took place in individual 331 aquaria that were submerged in large recirculating tanks as above. To determine changes in mass, fish were anesthetized with the MS-222 for initial and final weights. Changes in energy density were determined by the difference between initial and final energy densities. Initial energy densities were obtained from the "energy density" fish. Final energy densities were obtained by sacrificing the fish after $21 \mathrm{~d}$ and following methods to calculate energy density following Hartman and Brandt (1995) (see above). Consumption rates were calculated by recording food items consumed by each fish. A temperature logger was used to measure water temperature readings every $2 \mathrm{~h}$. All these values were inserted within the 
bioenergetics model and the activity multiplier (found within the respiration equation) was adjusted to balance the bioenergetics equation $(\mathrm{G}=\mathrm{C}-\mathrm{R}-\mathrm{F}-\mathrm{U}-\mathrm{SDA})$.

\section{Validation}

A longer series of similar experiments was then used to validate the derived bioenergetics model for brook trout. The remaining six fish (hereinafter referred to as the "validation group") were placed in individual 331 aquaria and fed wax worm larvae at the same rates described above. Thirty-one days later the fish were anesthetized, measured for length and weight and sacrificed. The 6 fish were dried and the resulting percent dry weight information was used to estimate energy density at the end of the experiment for the model validation group. Weight was measured to the nearest $0.01 \mathrm{~g}$ and represented the difference between start and final weights of each individual fish. To measure consumption, larvae were weighed to the nearest $0.0001 \mathrm{~g}$ prior to feeding and every 48 hours, the number of larva left in each tank were enumerated and subtracted from the initial number placed in the tank and removed. Consumption was calculated and reported as the sum of larvae $(\mathrm{g})$ introduced to the tank - sum of larvae $(\mathrm{g})$ removed from the tank. Time period for the validation group measurements was $31 \mathrm{~d}$. Initial energy densities were obtained from the "energy density" fish.

For calculations to estimate activity multipliers and in model validation calculations, the average energy density value from the "energy density" fish was used for initial predator energy density values. Final predator energy density values were obtained from each individual estimate from the sacrificed fish in the "activity" and "validation" groups. Because the food item was wax worm larvae and energy densities can change with instars, larvae were ordered in bulk and immediately frozen upon arrival. 
To determine energy densities of the wax worm larvae, a random $35 \mathrm{~g}$ sample was oven dried at $80^{\circ} \mathrm{C}$ and pulverized with a mortar and pestle until homogenous. Energy content of the larvae was obtained from bomb calorimetry on three $1 \mathrm{~g}$ samples of the homogenous mix by the energy department at Dominion Energy in a $1 \mathrm{~g}$ microbomb processor. The mean energy density of larvae was used in all estimates of ACT and in model validations to convert mass consumed into energy consumed by fish. To validate the model, "validation group" predicted values calculated from Fish Bioenergetics for growth and consumption were compared with actual values of growth (from $\mathrm{C}$ ) and consumption (from $\mathrm{G}$ ) observed in the experiment. Percent error was used to determine differences between laboratory and predicted values of growth and consumption.

\section{Results}

\section{Respiration equation development with temperature and size}

\section{dependence}

\section{Temperature and size dependence}

Metabolic rates $\left(\mathrm{J} \cdot \mathrm{J}^{-1} \cdot \mathrm{d}^{-1}\right)$ increased with temperature and declined with fish size (). Size dependence of respiration was evaluated at the optimum temperature of $20.2 \mathrm{C}$ (Figure 2). The model describing size-dependence was:

$$
\operatorname{Metabolism}\left(\mathrm{J} \cdot \mathrm{J}^{-1} \cdot \mathrm{d}^{-1}\right)=0.0236 \mathrm{~W}^{-0.2242}
$$

where $\mathrm{W}$ is the wet weight of the fish. This model was significant and explained $59 \%$ of the variability (). Revised input parameters for the respiration equation were: RA $=0.0236, \mathrm{RB}=-0.2242, \mathrm{RQ}=2.6, \mathrm{RTO}=20.2, \mathrm{RTM}=25$, and $\mathrm{SDA}=0.172$.

\section{Energy density, activity and validation}


Initial trout energy densities were $4161.9 \mathrm{~J} \cdot \mathrm{g}^{-1}$ wet weight $\pm 474.27 \mathrm{~J} \cdot \mathrm{g}^{-1}$ wet weight (s.d.). Energy density of the prey was $10870.83 \mathrm{~J} \cdot \mathrm{g}^{-1}$ wet weight $\pm 53.23 \mathrm{~J} \cdot \mathrm{g}^{-1}$ wet weight (s.d.).

Activity rates were calculated by inserted values into the bioenergetics models and the activity rate of each of the 6 fish was adjusted to balance the equations. The mean activity rate for all 6 fish was found to be $1.9132 \pm 0.717$ (s.d.).

Validation experiments found that model estimations of final weights were underestimated by $-4.5 \% \pm 11.06 \%$, (95\% C.I.) (Table 4). Consumption rates were overestimated by an average of $8.3 \% \pm 16.42 \%$ (95\% C.I.) (Table 4$)$.

\section{Discussion}

The validation of the brook trout model consisting of six replicates over 31 days demonstrated that the model presented by Hartman and Sweka (2001) along with the revised metabolism data does a good job of estimating final weights and consumption. The new model presented in this study confirm that the brook trout bioenergetics model is a robust tool for estimating the consumption and growth by brook trout in a laboratory setting. Model estimations of final weights were underestimated by $4.5 \%$ and consumption was overestimated by $8.3 \%$. Model predictions found in Hartman and Sweka (2001) for growth and consumption were underestimated by $1.4 \%( \pm 11.4 \%)$ and $19.7 \%( \pm 7.5 \%)$, respectively, and consumption predictions were improved with the refined metabolism parameters.

The refined respiration values represented a higher respiration rate than those found in Hartman and Sweka (2001). Changes in values from Hartman and Sweka (2001) were as follows: RA (0.0085 to 0.0236$), \mathrm{RB}(-0.223$ to -0.2242$)$, RQ (5.5 to 2.6), 
RTO (22 to 20.2), and ACT (1 to 1.9). Values within the respiration equation, RA, RQ and ACT, changed by almost a factor of two reflecting higher respiration rates than those found in Hartman and Sweka (2001). The increase in RA shows that more oxygen is consumed per gram of fish at RTO and the decrease in RQ shows the rate of respiration increases at lower temperatures. If respiration and activity is higher, more energy must be allocated towards this compartment than previously thought. This would explain the shift from underestimated consumption predictions found in Hartman and Sweka (2001) to the overestimated ones in this study. The values RTM and RB did not change significantly. RTO decreased slightly, but did not have much of an effect on the validation group at $15^{\circ} \mathrm{C}$.

Ney (1993) points out that the simplest approach to determining activity rates originated with Winberg (1956) where a multiplicative integer ranging from 1 (no energy expended) to 3 is integrated into standard metabolism. Problems have been identified using this simple method, and although this method has been found to be problematic, it has continued to remain the mainstay in bioenergetics model development (Ney 1993; Hansen et al. 1993; Boisclair and Leggett 1989; Hewett and Kraft 1993; Mehner and Wieser 1994; Boisclair 1992; Boisclair and Sirois 1993). For example, Minton and McLean (1982) found a good fit between observed and predicted values of growth during summer months but overestimations occurred in winter attributed to a poor fit of the activity multiplier. It would seem that activity rates could be sub-sampled from the population, but studies including this one have shown that variation between individuals can range up to two-fold. Boisclair and Leggett (1989) rearranged bioenergetics equations and found that activity was extremely variable among individual yellow perch, 
ranging from 1 to 3 times the energy expended. In the experiments presented here, certain fish seemed to be more active than others, but this was not a measurable observation within this study. When we rearranged the equations as Boisclair and Leggett (1989), we found that variability between the fish in the activity group ranged from 1.3 to 2.9. Although this could have been due to fish swimming around in the aquaria at different rates and for different periods of time, this variability could also be due to errors in all other model terms that are corrected for in the estimate of ACT. By forcing the model to balance thru fitting ACT, errors in all cost parameters and variability in initial energy densities of fish are summed into the activity multiplier. However, despite these sources of variability and uncertainty, the brook trout model appeared robust.

The extrapolation of allometric functions have also been identified as a source of bias or error (Hansen et al. 1993). Bartell et al.(1986) found that biases in the power functions explaining consumption and metabolism with weight are responsible for the largest errors found in bioenergetics models. These errors may be due to the extrapolation of laboratory based data to field modeling. Wahl and Stein (1991) found field comparisons of consumption with bioenergetic models to be underestimated by 39 to $52 \%$. These discrepancies were due to a non-temperature related reduction in metabolic rates that was not identified in the laboratory development phase. If the laboratory derived metabolism data was extrapolated into field based models, error would be expected if observed field metabolisms did not respond similar to those in the lab. In our study, we used metabolism and consumption parameters at several different temperatures and fish sizes, and when these parameters were validated in the lab, 
parameters were within the range of fish size and water temperature found within the model. However, the prey had a relatively high energy density value $\left(10870 \mathrm{~J} \cdot \mathrm{g}^{-1}\right)$ particularly in comparison to the trout $\left(4162 \mathrm{~J} \cdot \mathrm{g}^{-1}\right)$, and any slight error in consumption rates in either the developmental or validation groups would cause errors to propagate throughout the model. Although prey energy densities exceeding predator energy density may increase error percentages in validation studies such as this one, they do point out the need for accurate measures of these values in bioenergetics model development and application.

Ney (1993) points out that energy densities used in bioenergetics model development should be representative of the fish and prey items used in the models. Unrepresentative data can translate into an inaccurate model. Inaccurate energy densities for prey measurements are possible when published values are used rather than actual values. This is because energy density can change greatly with ontogeny. The waxworms used in this study develop through 7 instars, and each instar may have different energy contents (Finke 2002). To avoid this problem, wax-worms were bought in bulk and immediately frozen, and energy densities were estimated from bomb calorimetry. Likewise, predator energy densities must be accurate. Initial energy densities are problematic because these data represent the average energy density of the "energy density" group and not of the individual fish in the "validation group". The fish in the energy density group $(\mathrm{N}=6)$ ranged from 3524.5 to $5041.2 \mathrm{j} \cdot \mathrm{g}^{-1}$, and because of this variation, it must be assumed that the activity and validation groups were equally as variable. On the other hand, the final energy densities are obtained from the sacrificed 
individual fish at the conclusion of the experiment, and thus, represent the actual energy content found at the conclusion of the experiment.

A source of error has also been identified by borrowing physiological and behavioral parameters from other species (Ney 1993). Error reduction within internal variables is achieved by utilizing species-specific data and not borrowing physiological or behavioral parameters from other species. Because bioenergetics models require several inputs of external and internal variable estimations, basic research is required to estimate and quantify these inputs needed in bioenergetics models (Ney 1993). Inputs for the brook trout bioenergetics model, including ACT, respiration, consumption and growth were measured either in this study or in Hartman and Sweka (2001), or in Sweka et al. (2004). Models were parameterized with species-specific physiological rates and validated in the laboratory under controlled conditions. This satisfies the first of three tiers suggested by Hartman and Brandt (1993).

\section{Summary}

Following suggestions in Hartman and Brandt (1993) of a three tiered approach to bioenergetics model testing, more focus was placed on parameters and variables used in the model rather than just predictions of growth and consumption. Although our research adhered to strict methods in estimating parameters and variables, further work can be done to further reduce error. By using prey items that are less energy dense than the predator, a reduction in error might occur in the consumption parameter by decreasing the power of these errors on model results. Metabolic parameters were quite variable at all temperatures, and aside from having a homogenous population of fish (i.e. from the same hatchery brood stock), variability may be reduced by using fish that have not been 
stressed or been exposed to any previous experimental processes. Direct and indirect measures of external variables such as the predator and prey energy densities did allow energy transfers through system boundaries to be assessed with confidence in measures of energetic gains (prey) and losses. Further work needs to be done in the area of initial energy densities. The underlying principles of bioenergetics follow the inherent laws of thermodynamics which states that all energy transfers must be accounted. To account for all energy transfers, accurate initial set points for the predator and prey are absolutely essential. 


\section{References}

Bartell, S.M., Breck, J.E., Gardner, R.H., and Brenkert, A.L. 1986. Individual parameter perturbation and error analysis of fish bioenergetics models. Can. J. Fish. Aq. Sci. 43: $160-168$.

Boisclair, D. 1992. Relationship between feeding and activity rates for actively foraging juvenile brook trout (Salvelinus fontinalis). Can. J. Fish. Aq. Sci. 49: 2566-2573.

Boisclair, D. and Leggett, W.C. 1989. The importance of activity in bioenergetics models applied to actively foraging fishes. Can. J. Fish. Aq. Sci. 46: 1859-1867.

Boisclair, D. and Sirois, P. 1993. Testing assumptions of fish bioenergetics models by direct estimation of growth, consumption, and activity rates. Trans. Am. Fish. Soc. 122: 784-796.

Brandt, S.B. and Hartman, K.J. 1993. Innovative approaches with bioenergetics models: Future applications to fish ecology and management. Trans. Am. Fish. Soc. 122: 731-735.

Brett, J.R. 1973. Energy expenditure of sockeye salmon, Oncorhynchus nerka, during sustained performance. J. Fish. Res. Board Can. 30: 1799-1809.

De Staso III, J. and Rahel, F.J. 1994. Influence of water temperature on interactions between juvenile Colorado River cutthroat trout and brook trout in a laboratory stream. Trans. Am. Fish. Soc. 123: 289-297.

Elliott, J.M. 1976. The energetics of feeding, metabolism and growth of brown trout (Salmo trutta L.) in relation to body weight, water temperature and ration size. J. Anim. Ecol. 45: 923-948. 
Hansen, M.J., Boisclair, D., Brandt, S.B., Hewett, S.W., Kitchell, J.F., Lucas, M.C., and Ney, J.J. 1993. Applications of bioenergetics models to fish ecology and management: Where do we go from here? Trans. Am. Fish. Soc. 122: 1019-1030.

Hartman, K.J. and Brandt, S.B. 1995. Estimating energy density of fish. Trans. Am. Fish. Soc. 124: 347-355.

Hartman, K.J. and Sweka, J.A. 2001. Development of a bioenergetics model for Appalacian Brook Trout. Proc. Annu. Conf. S.E.A.F.W.A. 55: 38-51.

Hewett, S.W. and Kraft, C.E. 1993. The relationship between growth and consumption: Comparisons across fish populations. Trans. Am. Fish. Soc. 122 : 814-821.

Kitchell, J.F., Stewart, D.J., and Weininger, D. 1977. Applications of a bioenergetics model to yellow perch (Perca flavescens) and walleye (Stizostedion vitreum vitreum). J. Fish. Res. Brd. Can. 1922-1935.

Mehner, T. and Wieser, W. 1994. Energetics and metabolic correlates of starvation in juvenile perch (Perca fluviatilis). J. Fish. Biol. 45: 325-333.

Minton, J.W. and McLean, R.B. 1982. Measurement of growth and consumption of sauger (Stizostedion canadense): implications for fish energetics studies. Can. J. Fish. Aq. Sci. 39: 1396-1403.

Ney, J.J. 1993. Bioenergetics modeling today: Growing pains on the cutting edge. Trans. Am. Fish. Soc. 122: 736-748.

Sweka, J.A., Cox, M.K., and Hartman, K.J. 2004. Gastric Evacuation Rates of Brook Trout. Trans. Am. Fish. Soc. 133: 204-210.

Thornton, K.W. and Lessem, A.S. 1978. A temperature algorithm for modifying biological rates. Trans. Am. Fish. Soc. 107: 284-287. 
Wahl, D.H. and Stein, R.A. 1991. Food consumption and growth of three esocids: Field tests of a bioenergetic model. Trans. Am. Fish. Soc. 120: 230-246.

Winberg, G.G. 1956. Rate of metabolism and food requirements of fishes. Fish. Res. Board Can. Trans. Series . 194:1-202. 
Table 2. Model equations, functions and parameters describing the brook trout model. Models for each parameter (consumption, metabolism, egestion, and excretion) are listed as well the values for each internal variable found within them.

Consumption model equations for temperature dependence for cool and cold water species (Thornton and Lessem 1978).

Model form

$$
C=C_{\max } \mathrm{pf}(t)
$$

where:

$\mathrm{C}$ is the specific consumption rate $\left(\mathrm{g} \cdot \mathrm{g}^{-1} \cdot \mathrm{d}^{-1}\right)$;

$p$ is the proportionality constant having values of 0 to 1.0 , used to adjust ration when fitting an observed growth curve,or is the proportion of maximum consumption. Where 1.0 is the maximum feeding rate and 0 represents no feeding (this is based on the fish size and the water temperature;

$\mathrm{C}_{\max }=$ the maximum weight specific ration $\left(\mathrm{g} \cdot \mathrm{g}^{-1} \cdot \mathrm{d}^{-1}\right)$ at the optimum temperature $\left(\mathrm{T}_{0}\right)$

$\mathrm{f}(\mathrm{t})$ is the temperature-dependent proportional function;

$$
C_{\max }=C A \cdot W^{C B}
$$

where:

$\mathrm{CA}$ is the intercept of the allometric mass function;

$\mathrm{CB}$ is the slope of the allometric mass function;

$\mathrm{W}$ is the fish mass $(\mathrm{g})$;

$$
f(T)=K_{A}\left(K_{B}\right)
$$

where: 


$$
\begin{aligned}
& \mathrm{K}_{\mathrm{A}}=(\mathrm{CK} 1 * \mathrm{~L} 1) /(1+\mathrm{CK} 1 *(\mathrm{~L} 1-1)), \\
& \mathrm{L} 1=\mathrm{e}^{(\mathrm{G} 1(\mathrm{~T}-\mathrm{CQ}))} \\
& \mathrm{G} 1=(1 /(\mathrm{CTO}-\mathrm{CQ})) \ln ((0.98(1-\mathrm{CK} 1)) /(\mathrm{CK} 1 * 0.02)), \\
& \mathrm{K}_{\mathrm{B}}=(\mathrm{CK} 4 * \mathrm{~L} 2) /(1+\mathrm{CK} 4 *(\mathrm{~L} 2-1)), \\
& \mathrm{L} 2=\mathrm{e}^{(\mathrm{G} 2(\mathrm{CTL}-\mathrm{T}))}, \text { and } \\
& \mathrm{G} 2=(1 /(\mathrm{CTL}-\mathrm{CTM})) \ln ((0.98(1-\mathrm{CK} 4)) /(\mathrm{CK} 4 * 0.02)) .
\end{aligned}
$$

where:

$\mathrm{CQ}$ is the lower water temperature at which the temperature dependence is a small fraction (CK1) of the maximum consumption rate and CTO is the water temperature corresponding to 0.98 of the maximum consumption rate.

CTM is the water temperature $(>\mathrm{CTO})$ at which temperature is still 0.98 of the maximum rate and CTL is the temperature where dependence is a fraction (CK4) of the maximum.

The equations for respiration and specific dyaamic action.

Model form:

$$
\begin{gathered}
R=R A \cdot W^{R B} \cdot f(T) \cdot A C T \\
S=S D A \cdot(C-F)
\end{gathered}
$$

where:

$\mathrm{R}$ is the specific rate of respiration $\left(\mathrm{g} \cdot \mathrm{g}^{-1} \cdot \mathrm{d}^{-1}\right)$;

$\mathrm{W}$ is fish mass $(\mathrm{g})$;

RA is the intercept of the allometric mass function $\left(g \cdot g^{-1} \cdot d^{-1}\right)$;

$\mathrm{RB}$ is the slope of the allometric mass function;

$f(T)$ is the function for temperature of the dependence function;

$\mathrm{T}$ is water temperature $(\mathrm{C})$;

$\mathrm{ACT}$ is the activity multiplier; 
$\mathrm{S}$ is the proportion of assimilated energy lost to SDA;

SDA specific dynamic action;

$\mathrm{C}$ is the specific consumption rate $\left(\mathrm{g} \cdot \mathrm{g}^{-1} \cdot \mathrm{d}^{-1}\right)$;

$\mathrm{F}$ is the specific egestion rate $\left(\mathrm{g} \cdot \mathrm{g}^{-1} \cdot \mathrm{d}^{-1}\right)$;

Temperature dependance with the activity multiplier described by (Kitchell et al. 1977).

$$
f(T)=V^{X} \cdot e^{(X \cdot(1-V))}
$$

\section{$A C T I V I T Y=A C T$}

where:

$\mathrm{V}=(\mathrm{RTM}-\mathrm{T}) /(\mathrm{RTM}-\mathrm{RTO})$

$\mathrm{X}=\left(\mathrm{Z}^{2} \cdot\left(1+(1+40 / \mathrm{Y})^{0.5}\right)^{2}\right) / 400 ;$

$\mathrm{Z}=\mathrm{LN}(\mathrm{RQ}) \cdot(\mathrm{RTM}-\mathrm{RTO})$

$\mathrm{Y}=\mathrm{LN}(\mathrm{RQ}) \cdot(\mathrm{RTM}-\mathrm{RTO}+2)$;

RTO is the optimum temperature for respiration $(\mathrm{C})$;

RTM is the highest lethal water temperature (C);

$\mathrm{RQ}$ approximates the Q10 (the rate at which the function increases over relatively low water temperature);

RA is the number of grams of oxygen consumed by a 1 gram fish at RTO;

$\mathrm{RB}$ is the slope of the allometric mass function for standard metabolism;

$\mathrm{ACT}$ is a constant that is multiplied by the resting metabolism; sometimes

referred to as the "Winberg multiplier" (Winberg 1956).

Egestion and excretion equations based on mass, ration, and temperature (Elliott 1976). 
Model form

$$
\begin{gathered}
F=F A \cdot T^{F B} \cdot e^{(F G \cdot p)} \cdot C \\
U=U A \cdot T^{U B} \cdot e^{(U G \cdot p)} \cdot(C-F)
\end{gathered}
$$

where:

$\mathrm{F}$ is the egestion rate $(\mathrm{g} \cdot \mathrm{g}-1 \cdot \mathrm{d}-1)$;

$\mathrm{U}$ is the excretion rate $(\mathrm{g} \cdot \mathrm{g}-1 \cdot \mathrm{d}-1)$;

FA is the intercept of the proportion of consumed energy egested versus water temperature and ration;

UA is similarily defined as FA except for excretion;

$\mathrm{FB}=$ coefficient of water temperature dependence of egestion;

$\mathrm{FG}=$ is the coefficient for feeding level dependence (P-value) of egestion;

*UA, UB and UG can be similarly defined for excretion. 
Table 3. Values of the new bioenergetics model developed in Hartman and Sweka (2001) and of the refined respiration data.

\begin{tabular}{clllll} 
Consumption & \multicolumn{3}{c}{ Respiration } & \multicolumn{2}{c}{ Egestion and Excretion } \\
\hline CA & 0.3103 & RA & 0.0236 & FA & 0.212 \\
CB & -.3055 & RB & -0.2242 & FB & -0.222 \\
CQ & 7.274 & RQ2 & 3 & FG & 0.631 \\
CTO & 20.90 & RTO & 20.2 & UA & 0.0314 \\
CTM & 21.00 & RTM & 25 & UB & 0.58 \\
CTL & 24.05 & ACT & 2.0 & UG & -0.299 \\
CK1 & 0.500 & SDA & 0.172 & & \\
CK4 & 0.203 & & & \\
\hline
\end{tabular}


Table 4. Actual and predicted total end weights ( $\mathrm{g}$ ) fitted from consumption and actual and predicted total consumption (g) fitted from end weights over a 31 day experiment calculated from individual fish in the validation group. Models were run through Fish Bioenergetics 3.1 and predicted values were compared with observed values.

\begin{tabular}{lllllllrrr} 
& \multicolumn{3}{c}{ Weights } & \multicolumn{3}{c}{ Difference } & \multicolumn{2}{c}{ Consumption } & \multicolumn{2}{c}{ Difference } \\
\cline { 2 - 9 } ID & Start & Final & Predicted & Numerical & Percent & Actual & Predicted & Numerical & Percent \\
\hline 1 & 47.7 & 89.6 & 93.6 & 3.9 & 4.4 & 110.2 & 104.7 & -5.5 & -5.0 \\
2 & 64.0 & 120.7 & 108.1 & -12.6 & -10.4 & 120.4 & 138.3 & 17.9 & 14.9 \\
3 & 55.1 & 117.8 & 107.9 & -9.9 & -8.4 & 125.2 & 139.0 & 13.8 & 11.1 \\
4 & 66.4 & 142.5 & 107.9 & -34.6 & -24.3 & 124.7 & 175.6 & 51.0 & 40.9 \\
5 & 49.5 & 115.7 & 116.0 & 0.3 & 0.3 & 130.2 & 129.8 & -0.4 & -0.3 \\
6 & 48.4 & 84.6 & 94.2 & 9.6 & 11.4 & 103.9 & 91.9 & -12.0 & -11.5 \\
\hline
\end{tabular}




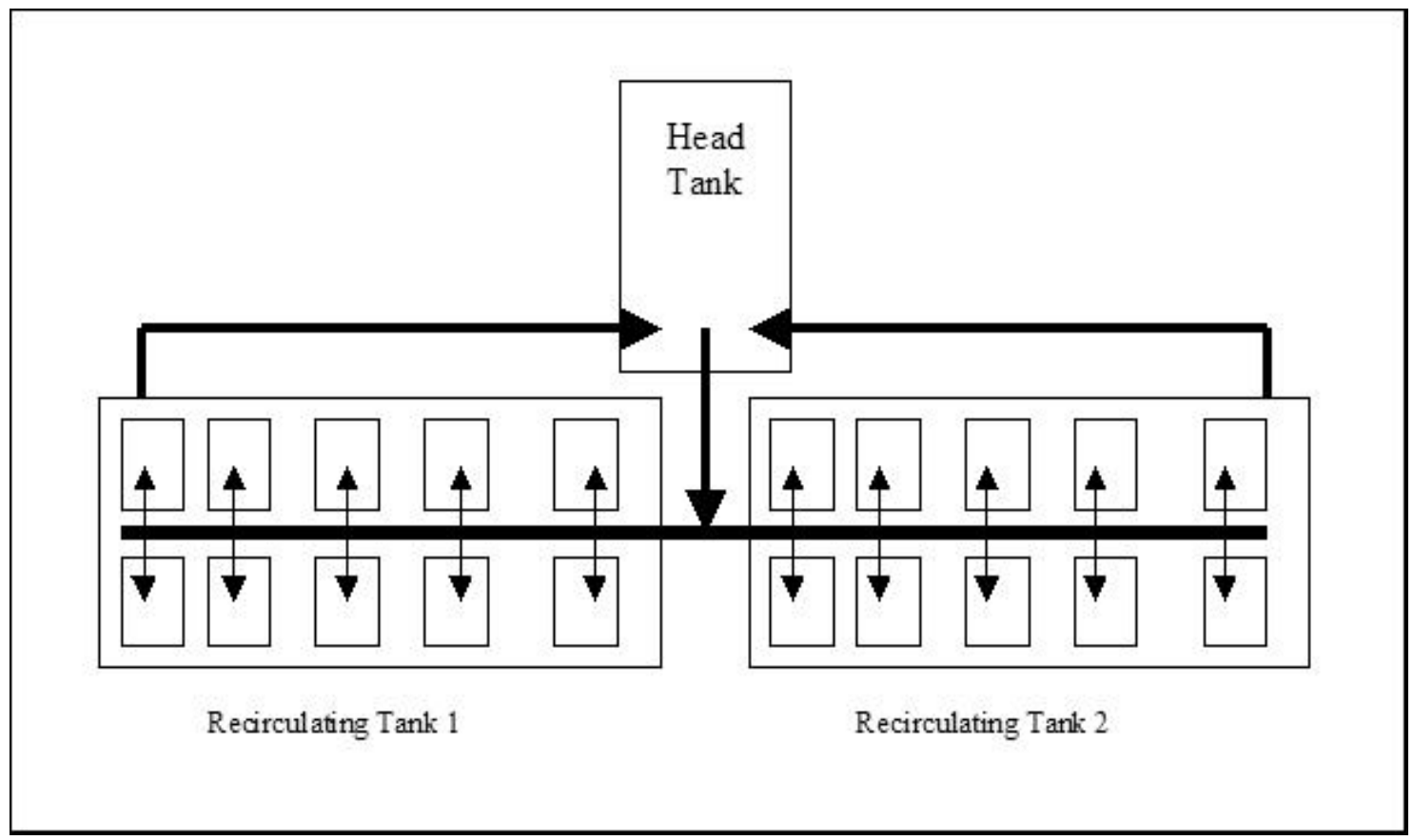

Figure 1. West Virginia University cold water re-circulating tanks used for consumption and metabolism experiments. 

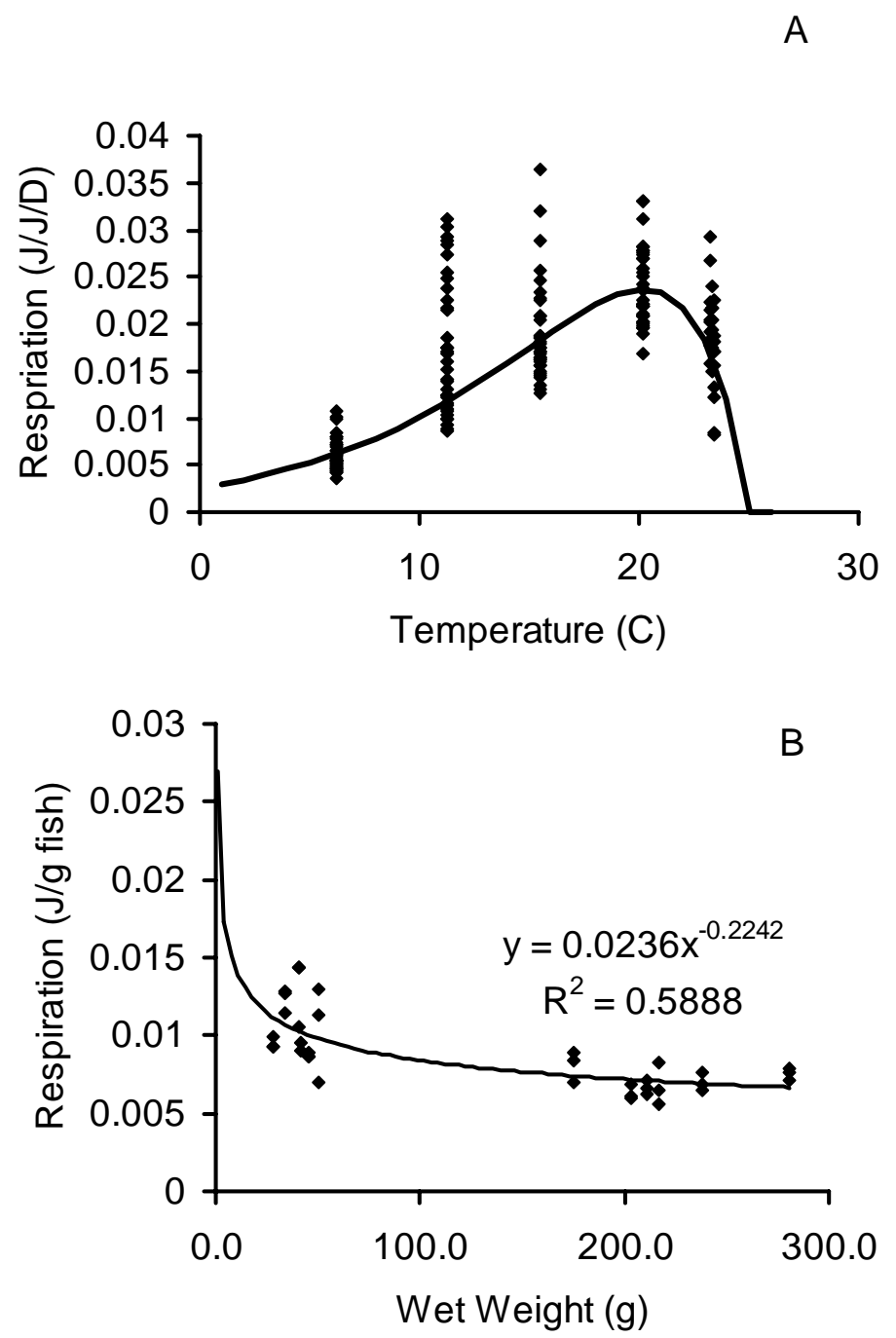

Figure 2. Size dependence (A) and temperature dependence (B) of specific metabolism of brook trout at temperatures between 6 and $24^{\circ} \mathrm{C}$. In A, all data are from $20.2^{\circ} \mathrm{C}$. In $\mathrm{B}$, all data have been normalized to a $1 \mathrm{~g}$ fish by using the slope found in $\mathrm{A}$. The solid line represents the fit best fit line of the model to the metabolism data. 
Chapter 3. Non-lethal estimation of proximate composition in fish.

\begin{abstract}
The need to precisely measure growth is common to many fisheries studies. Growth measures, other than total weights or lengths, are nearly non-existent because more precise measurements such as body composition analysis are often too difficult and time consuming. We present a means rapidly of estimating body composition in, and after validation, it does not require sacrificing the animal. Models built with brook trout (Salvelinus fontinalis) were linear with strong validation group correlations $\left(\mathrm{R}^{2}>0.86\right)$ for water, protein, fat and fat-free and dry weights. Subject responses to bioelectrical impedance analysis (BIA) were minimal, with only slight bruising $(\mathrm{p}<0.001)$ and with no effect on swimming, color, bleeding, or feeding. The model was also tested for its utility in predicting water and dry masses of ten warm water fish species. Strong correlations $\left(\mathrm{R}^{2}>0.95\right)$ suggested more general relationships may exist. Non-lethal estimation of body composition using bioelectrical impedance analysis will permit increased precision in monitoring bioenergetics energy flow and in compositional studies. Furthermore it will permit study of community energetics and condition on spatial and temporal scales not previously possible.
\end{abstract}

\title{
Introduction
}

Growth in fish is considered the ultimate expression of well being at the individual level, and it is also linked to the reproductive success of an organism (Shine and Schwarqkopf 1992; Brandt and Hartman 1993; Elliott and Hurley 1995). Actual growth reflects changes in the body composition or mass of growth components (e.g. fat and protein) relative to inert (ash) or compensating (water) components. However, the characterization of growth in most studies has been limited by the ability to accurately measure energetic growth. Since most animals are between $60-90 \%$ water, changes in this compartment can 
greatly influence estimates of growth based on total weight. In most growth studies, the more precise measurement of body composition has not been used because a quick, reliable, inexpensive method to estimate body composition is lacking.

A variety of in vivo and in vitro methods are available for assessing proximate composition in organisms but most appear to be impractical, inconvenient or cost-prohibitive for field or ecological work (Lukaski 1987). Proximate analyses include total body water (TBW), dry weight (DW), fat-free mass (FFM), total body protein (TBP), total body ash (TBA) and total body fat (TBF) masses. Direct measurements of individual compartments using chemical analysis require sacrificing the organism and by lengthy laboratory procedures (AOAC 1990). This negates the ability for repeated measures of the same individual and restricts compositional study of endangered species. Total body water is a good predictor of other body components, but in vivo methods to estimate TBW involve using radioisotope tracers such as tritium, deuterium and oxygen-18 which are difficult to analyze outside a specialized laboratory and are also cost prohibitive (Lukaski 1987). Fat free mass can be estimated non-sacrificially by counting intracellular potassium-40 with thallium activated sodium iodide crystal detectors, but high cost, instrumentation and technicality diminishes its practicality (Corcoran et al. 2000).

Electrical conductivity methods are non-sacrificial and include total body electrical conductivity (TOBEC) and bioelectrical impedance analysis (BIA) which both rely on impedance differences between fat and fat-free tissues. Lantry et al. (1999) found that the TOBEC method accurately estimates composition parameters for healthy individuals, but errors increase when subjects are undergoing weight or compositional changes, or when subjects with dissimilar body sizes are compared (conductivity changes with body geometry and size). Furthermore, the TOBEC unit is large and non-portable, making field studies impractical. Bioelectrical impedance analysis is available in an inexpensive, small, portable 
unit that has provided accurate and reliable estimations of water mass in humans, but as with the TOBEC, complex body geometries tend to decrease the accuracy of the composition estimations. However, we hypothesize that if BIA technology is applied to organisms with a more simplified body geometry (majority of the mass located in the a single volume), accuracy of measurements would not be lost and proximate composition estimations could accurately and non-lethally be made in lab and field settings for fish. Furthermore, because of the generality of electrical resistivity laws across various mediums, models for fish would not seem to have the restrictions of individual species specificity.

To investigate the applicability of BIA technology to fish, brook trout (Salvelinus fontinalis) were measured for bioelectrical impedance and sacrificed for analysis of total body proximate composition. Independent predictive models were made for TBW, DW, FFM, TBP, TBA, and TBF using derivatives of resistance and reactance equations. These models were then tested on an independent validation group of brook trout. Values from each predicted component were compared with actual numbers obtained from laboratory analyses. Generality of the brook trout model was tested on a second validation group that consisted of ten species of warm water fishes. Predicted values of DW, TBW and total weight were compared with actual values. An additional group of brook trout were used to test for harmful responses to BIA methods.

\section{Materials and Methods}

\section{Principles of BIA}

Proximate composition estimations are calculated by measuring the impedance (resistance and reactance) of a current $(800 \mu \mathrm{A}, \mathrm{AC}$, and $50 \mathrm{kHz})$ passed through an organism and regressing them with actual proximate body composition numbers for that organism. Resistance of a substance is proportional to the voltage of an applied current as it passes through a substance, or 


\section{(3) $R=V / C t$,}

where $R$ is resistance (ohms), $V$ is applied voltage (volts), and $C t$ is current (amps). Reactance $\left(\mathrm{X}_{\mathrm{c}}\right)$ is the opposition to alternating current by a capacitor (cell membranes), and can be mathematically expressed by the following equation:

$$
\text { (4) } X_{c}=1 /(2 n f C)
$$

where $X_{c}$ is reactance in Ohms, $f$ is frequency in Hertz and $C$ is capacitance in Farads (Keller et al. 1993). Impedance ( $R$ and/or $\left.X_{c}\right)$ is related to the cross sectional area, conductor length of the organism and the signal frequency of the current (Lukaski 1987). Impedance can be expressed by the equation:

\section{(5) $I=\rho L / A$}

where $I$ is resistance or reactance, $\rho$ is resistivity constant, $L$ is measured length, and $A$ is area $\left(\mathrm{mm}^{2}\right)$. If the signal frequency and the configuration are held constant, the impedance measurements can be related to its volume. This is demonstrated by the following: if

$$
\text { (6) } R=\rho L / A
$$

is multiplied by $L / L$, then

$$
\text { (7) } \quad R=\rho L^{2} N_{\varepsilon}
$$

by substitution,

$$
\text { (8) } \quad V_{\varepsilon}=\rho L^{2} / R \text {, }
$$

where $V_{\varepsilon}$ is volume epsilon $\left(\mathrm{mm}^{3}\right)$ and $\rho$ (rho) is determined statistically by regressions of $V_{\varepsilon}$ on impedance.

Cell membranes consist of a non-conductive lipid bi-layer sandwiched between two conductive protein layers and at low voltages and high frequencies such as those used here, current mainly passes through extra cellular fluids, while at higher frequencies the cell walls 
become capacitive (Pethig 1979). This allows reactance and resistance numbers to be sensitive to changes in volume of extra cellular and cellular material.

\section{BIA Model}

A total of 50 brook trout, 22 from headwater streams and 28 from the West Virginia Bowden State fish hatchery, Bowden, West Virginia were obtained for development and testing of the BIA model. Previous food rations for the hatchery trout were standard trout pellets fed ad libitum approximately three times per day. Gender was not determined, and condition for all but one of the fish appeared to be normal. The fish that did not appear normal was not removed from the group. Bioelectrical impedance analysis procedures were performed on 10 hatchery fish on site and the remaining 18 hatchery fish were transported back to the West Virginia University. Transported fish were maintained in re-circulating tanks $(0.5 \times 1.5 \mathrm{~m})$ at $14 \pm 1^{\circ} \mathrm{C}$, and food was withheld for $30 \mathrm{~d}$ in order to achieve a lower plane of condition. The 22 stream fish were captured by electrofishing, and immediately analyzed with BIA, iced and transported to the West Virginia University and frozen. While still anesthetized, fish were measured for length and weight, euthanatized with MS-222 and frozen. Parameters including, TBP, TBA and TBW were analyzed by the West Virginia University Rumen Profiling Fermentation Laboratory following standard techniques of the AOAC (1990). Mass balance equations were used to calculate DW, FFM and TBF. All fish were then placed into a dataset from which the "model" or "validation" groups were selected. The model group consisted of 30 fish that: (1) satisfied conditions of having individual fish with the maximum and minimum values for length, weight, resistance, reactance and fat values and (2) were then randomly selected until a total number of 30 had been reached. The remaining 20 fish not placed in the model group were placed in the "validation" group.

Fish in the model and validation groups were anesthetized and measured for BIA in an identical manner. Fish were removed from water and anesthetized with MS-222, blot 
dried and placed on a non-conductive board in a left lateral recumbent position. Electrical impedance (resistance and reactance) was measured with a tetrapolar bioelectrical impedance analyzer (RJL Systems, Detroit, MI.). The analyzer has two sets of needle electrodes (stainless, 28 gage, $12 \mathrm{~mm}$; Grass Telefactor, West Warwick, R.I.) each consisting of one signal and one detecting electrode. One set was placed in the anteriad dorsad region and the second set was placed in the caudle peduncle region of the fish with the detecting electrodes of each set placed $1.0 \mathrm{~cm}$ proximal to the signal electrodes. The distance between the two detecting electrodes was measured for each fish, and a current was introduced through the signal electrodes and the proximal detecting electrodes measured the voltage drop. These two electrical values, resistance and reactance, were then used to calculate values from common electrical property equations that included resistance in series and in parallel, reactance in series and in parallel, combined resistance and reactance in series and in parallel, and capacitance. These values were then used as independent variables in the regression model.

Independent models for each parameter were built from the "model" group. Dependent variables in the regression model were the body composition values measured in the laboratory immediately following BIA procedures and independent variables were values from the electrical property equations. Relationships between the two variables (equations and actual parameter values) are explained with correlation analysis for strength of linear relationships and predictability, residual plots and F values (to test significance of slopes in linear regressions), and confidence limits on the regression coefficients (to test for 1:1 relationships).

Best-fit linear models were then used to predict parameter estimates in validation groups. Predicted values for each parameter in both validation groups were expressed by the following equation: 


\section{(9) $P \theta=(P P / P W)^{*}$ weight,}

where $P \theta$ is the new predicted parameter value $(\mathrm{g}), P P$ is the initial predicted parameter $(\mathrm{g}), P W$ is the predicted total weight $(\mathrm{g})$ and weight is the measured actual wet weight of the fish. Statistical and analytical procedures were completed with $\mathrm{SAS} \circledast 8.1$ software. The best fit linear models were then tested using the validation group.

To test brook trout model generality, water and dry weight models developed for brook trout were used to predict TBW and DW of a group of warm water fish. Eighty-three fish consisting of ten species were collected in the summer of 2003 by nighttime electroshocking on the Kanawha River in Charleston, West Virginia. Species included white crappie (Pomoxis annularis), freshwater drum (Aplodinotus grunniens), gizzard shad (Dorosoma cepedianum), longear sunfish (Lepomis megalotis), logperch (Percina caprodes), Moxostoma spp., redbreast sunfish (Lepomis auritus), sauger (Sander canadensis), smallmouth bass (Micropterus dolomieu), and spotted bass (M. punctulatus). Fish were measured for resistance and reactance following aforementioned procedures and values were inserted into the brook trout model equations for TBW and DW. These independent terms (TBW and DW) were summed to estimate predicted weights in the warm water species data set. Actual water and dry weights were measured following AOAC (1990) methods.

To test subject responses to BIA procedures, twenty hatchery brook trout were placed individually into 37-liter aquaria. Half of the fish were randomly assigned to a treatment group that was to receive BIA measurements and the other half assigned to a control group that was not measured with BIA. Regardless of group, once weekly for three weeks, each fish was anesthetized, and measured for length and weight with the additional measurement of impedance taken from the treatment group fish. Following measures, fish from both groups were immediately returned to the aquaria and changes in color, feeding, swimming, bruising and bleeding were observed daily. Throughout the experiment, fish from both 
groups were fed a maintenance ration of house fly larvae (Gruco Inc., Hamilton, Ohio). A dichotomous variable score ( 0 or 1 , i.e. $0=$ no bruising, $1=$ bruising $)$ was used to monitor basic observations. This repeated measures experiment was analyzed with a logistic regression.

\section{Results}

Strong linear relationships were found between independent variables calculated from BIA values, and observed body composition values. Independent and dependent variables with associated $\mathrm{R}$ values are as follows: resistance in series with TBW $(\mathrm{R}=0.9872)$, reactance (in parallel) with DW $(\mathrm{R}=0.9862)$, combined resistance and reactance in series with FFM $(\mathrm{R}=0.9873)$, resistance in series $(\mathrm{R}=0.9863)$, resistance in parallel with TBA $(\mathrm{R}$ $=0.9864)$, and capacitance with TBF $(\mathrm{R}=0.9779)($ Table 5).

Tests of the linear regression models using the validation group of brook trout showed the models were good predictors of all body composition values. Predicted and actual values for all body composition parameters were highly correlated $(\mathrm{p}<0.0001)$ with $\mathrm{R}^{2}$ scores ranging from 0.8507 to 0.9986 in TBF and TBW, respectively (Figure 3). F tests (p < 0.0001 ) and residuals revealed a linear relationship between impedance values and the predicted values (Figure 3). Correlations between predicted and observed values in all proximate composition categories indicated a strong linear relationship with values not differing from 1:1 (Figure 4).

Linear regression models developed for brook trout were also good predictors of DW, TBW and weight across all species of fish tested from the Kanawha River. Predicted values of DW, TBW and weight were also strongly correlated with actual values (Figure 4 and Table 6). Dry weight predicted and actual values were highly correlated with $\mathrm{R}^{2}$ ranging from 0.9537 in logperch to 0.9975 in smallmouth bass. Predicted and actual values of total body water were highly correlated with $\mathrm{R}^{2}>0.9900$. Predicted and actual total weight values were 
highly correlated with $\mathrm{R}^{2}>0.9950$ for longear sunfish, logperch and rockbass, with the remaining five species of fish (drum, gizzard shad, Moxostoma. spp., sauger and smallmouth bass) having $\mathrm{R}^{2}=1.0000$.

In repeated measures laboratory experiments, brook trout showed little response to being measured with BIA. Measured parameters of swimming, feeding, bleeding and color were not significantly different between the two groups (applied BIA and not). Bruising was significant (logistic regression $\mathrm{p}<0.0001$ ) in response to BIA, but we observed this was slight and only lasted for two days (Table 7).

\section{Discussion}

Bioelectrical impedance analysis models provided a means of estimating body composition in brook trout and a group of warm water fish species with a high degree of predictability $\left(\mathrm{R}^{2}>0.8507\right)$. Additional experiments showed that the methods of BIA are non-lethal and appear to produce little measurable effect upon fish health or behavior. Once a model is built, BIA estimations are derived from three measurements: resistance (measure of extracellular resistance), reactance (measurement of "celled" mass) and distance between detecting electrodes. These three measurements are used to predict TBW, DW, FFM, TBP, TBA and TBF, and are obtained on live, anaesthetized organisms in about the time it takes to measure live weight.

The strong predictability and accuracy found in fish data is a result of the body geometry of fish being more simplified than the higher vertebrates used in previous BIA studies (Berg and Marchello 1994; Marchello et al. 1999). More specifically, trout have a fusiform geometric shape that approximates a cylinder with a majority of the mass located in the thorax (Jobling 1995). The thorax accommodates all major body composition components, and likewise, it is the main region for hypertrophic or hypotrophic growth.

Since volume is proportional to impedance and length between detecting electrodes (see 
equations 1-4 in methods), a single impedance measurement represents the whole body and likewise, compositional changes that occur within it. If the majority of mass is not located within a single volume as with many higher vertebrates, it must be distributed into limbs or appendages. Since each limb or appendage has its own volume and tissue heterogeneity a single measurement of impedance cannot represent the whole organism (e.g. two different sized volumes with identical composition would have different impedance measurements) (Keller et al. 1993). Likewise, measuring impedances for each separate volume and combining them would result in complex methodology and conversely a complex model with error propagations occurring with each volume. For a single measurement of impedance to be representative of the whole body, a simple body geometry with the majority of the mass located in one volume is essential.

A validation of the brook trout BIA model with an independent BIA dataset showed the models accurately predicted actual values $\left(\mathrm{R}^{2}>0.9277\right)$ except for lower predictability of fat mass $\left(\mathrm{R}^{2}=0.8507\right)$. The reasoning for the weaker correlations for fat mass may be explained by electrical resistivity properties. The nature of current division described by Ohms law and Kirchhoff's rules dictates that current will pass through an entire circuit, but the path with the least resistance will carry more current. Fat deposits are 1) concentrated in the ventral gut region of the fish and 2) have a higher resistance than other visceral or somatic tissues. Since electrode placement was in the dorsal region, and resistance is higher in fat, it is possible that the current does not represent the fat that is located in the lower ventral region. All other parameters such as TBW and TBP are more systemic, have a lower electrical resistance and therefore are better represented by impedance values in this study. This leads to the possibility of localized or tissue-specific BIA modeling via electrode placement. 
Furthermore, strong linear relationships in the warm water species portion of this study suggest that the brook trout model may predict compositional parameters for other species. This may be due to the similar geometric shapes found among the species of fish used in this study. The warm water species validation group had of a cylindrical shape with the majority of the mass (body composition components) located within one volume, and predictions with the brook trout BIA model were strongly correlated with actual parameter estimations. Some of the variation between predictions with the brook trout model and observed values for the warmwater species, especially in the dry weight parameter may have been due to regional tissue deposits. Determining error constitutes is outside the scope of this study, but the authors believe that vertebrates such as fish, amphibians, reptiles and some mammals that fit the criteria mentioned above would be suitable for BIA modeling. The brook trout models used here were to test for model generality, and we conclude that general relationships observed for brook trout will hold for other species.

The ability to precisely and non-lethally estimate proximate composition through BIA will permit increased precision in energy flow and proximate composition studies on spatial and temporal scales that were previously impractical. At the individual level, BIA will permit repeated measures on the same individual during the course of investigation, yielding better tracking of energetics components and improved precision in bioenergetic models. At the population level, BIA will permit assessment of condition of cohorts over time and permit detailed comparisons across cohorts and temporal and spatial scales, such as evaluating body conditional properties of highly migratory species at different points during migration. At the community level, BIA will permit the evaluation of growth and energy flow dynamics across species. This capability may allow elucidation of community dynamics that were previously unknown, or permit correlation of body composition with outbreaks of disease. This approach also has potential for the non-lethal study of threatened or endangered species by 
using models developed for closely related species. Finally, this could be applied to other taxa, particularly amphibians and reptiles, with similar results and uses as described here. 


\section{References}

AOAC 1990. Official Methods of Analysis. Association of Official Analytical Chemists, Washington, DC.

Berg, E.P. and Marchello, M.J. 1994. Bioelectrical impedance analysis for the prediction of fat-free mass in lambs and lamb carcasses. J. Anim. Sci. 72: 322-329.

Brandt, S.B. and Hartman, K.J. 1993. Innovative approaches with bioenergetics models: Future applications to fish ecology and management. Trans. Am. Fish. Soc. 122: 731735.

Corcoran, C., Anderson, E.J., Burrows, B., Stanley, T., Walsh, M., Poulos, A.M., and Grinspoon, S. 2000. Comparison of total body potassium with other techniques for measuring lean body mass in men and women with AIDS wasting. Am. J. Clin. Nutr. 72: 1053-1058.

Elliott, J.M. and Hurley, M.A. 1995. The functional relationship between body size and growth rate in fish. Funct. Ecol. 9: 625-627.

Jobling, M. 1995. Environmental Biology of Fishes. Chapman and Hall, London.

Keller, F.J., E.W. Gettys, and M.J. Skove 1993. Physics. McGraw-Hill, New York.

Lantry, B.F., Stewart, D.J., Rand, P.S., and Mills, E.L. 1999. Evaluation of total-body electrical conductivity to estimate whole-body water content of yellow perch, Perca flavescens, and alewife, Alosa pseudoharengus. Fish. Bull. 97: 71-79.

Lukaski, H.C. 1987. Methods for the assessment of human body composition: traditional and new. Am. J. Clin. Nutr. 46: 537-556.

Marchello, M.J., Berg, P.T., Swantek, P.M., and Tilton, J.E. 1999. Predicting live and carcass lean using bioelectrical impedance technology in pigs. Livest. Prod. Sci. 58: 
$151-157$.

Pethig, R. 1979. Dielectric and Electronic Properties of Biological Materials. John Wiley and Sons, New York.

Shine, R. and Schwarqkopf, L. 1992. The evolution of reproductive effort in lizards and snakes. Evol. 46: 62-75. 
Table 5. Relationships between proximate body composition components and impedance equations for brook trout (Salvelinus fontinalis) in the model group.

\begin{tabular}{|c|c|c|c|c|c|c|}
\hline Component & $\mathrm{N}$ & $\begin{array}{l}\mathrm{a} \\
\text { (SE) }\end{array}$ & $\begin{array}{l}\mathrm{b} \\
(\mathrm{SE})\end{array}$ & $X$ & $\begin{array}{l}\text { F-statistic } \\
\text { (p-value) }\end{array}$ & $\mathrm{R}^{2}$ \\
\hline TBW & 30 & $\begin{array}{l}1.32045 \\
(1.94826)\end{array}$ & $\begin{array}{l}3.46187 \\
(0.10560)\end{array}$ & $\mathrm{L}^{2} / \mathrm{R}_{\mathrm{m}}$ & $<0.0001$ & 0.9746 \\
\hline DW & 30 & $\begin{array}{l}0.29558 \\
(0.77843)\end{array}$ & $\begin{array}{l}4.31575 \\
(0.13679)\end{array}$ & $L^{2} / X_{c p}$ & $<0.0001$ & 0.9726 \\
\hline FFM & 30 & $\begin{array}{l}-0.51881 \\
(0.56108)\end{array}$ & $\begin{array}{l}0.99968 \\
(0.03041)\end{array}$ & $\mathrm{L}^{2} / \mathrm{R}_{\mathrm{m}}$ & $<0.0001$ & 0.9747 \\
\hline TBP & 30 & $\begin{array}{l}-0.67352 \\
(0.52328)\end{array}$ & $\begin{array}{l}0.89630 \\
(0.02836)\end{array}$ & $L^{2} / R_{m}$ & $<0.0001$ & 0.9727 \\
\hline TBA & 30 & $\begin{array}{l}0.11516 \\
(0.06089)\end{array}$ & $\begin{array}{l}0.11749 \\
(0.00370)\end{array}$ & $L^{2} / R_{p}$ & $<0.0001$ & 0.9730 \\
\hline TBF & 30 & $\begin{array}{l}-1.79087 \\
(0.32015)\end{array}$ & $\begin{array}{l}1.80382^{-23} \\
\left(7.28985^{-25}\right)\end{array}$ & $L^{2} / X_{c p}$ & $<0.0001$ & 0.9563 \\
\hline
\end{tabular}

Analysis results of the linear relationships between the measured bioelectrical impedance equations and actual numbers of proximate body composition components: total body water (TBW), dry weight (DW), fat-free mass (FFM), total body protein (TBP), total body ash (TBA), and fat mass (TBF). In the table, $\underline{x}$ represents the specific impedance equation providing the best-fit, where $\underline{L}=$ length, $\underline{\mathrm{R}}=$ resistance, $\underline{\mathrm{Z}}=$ impedance, $\underline{\mathrm{X}}$ is reactance, subscript $\underline{p}$ or $\underline{m}$ represent parallel or series circuitry, and $\underline{a}$ and $\underline{b}$ represent the intercept and slope of the regression, respectively. 
Table 6. Correlation of coefficient scores $\left(\mathrm{R}^{2}\right)$ of predicted and actual parameter values including total body water (TBW), dry weight (DW), and total weight for various warm water species (drum, gizzard shad, longear sunfish, logperch, Moxostoma. spp., rockbass, sauger, and smallmouth bass) using the brook trout BIA model.

\begin{tabular}{lllll}
\hline & & & $\mathrm{R}^{2}$ & \\
\cline { 3 - 5 } Species & $\mathrm{N}$ & $\mathrm{DW}$ & $\mathrm{TBW}$ & Weight \\
\hline Freshwater drum & 11 & 0.9947 & 0.9995 & 1.0000 \\
Gizzard shad & 15 & 0.9854 & 0.9982 & 1.0000 \\
Longear sunfish & 10 & 0.9960 & 0.9973 & 0.9993 \\
Logperch & 6 & 0.9537 & 0.9906 & 0.9952 \\
Moxostoma spp. & 11 & 0.9932 & 0.9989 & 1.0000 \\
Rockbass & 4 & 0.9973 & 0.9988 & 0.9999 \\
Sauger & 11 & 0.9956 & 0.9994 & 1.0000 \\
Smallmouth bass & 11 & 0.9975 & 0.9996 & 1.0000 \\
\hline
\end{tabular}

*Spotted bass and white crappie were not included here because of low sample sizes (1 fish each). 
Table 7. The number of negative responses (e.g. not swimming or feeding, bruising, bleeding, loss of color) of individual brook trout that underwent bioelectrical impedance analysis (BIA) compared to those that received no BIA analysis (control).

\begin{tabular}{lllllll} 
Treatment & $\mathrm{N}$ & Color & Feeding & Swimming & Bruising & Bleeding \\
\hline Control & 210 & 4 & 22 & 3 & 1 & 0 \\
BIA & 210 & 0 & 13 & 1 & $110 \dagger$ & 3 \\
\hline
\end{tabular}

$\dagger$ Significant $(\mathrm{P}<0.0001$, repeated measures logistic regression $)$. 

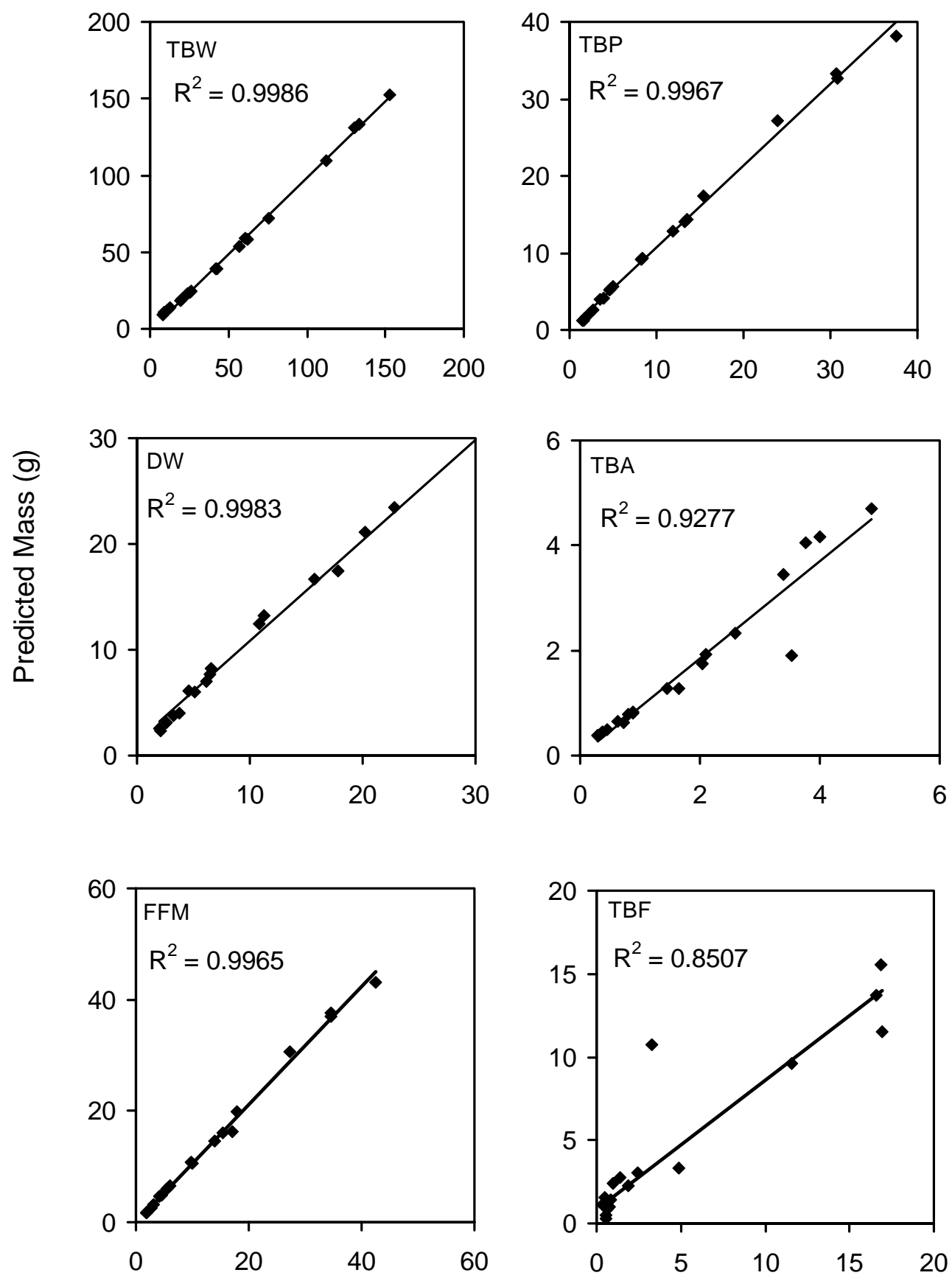

Observed Mass (g)

Figure 3. Regression analysis of predicted and actual values for the brook trout validation group $(n=20)$ including total body water $(T B W)$, dry weight $(\mathrm{DW})$, fat free mass (FFM), total body protein (TBP), total body ash (TBA), and total body fat (TBF). 

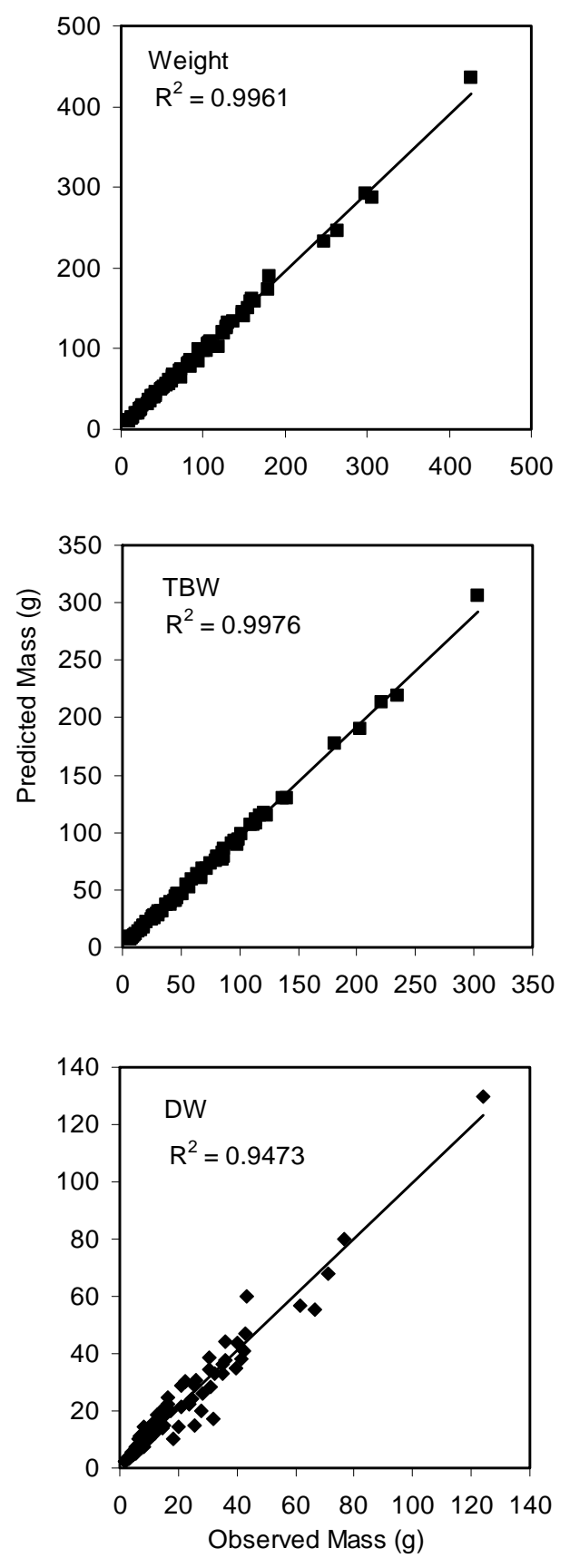

Figure 4. Regression analysis of predicted and actual values for the warm water species validation group $(n=81)$. Predicted values of dry weight $(\mathrm{DW})$, total body water (TBW) and weight were calculated using the existing brook trout model. 
Chapter 4. Field applicability of bioelectrical impedance analysis to the estimation of fish proximate composition.

\begin{abstract}
Variables including temperature, gut-fill, electrode placement, and repeated measures were adjusted during bioelectrical impedance analysis (BIA) to assess their influence on predicted composition estimates. Temperature affected predicted estimates of total body water, dry weight and total weight linearly, but when data was normalized by weight, the temperature term was effectively canceled out. Gut-fill did not effect BIA predictions of any body composition parameter estimate while electrode placement did. Dorsal predicted estimates did not change with increases in gut-fill, but ventral measures indicated a stronger predictability $\left(\mathrm{R}^{2}=0.92\right)$ for fat than did the dorsal measures $\left(\mathrm{R}^{2}=0.56\right)$. Repeated measures of BIA on the same fish did not affect fish except for observed bruising that lasted 2 days. This study shows that BIA should be applicable in a field situation without having to control for temperatures or stomach fullness, and introduces new model development possibilities including regional specificity within the fish and the use of repeated measures on the same individual fish.
\end{abstract}

\title{
Introduction
}

For nearly a century, fisheries biologists have struggled with developing a means to simply and accurately assess fish health and condition or that of their ecosystem (Blackwell et al. 2000; Wedemeyer et al. 1983; Shearer et al. 1994; Wechsler 1984; Marien and Patrick 2001). Early attempts at assessing health or condition focused on simple relationships between the length and weight of fish and these attributes (Anderson and Neumann 1996; Le Cren 1951). These early methods were later replaced by more complicated formulations relying on easily obtained length and weight information such as relative weight (Wr) (Wege 
and Anderson 1978; Murphy et al. 1991), and more difficult and technical measures involving necropsy, histology, or pathology (NHP) (Strange 1996). These two approaches represent a compromise in that condition indices such as $\mathrm{Wr}$ are easily obtained, but lack sensitivity and precision in evaluating fish health (Anderson and Neumann 1996). The more technical approaches of NHP have provided detailed information about individual fish, but the cost and technical expertise required to conduct them has restricted the ability of fieldbiologists to effectively apply these methods on broad scales. Currently, there is a trade-off between cost or simplicity and the accuracy and applicability of these methods. Common ground between these tradeoffs has been found with the use of bioelectrical impedance analysis (BIA). This method uses electrical conductivity relationships between the organism and body composition parameters such as total body water (TBW), dry weight (DW), fat-free mass (FFM), total body protein (TBP), total body ash (TBA) and total body fat (TBF). It is useful and accurate in lab settings under carefully controlled conditions (Kushner and Schoeller 1986), but applicability of BIA under field conditions is unknown.

Bioelectrical impedance analysis under controlled conditions accurately estimates body composition in brook trout (Salvelinus fontinalis), but variables such as gut fullness and temperature may affect predictions. Bioelectrical impedance analysis technology has been a useful tool in human growth studies for over 50 years, and is available as an inexpensive, small, portable unit. Compartment estimations are derived from electrical impedance values that are reflective of the summation of the various cylindrical appendages found in the human body via electrode patches. Likewise, impedance values are measured on fish by inserting four needle electrodes in the fish, measuring the distance between them, and recording two impedance values. In our work, when BIA technology was applied to brook trout, the accuracy was improved over studies with higher vertebrates (Slanger and Marchello 1994; Stanton et al. 1992; Gudivaka et al. 1999) due to brook trout having a more simplified body 
geometry (i.e. the majority of their mass located in a single cylindrical volume) (Stanton et al. 1992). Results with brook trout indicated strong correlations between predicted and observed values $\left(\mathrm{R}^{2}>0.98\right)($ Table 8$)$. Needle electrode placements in the original model were in the dorsal musculature of the fish because this area does not contain vital organs or major arteries. Subject responses to the needle electrodes and BIA measures were not measured because all subjects were sacrificed for model development. Analyses using BIA were also conducted in the laboratory under controlled conditions to minimize outside variable influences such as temperature, gut-fill, and varying electrode placement. For BIA to be used, its applicability as a biological tool must be assessed not only under strict laboratory control, but also under variable conditions more typical of the field.

To further investigate the applicability of bioelectrical impedance analysis (BIA) on brook trout (Salvelinus fontinalis), variables that were standardized in original model were adjusted to assess their influences on composition parameter estimations of TBW, DW, FFM, TBP, TBA and TBF. Adjusted, independent variables included stomach fullness, electrode placement (length and region measured), frequent measurements and temperature. Subject responses to procedures were also assessed.

\section{Materials and Methods}

Brook trout used in the following experiments were obtained from the Bowden State fish hatchery, Bowden, West Virginia. Approximately 100 fish were maintained in a living stream tank for as long as six months at approximately $16^{\circ} \mathrm{C}$ and were fed standard hatchery pellets at a rate of $<3 \% \cdot$ body weight ${ }^{-1} \cdot \mathrm{d}^{-1}$ until used in experiments.

\section{Gut-fill and electrode placement}


To determine if BIA estimates of total body water (TBW), dry weight (DW), Fat-free mass (FFM), total body protein (TBP), total body ash (TBA) and total body fat (TBF) change with gut-fill and with electrode placement, brook trout with full and empty guts, and with different lengths between electrodes were used in a two factor analysis of variance study design. Twenty brook trout (110-130 mm in length) were randomly split into four groups: 1) half-length full gut, 2) half-length empty gut, 3) whole length full gut and 4) whole length empty gut (i.e. five replicates for each of the four combinations). Half-length refers to one set of electrodes being placed towards the head region and the second being placed around mid-point (under the dorsal fin) (Figure 5). Whole-length refers to one set of electrodes being placed towards the head region and the second set being placed towards the tail region (Figure 5). Full-gut and empty-gut refer to whether the stomach and alimentary canal were full or not.

The experiment was initiated by feeding brook trout with the full-gut designation fly larvae Sarcophaga bullata (Grubco Inc., Hamilton, Ohio) to satiation while those with the empty-gut designation remained unfed. Fish were then anesthetized in a tricane methanesulfonate (MS-222) solution of $1 \mathrm{~g} \cdot 91$ water $^{-1}$ and measured with BIA on either their whole or half body basis (Figure 5). These impedance values were inserted into the BIA model and predictions of TBW, DW, FFM, TBP, TBA and TBF were compared between the four groups of fish.

\section{Electrode placement}

To test effects of regional electrode placement, 20 brook trout were randomly selected from the stock of fish and BIA measurements were taken from both the ventral and dorsal regions of each of the selected trout. Dorsal impedance measurements were taken along the whole body of the trout with electrodes placed in the dorsal musculature of the fish (Figure 5). Ventral impedance measurements were taken by placing one set of electrodes slightly 
interior of the pectoral fins and the second set to the side of the anus (Figure 5). After the BIA measurements were taken, all fish were euthanatized with MS-222 and analyzed for body composition following methods found in AOAC (1990). Following analysis, data from 10 fish were placed into a "model" group and data from the other 10 fish were placed in a "validation" group. Placement of fish in the model group included those fish with the maximum and minimum values for length, weight, resistance and reactance followed by randomly selecting fish until a total of 10 was achieved. The remaining 10 fish not placed in the "model" group were placed in the "validation" group. The model group was used to develop a new ventral equation for each of the body composition parameters. The validation group was used to test and compare different body composition estimates with observed values.

Three estimates for each body composition parameter were calculated by: 1) dorsal impedance measurements used with the original model developed by Cox and Hartman (in review), 2) ventral impedance measurements used with the original model developed by Cox and Hartman (in review), and 3) ventral impedance measurements with the new equation for each parameter. Regression scores (correlation of coefficients) were used to compare observed values with each of the 3 individual body composition estimations in the validation group.

\section{Subject response to weekly BIA procedures}

To test subject responses to BIA procedures, 20 brook trout were randomly selected from the stock of brook trout and placed in individual 37-liter aquaria and fed a maintenance ration of fly larvae. Half $(\mathrm{N}=10)$ of the fish were randomly assigned to a treatment group where impedance was measured via BIA and the other half assigned to a control group where impedance was not measured. Once weekly for three weeks, each fish was anesthetized, and measured for length and weight. The additional measurement of impedance via BIA was 
taken on the treatment fish. Following measurements, fish were immediately returned to the aquaria and changes in color, feeding, swimming, bruising and bleeding were observed daily. A dichotomous variable score $(0$ or 1 , i.e. $0=$ no bruising, $1=$ bruising $)$ was used to monitor basic observations. This repeated measures experiment was analyzed with a logistic regression with SAS 8.0 software.

\section{Repeated procedures and temperature}

A two-factor repeated measures design was used to simultaneously examine effects of repeating 4 BIA measurements on the same fish with and without temperature increases on BIA parameter estimates. Eight small and 8 large (mean total length $=153$ and $291 \mathrm{~mm}$, respectively) brook trout were randomly selected from the stock fish and placed into individual 331 aquaria. Four fish in each size class were randomly selected to be in a control group and the remaining fish were placed in a treatment group resulting in 4 groups of 4 fish (small control, large control, small treatment, and large treatment). The control group measurements were taken 4 times at a constant temperature $\left(12^{\circ} \mathrm{C}\right)$ while the 4 treatment group measurements were taken 4 times, once at 4 different temperatures $\left(5,12,16,21^{\circ} \mathrm{C}\right)$. Prior to measuring, the treatment group was adjusted to the set temperature (starting with warmest) for 30 minutes prior to allow fish core temperature to approximate water temperature. Measurements for the control group immediately followed the treatment group. Water chillers were used to adjust treatment group temperatures and the approximate time between each set of measurements was $1 \mathrm{~h}$. Parameter estimations were calculated from BIA equations (Table 1), normalized for weight and tested for normality. The 4 repeated measurements were analyzed for differences within and between each group (control and treatment) for all body composition parameters (TBW, DW, FFM, TBP, TBA and TBF). A two factor analysis of variance with a repeated measures design was used in SAS 8.0 software. 


\section{Results}

\section{Gut-fill and electrode placement data}

Gut-fill had no effect on BIA measures and did not significantly affect any body composition variables within the whole length or half-length electrode placement groups (Figure 6). The effect of electrode placement was significant $(\mathrm{p}<0.0001)$. Half length measurements overestimated TBW and TBA, and underestimated TBP, TBF, DW and FFM compared to the whole length group (Figure 6). Variation of the estimations was also greater in the half-length measures.

Electrode location was important in the TBF estimations. Original models with ventral and dorsal measurements explained less variation $\left(\mathrm{R}^{2}=0.28\right.$ and 0.56$)$ than the new model developed from the ventral measurements $\left(R^{2}=0.92\right)$. All other parameters regardless of location had high correlation coefficients greater than 0.98 (Table 10).

\section{Impact of weekly BIA procedures on fish}

Bruising was the only effect of weekly BIA measurements. Swimming, feeding, bleeding and color were not affected. Bioelectrical impedance analysis did increase bruising (logistic regression $\mathrm{p}<0.0001$ ) due to BIA measurements. Bruising could be detected for 2 days and then dissipated (Table 11).

\section{Temperature and hourly repeated procedures}

Predicted compositional masses increased at nearly a linear rate with temperature but, when data were normalized for weight (predicted parameter estimate in grams / predicted total weight in grams) temperature terms were canceled out (Figure 7). Repeated measures affected some parameter estimations, but differences between the 4 measures were small. (Table 12 and Table 13). 
Mean predicted values for all four measurements for the small fish are in Table 12. Treatment and control groups values as well as $p$ values (alpha $=0.05)$ were used to show the differences $(p<0.0020)$ between the four estimates. The control group results indicated significant differences between the 4 measurements in TBW, TBP and FFM. When BIA estimations between the control and treatment group were compared, there were no differences $(p>0.05)$ between the groups in all parameters. The standard errors were small in both the treatment and control group and ranged from 0.00052 to 0.00658 .

The BIA parameter estimates for the large fish from both the treatment and control groups as well as the associated $\mathrm{p}$ values $(\mathrm{alpha}=0.05)$ are in Table 13. The treatment group of large fish was measured with BIA 4 times (once at each temperature), and results indicated significant differences $(\mathrm{p}<0.05)$ between the four measures in TBW, TBP, DW and TBA parameters. The control group of large fish was measured with BIA 4 times (all at the same temperature), and results indicated no significant differences between the 4 measurements in all parameters. When BIA predicted responses between the control and treatment group were compared, there were significant differences in TBW. The standard errors were also small in both the treatment and control group and ranged from 0.00004 to 0.01903 .

Ranking the four groups by the total number of within group significant differences between estimates resulted in the following rank order (from most differences to least): large control, large treatment, small control and small treatment.

\section{Discussion}

The stomach fullness and electrode placement experiment revealed that BIA was sensitive to anatomical regions of the fish. This supports electrical resistivity laws that state if cross sectional areas are homogenous, resistance will be constant for all points within the area between the electrodes (Keller et al. 1993). Because the cross sectional area of the fish is not homogenous, the electrode placement and the frequency of the current determine the 
region of the fish that is to be represented by the electrical current (Keller et al. 1993). Methods in Chapter 3 placed electrodes in the anteriad dorsad region (above the lateral line) and in the caudal peduncle region of the fish that represents the dorsal musculature of the fish. This is important for field applications where electrode placement can be controlled but stomach fullness cannot, and reinforces the need to precisely follow electrode placement methods or develop new models representative of different constituent body regions. Just as the original model is representative of the dorsal musculature, variations of the original model could be made with different electrode placements. For larger species, it may necessary to use smaller measured increments rather than whole body measurements due to limitations of their large size. Electrode placement in this model is therefore not sensitive to stomach fullness but to specific anatomical regions.

Ventral measurements were more sensitive to fat content in the ventral region of the fish. Electrical currents were not impeded in the visceral region of the fish during dorsal impedance measurements. The nature of current division described by Ohms law and Kirchhoff's rules dictates that current will pass through an entire circuit, but the path with the least resistance will carry more current. Dorsal measurements allow the current to travel along the dorsal region without being influenced much by the ventral visceral region. The properties of biological tissue are not clearly known and their study is outside the scope of this research, but ventral impedance measurements did result in high correlations between predicted and actual fat values. Other body composition predictions remained highly correlated to the actual values; these relationships may be due to these parameters being more systemic rather than regional. As stated earlier, current will pass through the entire circuit (the entire measured tissue), and these other parameters have a lower resistance than fat, and are therefore well represented and less dependent on electrode location. 
Weekly BIA measurements on fish resulted in only minimal impacts to fish. Slight bruising that lasted a few days was the only significant response observed. Although electrodes puncture the skin, the electrodes are small (28 gauge) and are inserted to a depth of $2 \mathrm{~mm}$ in the anteriad dorsad and caudal peduncle regions with a total puncture time of less than $60 \mathrm{~s}$. These areas are surrounded by musculature and are relatively clear of vital organs or arteries making these ideal locations for invasive, but non-lethal procedures. The only vital organ in either region is the hepatic artery which is located in the posterior area, but procedures place electrodes dorsally to it. This non-lethal method for estimating proximate composition in fish creates a wide range of possibilities for non-lethal compositional study of many fish species, especially threatened or endangered ones, and supports the opportunity for repeated measures study designs.

Temperature and hourly measurements significantly affected BIA estimations both within and between treatment and control groups of large and small fish. Differences were due to the small standard errors of the estimation means, hourly electrode punctures injuring the tissue, and temperature affecting impedance values. The small standard errors of the estimates indicate a precise technique with a high degree of repeatability (Dowdy et al. 1991). Although temperature and hourly measurements caused shifts in the means, the standard errors remained small for each mean value. With the exception of fat mass, estimation means were similar within groups. It is likely that shifts in estimation means were due to electrode punctures that were administered at a rate of approximately one measurement per hour. Each puncture from the electrodes lyses cells and subsequently releases intra-cellular fluids in each of these areas therefore affecting impedance values. Each subsequent puncture further injured the tissue and affected parameter estimations. The rate of punctures that these fish were subjected to was high, and the high frequency of measurements of time would not seem likely in most compositional studies. This is important because most growth and ecological 
studies would not repeatedly measure body composition with BIA at this rate which would decrease the chances of error associated with tissue damage shifting estimation means.

Ancillary to puncture effects, significance differences were also found due to temperature. The model found in Chapter 3 was developed at $15^{\circ} \mathrm{C}$, and application of that and other similar models will not always be at $15^{\circ} \mathrm{C}$. Electrical impedance of any substance varies almost linearly with temperature, so a change in temperature would cause an expected shift in the impedance values used in model formation (Keller et al. 1993). This can be seen in Figure 7, where estimations of wet and water weights $(\mathrm{g})$ increase with temperature at almost a linear rate. Interestingly, when data is then normalized to total weight (i.e.

parameter mass / predicted wet weight), the temperature effect is negated resulting in similar proportion estimations over time (Figure 3). If both impedance values do not change with temperature at the same rate, error surrounding each term occurs. When estimates are then divided by one another, the error surrounding each term is then propagated resulting in different estimations. In this study, errors generated by hourly measures and changes in temperature propagated and contributed to the shifts in estimation means that were found in each of the four measurements of each parameter. Mean differences within and between the four repeated measurements were quite small and depending on the question at hand, may not be biologically significant.

\section{Conclusion}

The use of BIA for proximate composition analysis in field or biological study is promising. Initial results in Chapter 3 revealed a method that is simple to use and precise in estimating all compartments of proximate analysis in brook trout. The simplicity and portability of BIA is apparent with measurements taken with a small, portable hand held impedance analyzer. The handheld unit, a tetrapolar bioelectric impedance analyzer (RJL Systems INC., Detroit, MI) weighs less than $450 \mathrm{~g}$ and is battery operated and simple to use. 
Measurements of detector length, resistance, and reactance are taken from anesthetized fish in about the same amount of time it takes to measure length and weight. The small electrodes allow measurements to be taken in a non-lethal manner, and the low voltage current is undetectable in human subjects (Stanton et al. 1992). Bioelectrical impedance analysis is not only precise in a controlled environment with constant variables (i.e. stomach fullness, electrode placement, single measurements and temperature), but as this study shows, it is consistent under fluctuating conditions representing field applications. This method allows attributes from both field and lab-based assessments to be integrated into a simple, portable, accurate approach to analyze composition components in fish. This capability increases precision in energy flow and proximate composition studies on spatial and temporal scales that were previously impractical. This approach also has potential for the non-lethal study of threatened or endangered species if models are available or if it is found to be possible to use models developed from closely related species. Furthermore, new models may be developed to represent various anatomical regions within a fish. Bioelectrical impedance analysis allows non-lethal measurement of composition and bridges the gap between quick simple field methods and accurate reliable lab methods. 


\section{References}

Anderson, R.O. and Neumann, R.M. 1996. Length, Weight, and Associated Structural Indices. In Fisheries Techniques. Edited by B.R. Murphy and D.W. Willis. American Fisheries Society, Bethesda, Maryland pp. 447-512.

AOAC 1990. Official Methods of Analysis. Association of Official Analytical Chemists, Washington, DC.

Blackwell, B.G., Brown, M.L., and Willis, D.W. 2000. Relative Weight (Wr) Status and Current Use in Fisheries Assessment and Management. Rev. Fish. Sci. 8: 1-44.

Dowdy, S. and S. Wearden 1991. Statistics for research. John Wiley and Sons, New York.

Gudivaka, R., Schoeller, D.A., Kushner, R.F., and Bolt, M.J.G. 1999. Single and multifrequency models for bioelectrical impedance analysis of body water compartments. J. Appl. Physio. 87: 1087-1096.

Keller, F.J., E.W. Gettys, and M.J. Skove 1993. Physics. McGraw-Hill, New York.

Kushner, R.F. and Schoeller, D.A. 1986. Estimation of total body water by bioelectrical impedance analysis. Am-J-Clin-Nutr. 44: 417-424. ill., charts.

Le Cren, E.D. 1951. The length-weight relationship and seasonal cycle in gonad weight and condition in the perch Perca fluviatilis. J. Anim. Ecol. 20: 201-219.

Marien, K. and Patrick, G.M. 2001. Exposure analysis of five fish-consuming populations for overexposure to methylmercury. J Expo Anal Environ Epidemiol. 11: 193-206.

Murphy, B.R., Brown, M.L., and Springer, T.A. 1991. Evaluation of the relative weight (Wr) index with new applications to walleye. N. Am. J. Fish. Manage. 10: 85-97.

Shearer, K.D., Aasgaard, T., Andorsdoettir, G., and Aas, G.H. 1994. Whole body element and proximate composition of Atlantic salmon (Salmo salar) during the life cycle. J. Fish. Biol. 44: 785-797. 
Slanger, W.D. and Marchello, M.J. 1994. Bioelectrical impedance can predict skeletal muscle and fat-free skeletal muscle of beef cow primal cuts. J. Anim. Sci. 72: 3124-3130.

Stanton, C.A., Hamar, D.W., Johnson, D.E., and Fettman, M.J. 1992. Bioelectrical impedance and zoometry for body composition analysis in domestic cats. Am. J. Vet. Res. 53: 251-257.

Strange, R.J. 1996. Field examination of fishes. In Fisheries Techniques. Edited by B.R. Murphy and D.W. Willis. American Fisheries Society, Bethesda, MD pp. 433-446.

Wechsler, S.J. 1984. Fish health assessment: A preliminary report on the use of impressiom smears of skin mucus. J. Fish. Biol. 25: 365-370.

Wedemeyer, G.A., Gould, R.W., and Yasutake, W.T. 1983. Some potentials and limits of the leucocrit test as a fish health assessment method. J. Fish. Biol. 23: 711-716.

Wege, G.J. and Anderson, R.O. 1978. New approached to the management of small impoundments. American Fisheries Society, North Central Division, Special Publication 5, Bethesda, Maryland pp. 79-91. 
Table 8. Impedance equations developed in Chapter 3 to estimate proximate body composition in brook trout.

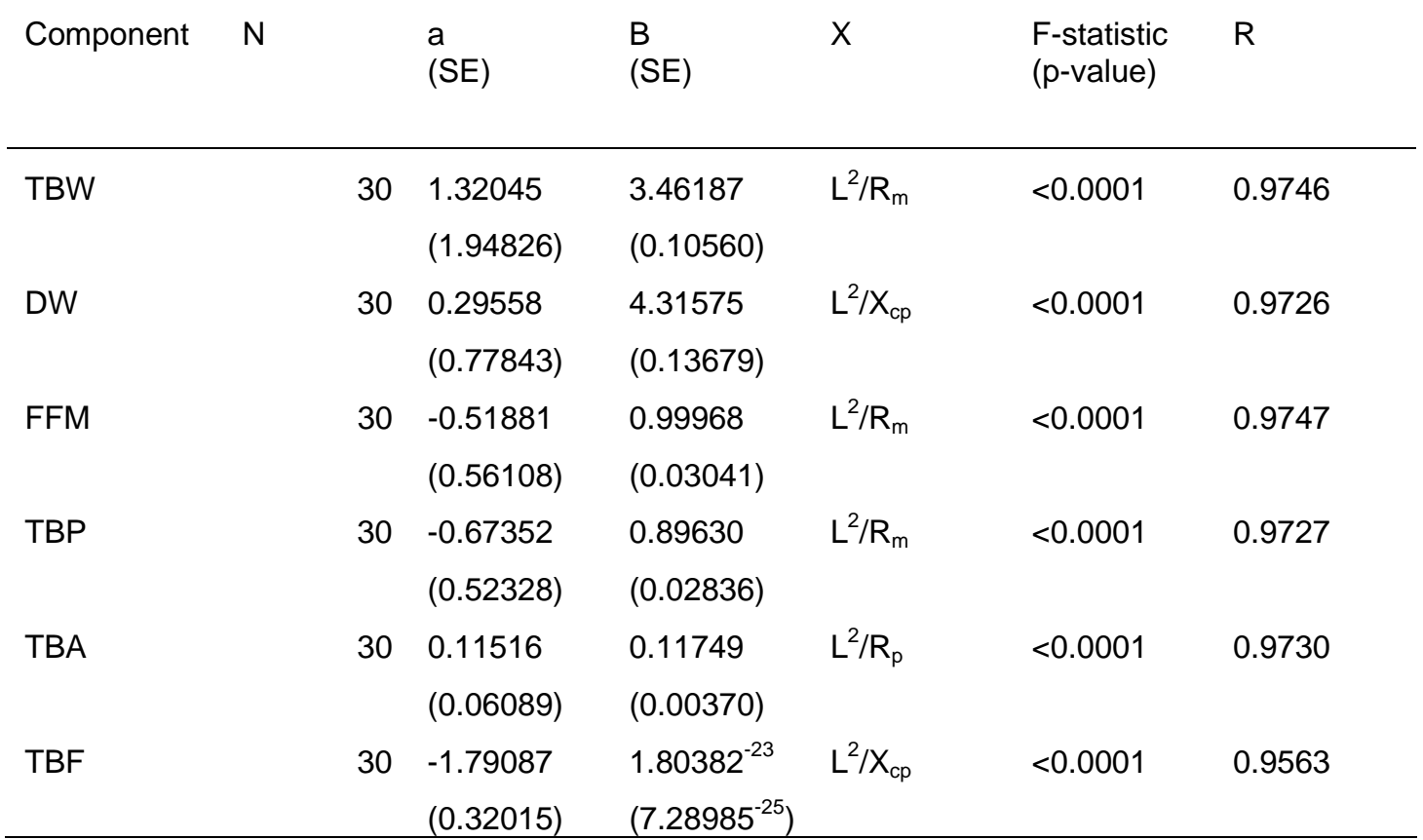

Analysis results of the linear relationships between the measured bioelectrical impedance equations and actual numbers of proximate body composition components: total body water (TBW), dry weight (DW), fat-free mass (FFM), total body protein (TBP), total body ash (TBA), and fat mass (TBF). In the table, $x$ represents the specific impedance equation providing the best-fit, where $\mathrm{L}=$ length, $\mathrm{R}=$ resistance, $\mathrm{Z}=$ impedance, $\mathrm{X}$ is reactance, subscript $\mathrm{p}$ or $\mathrm{m}$ represent parallel or series circuitry, and a and $\mathrm{b}$ represent the intercept and slope of the regression, respectively. 
Table 9. Impedance equations developed in Chapter 3 to estimate proximate body composition in brook trout.

\begin{tabular}{lllll} 
Component & $N$ & $A$ & $B$ & $X$ \\
& & $(S E)$ & $(S E)$ & \\
\hline TBW & 10 & 0.6853 & 9.0684 & $L^{2} / R_{m}$ \\
& & $(0.0360)$ & $(1.673)$ & \\
DW & 10 & 0.2164 & 1.7026 & $L^{2} / X_{c p}$ \\
& & $(0.168)$ & $(0.7672)$ & \\
FFM & 10 & 0.1831 & 1.7018 & $\mathrm{~L}^{2} / \mathrm{R}_{\mathrm{m}}$ \\
& & $(0.0123)$ & $(0.5606)$ & \\
TBP & 10 & 0.1590 & 1.3829 & $\mathrm{~L}^{2} / \mathrm{R}_{\mathrm{m}}$ \\
& & $(0.0111)$ & $(0.5056)$ & \\
TBA & 10 & 0.0241 & 0.3188 & $\mathrm{~L}^{2} / \mathrm{R}_{\mathrm{p}}$ \\
& & $(0.0016)$ & $(0.0723)$ & \\
TBF & 10 & 0.0333 & 0.0082 & $\mathrm{~L}^{2} / \mathrm{X}_{\mathrm{cp}}$ \\
& & $(0.0057)$ & $(0.2583)$ & \\
\hline
\end{tabular}

Analysis results of the linear relationships between the measured bioelectrical impedance equations and actual numbers of proximate body composition components: total body water (TBW), dry weight (DW), fat-free mass (FFM), total body protein (TBP), total body ash (TBA), and fat mass (TBF). In the table, $x$ represents the specific impedance equation providing the best-fit, where $\mathrm{L}=$ length, $\mathrm{R}=$ resistance, $\mathrm{Z}=$ impedance, $\mathrm{X}$ is reactance, subscript $\mathrm{p}$ or $\mathrm{m}$ represent parallel or series circuitry, and a and b represent the intercept and slope of the regression, respectively. 
Table 10. Regression scores (correlation of coefficients) of actual and predicted values for all body composition parameters (predicted weight (WGT), total body water (TBW), dry weight (DW), fat-free mass (FFM), total body protein (TBP), total body ash (TBA) and total body fat (TBF) to compare methods from the original model (Chapter 3) with dorsal measurements from the validation group (A), the original model (Chapter 3) with ventral measurements from the validation group (B), and a new independent model for each parameter using ventral measures from the model group (C).

\begin{tabular}{lcccc}
\hline & \multicolumn{4}{c}{ Model } \\
\cline { 2 - 5 } Parameter & $\mathrm{N}$ & $\mathrm{A}$ & $\mathrm{B}$ & $\mathrm{C}$ \\
\hline Wgt & 10 & 0.9999 & 1.0000 & 1.0000 \\
TBW & 10 & 0.9976 & 0.9984 & 0.9984 \\
DW & 10 & 0.9898 & 0.9860 & 0.9859 \\
FFM & 10 & 0.9904 & 0.9915 & 0.9914 \\
TBP & 10 & 0.9882 & 0.9904 & 0.9902 \\
TBA & 10 & 0.9895 & 0.9855 & 0.9914 \\
TBF & 10 & 0.5601 & 0.2810 & 0.9195 \\
\hline
\end{tabular}


Table 11. Number of negative responses (e.g. not swimming or feeding, bruising, bleeding, loss of color) of fish receiving BIA measurements (BIA) versus control (no BIA).

\begin{tabular}{lllllll} 
Treatment & $\mathrm{N}$ & Color & Feeding & Swimming & Bruising & Bleeding \\
\hline No BIA & 210 & 4 & 22 & 3 & 1 & 0 \\
BIA & 210 & 0 & 13 & 1 & 110 & 3 \\
\hline
\end{tabular}

Bruising was significant $(\mathrm{P}<0.0001$, alpha $=.05)$. 
Table 12. Mean proportions ( $\pm \mathrm{SE}$ ) of body composition compartments for each of four consecutive hourly measurements and p-values for tests within and between groups

\begin{tabular}{|c|c|c|c|c|c|c|c|}
\hline \multirow[b]{2}{*}{ Parameter } & \multirow[b]{2}{*}{ Group } & \multicolumn{4}{|c|}{ Measurement } & \multicolumn{2}{|c|}{ P-value } \\
\hline & & 1 & 2 & 3 & & ithin & Between \\
\hline \multirow[t]{4}{*}{ Total Body Water } & Control & 0.75277 & 0.75187 & 0.75237 & 0.75118 & 0.53290 & \\
\hline & & $(0.00547)$ & $(0.00551)$ & $(0.00521)$ & $(0.00566)$ & & 0.73590 \\
\hline & Treatment & 0.74495 & 0.74692 & 0.75149 & 0.75763 & 0.00010 & \\
\hline & & $(0.00541)$ & $(0.00493)$ & (0.00618) & $(0.00658)$ & & \\
\hline \multirow[t]{4}{*}{ Total Body Protein } & Control & 0.16048 & 0.16072 & 0.15958 & 0.16009 & 0.01990 & \\
\hline & & (0.00188) & (0.00193) & (0.00190) & $(0.00212)$ & & 0.80680 \\
\hline & Treatment & 0.16338 & 0.16166 & 0.16025 & 0.15824 & 0.00010 & \\
\hline & & $(0.00205)$ & $(0.00176)$ & $(0.00200)$ & (0.00207) & & \\
\hline \multirow[t]{4}{*}{ Total Body Fat } & Control & 0.05872 & 0.05858 & 0.05315 & 0.05398 & 0.00180 & \\
\hline & & $(0.00142)$ & $(0.00151)$ & (0.00197) & $(0.00224)$ & & 0.82740 \\
\hline & Treatment & 0.06149 & 0.05546 & 0.05539 & 0.05460 & 0.00220 & \\
\hline & & $(0.00309)$ & (0.00195) & (0.00069) & $(0.00052)$ & & \\
\hline \multirow[t]{4}{*}{ Dry Weight } & Control & 0.24652 & 0.24718 & 0.24520 & 0.24638 & 0.10270 & \\
\hline & & $(0.00468)$ & $(0.00476)$ & $(0.00462)$ & (0.00513) & & 0.76290 \\
\hline & Treatment & 0.25355 & 0.25019 & 0.24654 & 0.24146 & 0.00010 & \\
\hline & & $(0.00490)$ & $(0.00431)$ & (0.00509) & $(0.00532)$ & & \\
\hline \multirow[t]{4}{*}{ Total Body Ash } & Control & 0.02670 & 0.02654 & 0.02639 & 0.02623 & 0.47590 & \\
\hline & & $(0.00087)$ & $(0.00087)$ & (0.00081) & (0.00086) & & 0.73790 \\
\hline & Treatment & 0.02551 & 0.02557 & 0.02634 & 0.02734 & 0.00010 & \\
\hline & & $(0.00084)$ & $(0.00078)$ & (0.00101) & (0.00109) & & \\
\hline \multirow[t]{4}{*}{ Fat Free Mass } & Control & 0.18716 & 0.18726 & 0.18609 & 0.18643 & 0.00240 & \\
\hline & & (0.00109) & $(0.00113)$ & (0.00116) & $(0.00132)$ & & 0.88680 \\
\hline & Treatment & 0.18895 & 0.18739 & 0.18667 & 0.18557 & 0.00030 & \\
\hline & & $(0.00133)$ & $(0.00107)$ & (0.00109) & (0.00109) & & \\
\hline
\end{tabular}

(control and treatment) for all small brook trout. 
Table 13. Mean proportions ( \pm SE) of body composition compartments for each of four consecutive hourly measurements and p-values for tests within and between groups

\begin{tabular}{|c|c|c|c|c|c|c|c|}
\hline \multirow[t]{2}{*}{ Parameter } & \multirow[t]{2}{*}{ Group } & \multicolumn{3}{|c|}{ Measurement } & \multicolumn{3}{|c|}{ P-value } \\
\hline & & 1 & 2 & 3 & & ithin & Between \\
\hline \multirow[t]{4}{*}{ Total Body Water } & Control & 0.71890 & 0.71930 & 0.71929 & 0.71915 & 0.34560 & \\
\hline & & $(0.00032)$ & $(0.00055)$ & $(0.00057)$ & $(0.00051)$ & & 0.01310 \\
\hline & Treatment & 0.71714 & 0.71760 & 0.71800 & 0.71921 & 0.00010 & \\
\hline & & $(0.00010)$ & $(0.00006)$ & $(0.00006)$ & $(0.00009)$ & & \\
\hline \multirow[t]{4}{*}{ Total Body Protein } & Control & 0.17596 & 0.17544 & 0.17465 & 0.17468 & 0.32740 & \\
\hline & & $(0.00111)$ & $(0.00063)$ & $(0.00057)$ & $(0.00062)$ & & 0.66400 \\
\hline & Treatment & 0.17619 & 0.17551 & 0.17477 & 0.17450 & 0.03570 & \\
\hline & & $(0.00043)$ & $(0.00032)$ & $(0.00016)$ & $(0.00012)$ & & \\
\hline \multirow[t]{4}{*}{ Total Body Fat } & Control & 0.08463 & 0.08292 & 0.07935 & 0.07927 & 0.29880 & \\
\hline & & $(0.00457)$ & $(0.00258)$ & (0.00209) & $(0.00252)$ & & 0.95080 \\
\hline & Treatment & 0.08354 & 0.08108 & 0.07824 & 0.07864 & 0.19370 & \\
\hline & & $(0.00198)$ & $(0.00141)$ & $(0.00077)$ & $(0.00060)$ & & \\
\hline \multirow[t]{4}{*}{ Dry Weight } & Control & 0.28167 & 0.28072 & 0.27944 & 0.27954 & 0.39620 & \\
\hline & & $(0.00186)$ & $(0.00108)$ & $(0.00106)$ & $(0.00108)$ & & 0.42600 \\
\hline & Treatment & 0.28226 & 0.28134 & 0.28003 & 0.27923 & 0.00560 & \\
\hline & & $(0.00068)$ & $(0.00052)$ & $(0.00027)$ & $(0.00019)$ & & \\
\hline \multirow[t]{4}{*}{ Total Body Ash } & Control & 0.02222 & 0.02219 & 0.02200 & 0.02197 & 0.36140 & \\
\hline & & $(0.00022)$ & $(0.00016)$ & $(0.00009)$ & $(0.00013)$ & & 0.09870 \\
\hline & Treatment & 0.02185 & 0.02180 & 0.02172 & 0.02194 & 0.03690 & \\
\hline & & $(0.00011)$ & $(0.00007)$ & $(0.00004)$ & $(0.00004)$ & & \\
\hline \multirow[t]{4}{*}{ Fat Free Mass } & Control & 0.19816 & 0.19765 & 0.19676 & 0.19677 & 0.26590 & \\
\hline & & $(0.00121)$ & (0.00068) & $(0.00056)$ & 0.00065 & & 0.97270 \\
\hline & Treatment & 0.19809 & 0.19741 & 0.19666 & 0.19658 & 0.09550 & \\
\hline & & $(0.00049)$ & $(0.00035)$ & $(0.00018)$ & $(0.00014)$ & & \\
\hline
\end{tabular}

(control and treatment) for all large trout. 


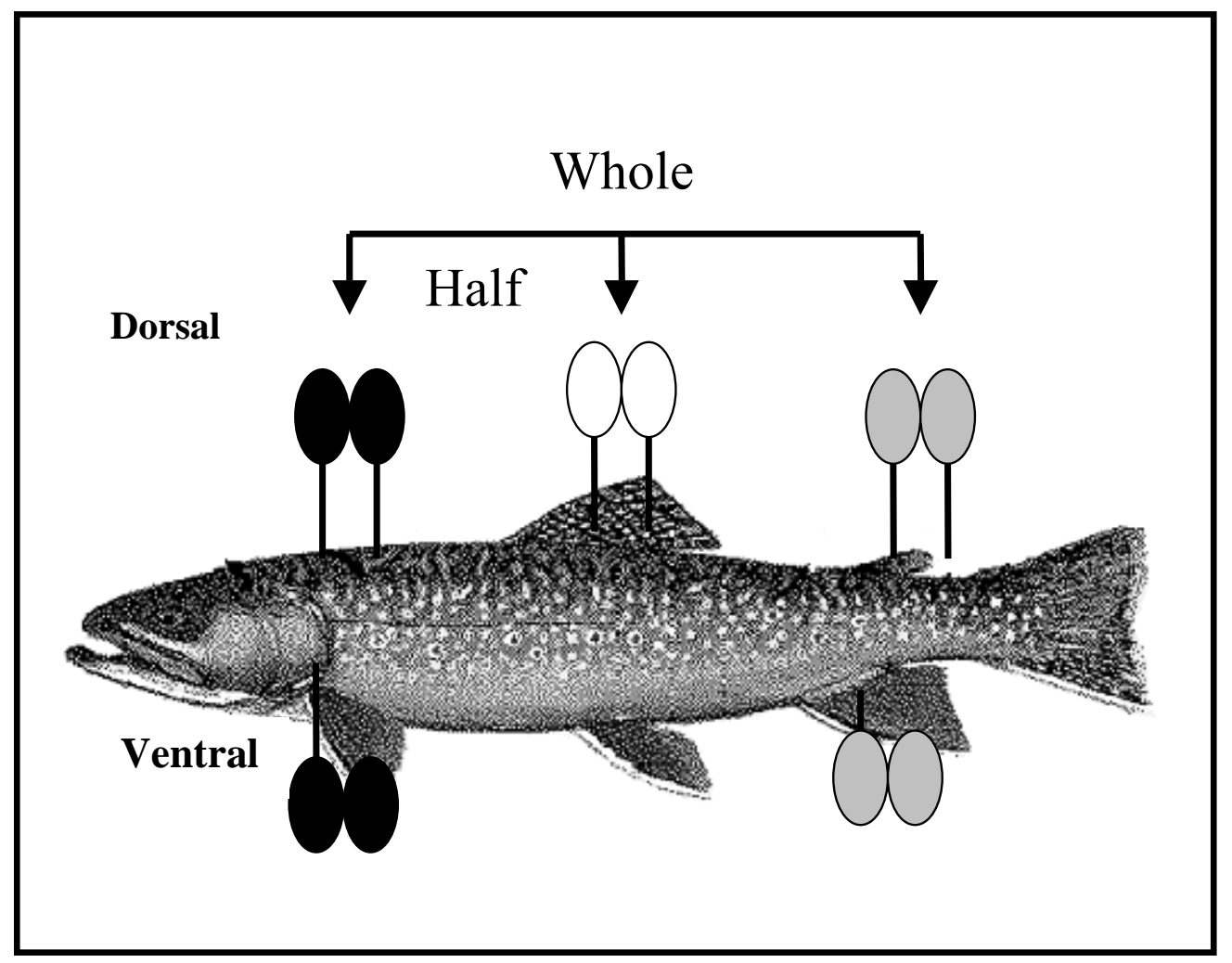

Figure 5. Schematic of whole and half length electrode placement locations used for evaluating BIA estimates of brook trout proximate analysis. 


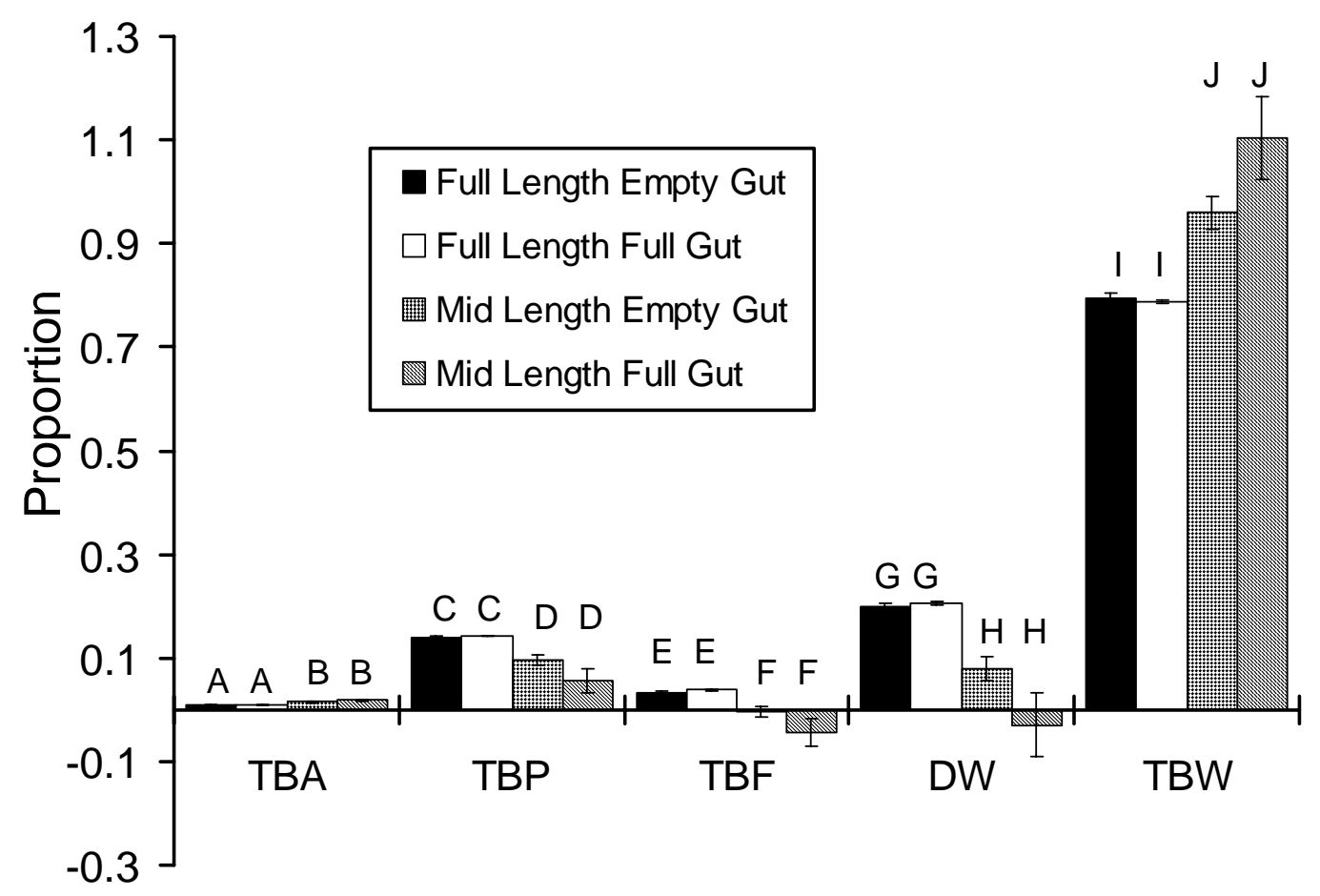

Figure 6. Estimated proximate composition proportions of brook trout for full and half length electrode placement with full or empty guts used in evaluating electrode placement and stomach fullness effects on estimates of proximate analysis. Different letters within a compartment indicate significant differences between total body ash (TBA), total body protein (TBP), total body fat (TBF), dry weight (DW) and total body water (TBW) $($ alpha $=0.05$, data was rank sum transformed prior to significance testing). 


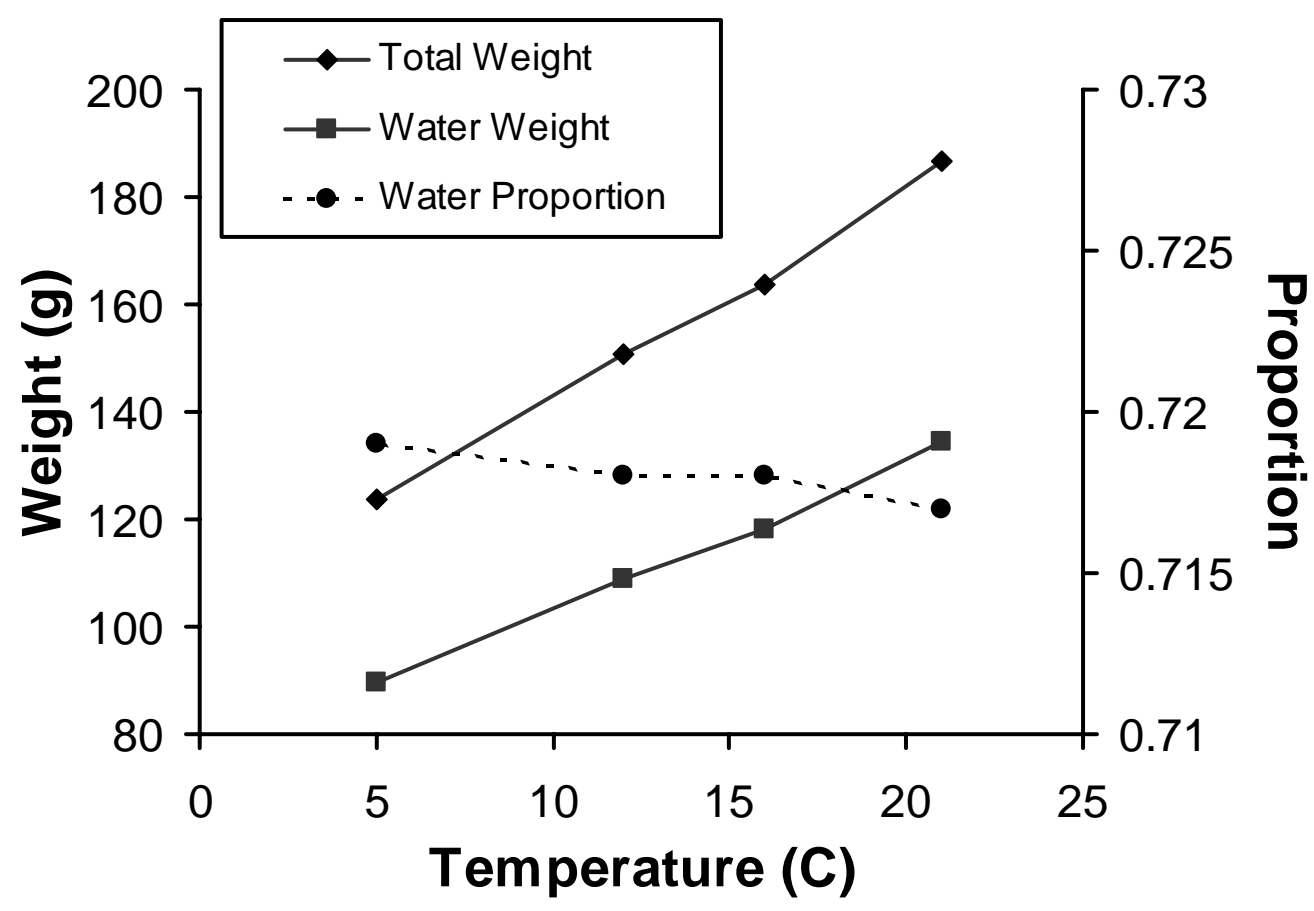

Figure 7. Linear influence of temperature upon the total weight, water weight and water proportion of brook trout at four temperatures. 
Chapter 5. Compensatory growth and compositional change in brook trout (Salvelinus fontinalis).

\begin{abstract}
One of the assumptions in most compensatory growth studies is that the weight gains found are due to energetic conversions from foodstuffs. Brook trout (Salvelinus fontinalis) were randomly split into 3 groups $(\mathrm{N}=8)$ with each group having a different feeding regime (starved, compensatory or ad libitum). Changes in weight, gross growth efficiency, and body composition were measured repeatedly on individual fish using standard laboratory measures as well as bioelectrical impedance analysis (BIA) to determine if 1) compensatory growth occurred and 2) if the weight changes were energetic. In the compensatory group, the no-feed / re-feed period of $2 / 5$ days did elicit a compensatory growth response when compared to the ad libitum group. No significant differences were found between initial weights ( $p>0.1)$, final weights $(\mathrm{p}>0.1)$, growth rates $(p>0.1)$, cumulative consumption $(p>0.1)$ or growth efficiencies $(p>0.1)$ between the ad libitum and compensatory groups. The starved group was found to be different from the ad libitum and compensatory groups ( $\mathrm{p}<0.0001$, ANOVA). Bioelectrical impedance analysis and standard compositional analysis determined that weight gains were energetic due to increases in protein, dry mass and fat, and not due to non-energetic gains (water). Furthermore, BIA found no significant differences in compositional changes between the treatment and control groups throughout the experiment.
\end{abstract}




\section{Introduction}

Compensatory growth is defined as an animal exhibiting increased growth and feeding rates when fed ad libitum following a period of no feed when compared to a similar animal during normal feeding (Johansen et al. 2001). By achieving higher growth rates, compensatory growth is important to aquaculture and ecological sciences.

Generally, compensatory growth responses are measured by the growth and consumption rates of the organism that in turn are calculated using the live weight of the organism. Although an increase or decrease in live weight can indicate growth or atrophy changes, these changes do not necessarily reflect energetic changes. Body composition analysis would provide a better description of specific weight gains. However, the methodology requires either sacrificing the animal or is too expensive, time consuming, and laborious for most applications.

The study of compensatory growth is important within agricultural and ecological sciences. Agricultural importance is seen by increasing animal growth with reduced feed levels. One of the better examples of compensatory growth is shown by Hayward et al. (1997) in which he used a compensatory growth response to double the growth rates of hybrid sunfish when compared to controls. Implications for agriculture use are obvious with work being done on cattle (Fox et al. 1972), poultry (Plavnik and Hurwitz 1985) and swine (Kyriazakis et al. 1991). Ecologically, compensatory growth may provide valuable insight into energy allocation and investment theories of organisms especially during time of nutritional restriction or stress. Changes in growth rates, body composition and weight due to energy allocation shifts are noted in ecological literature (Weatherup and McCracken 1999),(King and Farner 1966; Elliott 1976b; Mrosovsky and Sherry 1980; 
Craig et al. 1989; Elliott and Hurley 1995; Hartman and Brandt 1995a; Jonsson et al. 1997; Koskela et al. 1997) and tracking compositional changes within the framework of compensatory growth may provide insight and rational into these theories.

The majority of studies on compensatory growth use live weight as a growth indicator (Dobson and Holmes 1984),(Paul et al. 1995; Paul et al. 1995; Jobling and Koskela 1996; Hayward et al. 1997; Hayward et al. 1997; Whitledge et al. 1998) but the problem with live weight measurements is they do not accurately represent energetic changes. Typical vertebrate species are composed of $60-80 \%$ water, and several studies found that changes in weight were due to fluctuations in the relative proportions of fat and water (Elliott 1976a; Weatherup and McCracken 1999; Johansen et al. 2001). When live weights are used in compensatory growth analysis, a change in water content may falsely indicate a change in growth and growth efficiency rates.

Bioelectrical impedance analysis (BIA) has provided body composition analysis in humans for over 50 years (Thomson et al. 1997), and recently this technology has been introduced into fisheries biology (Cox and Hartman, in review). In a study by Cox and Hartman (in review), body composition models formulated from BIA measures provided a means of estimating body composition in brook trout and a group of warm water fish species with a high degree of predictability $\left(\mathrm{R}^{2}>0.8507\right)$. Additional experiments showed that BIA methods are non-lethal and appear to produce little measurable effect on fish health or behavior. Once a model is built, BIA estimations are derived from: resistance (measure of extracellular resistance), reactance (measurement of "celled" mass) and distance between detecting electrodes. These three measurements are used to predict total body water (TBW), dry weight (DW), fat-free mass (FFM), total body 
protein (TBP), total body ash (TBA) and total body fat (TBF), and are obtained on live, anaesthetized organisms in about the time it takes to measure live weight.

The purpose of this study is determine if brook trout (Salvelinus fontinalis) fed at a 5 day feed $\cdot 2$ day no-feed cycle will exhibit compensatory growth, and if so, is the growth due to energetic changes. Furthermore, actual energetic quantities will be measured using standard proximate analysis techniques and compared with predicted values from BIA. Compensatory growth is discussed in terms of final weights, growth rates, and consumption and compositional values (from laboratory and BIA methods).

\section{Methods}

Twenty four juvenile brook trout (mean $15.29 \mathrm{~g}, 1.30$ s.d.) were obtained from the Bowden state fish hatchery, Bowden, West Virginia. Previous food rations for the trout were standard hatchery trout pellets fed ad libitum approximately 3 times $\cdot$ day $^{-1}$. Gender was not determined, and condition of all fish appeared to be normal. Fish used in this experiment were housed in individual 331 aquaria in large $2 \times 3 \mathrm{~m}$ re-circulating tanks. Water was chilled and maintained at 14 to $16^{\circ} \mathrm{C}$ in a head tank, pumped up into individual aquaria, allowed to overflow back into the large tanks and drained via gravity back into the head tank to be re-chilled (Figure 1).

Fish were randomly selected to be in one of three groups $(\mathrm{N}=8$ in each group): starvation (no food), treatment (ad libitum for five days followed by no feed for two days), and control (ad libitum). Daily ration and consumption rates were calculated for individual fish during feed times and were fed fly larvae (Sarcophaga bullata) (Grubco Inc., Hamilton, Ohio). To measure consumption, fly larvae were weighed to the nearest $0.0001 \mathrm{~g}$ prior to feeding and every 24 hours, the number of fly larva left in each tank 
were removed, enumerated and subtracted from the initial number placed in the tank. Consumption was calculated and reported as $\mathrm{g}$ fly larvae consumed $\cdot \mathrm{g} \mathrm{fish}^{-1} \cdot \mathrm{day}^{-1}$. Fish weight was measured to the nearest $0.01 \mathrm{~g}$ and gains or losses represented the difference between initial and final weights of each individual fish. Each week for eight weeks, all fish were anesthetized with a solution of MS-222 (1 g. 91 water $\left.^{-1}\right)$, and length, weight, resistance and reactance measurements were taken (i.e. eight replicates for each of three groups every week for eight weeks) following methods in Cox and Hartman (in review). Bioelectrical impedance analysis predictions were used in a repeated measures design to follow changes in proximate composition and energy allocation for individual brook trout in the three different feeding regimes. Measurements of fat, dry, protein, ash and water masses followed methods in Craig et al. (1978), and dry weights were used to estimate energy using regression equations found in Hartman and Brandt (1995b). Consumption measures included daily specific consumption ( $\mathrm{SC}, \mathrm{g}$ food $\cdot \mathrm{g}$ fish $\left.{ }^{-1} \cdot \mathrm{day}^{-1}\right)$, and cumulative consumption $(\mathrm{CC})$ where $\mathrm{CC}$ is the total amount of food consumed (g) throughout the experiment. Measures of growth included gross growth efficiency $(\mathrm{GGE})$, where $\mathrm{GGE}=\left(\right.$ weight $_{\text {final }}-$ weight $\left._{\text {initial }}\right)$ $\cdot \mathrm{CC}^{-1}$, and absolute growth rate $(\mathrm{AGR})$, where $\mathrm{AGR}=\left(\right.$ weight $_{\text {final }}-$ weight $\left._{\text {initial }}\right) \cdot$ total days of the experiment ${ }^{-1}$. Statistical and analytical procedures including proc means, general linear models and t-tests were completed with SAS ${ }^{\circledR} 8.1$ software. Measurements of growth, SC, CC, GGE, AGR and individual body composition parameters were compared using analysis of variance (ANOVA) statistical tests between the three groups of brook trout with an pre-set alpha level of 0.05 . 


\section{Results}

Wet weight and length increased at similar rates in the treatment and control groups while weight decreased and the length stayed the same in the starved group (Figure 9 and Table 12. Mean proportions $( \pm \mathrm{SE}$ ) of body composition compartments for each of four consecutive hourly measurements and p-values for tests within and between groups (control and treatment) for all small brook trout.). Initial mean weights of control, treatment and starved groups were not significantly different $(p=0.743$, ANOVA). End weights of the control and treatment groups were significantly greater than the starved group ( $\mathrm{p}<0.0001$ and Table 12), but no difference was detected between the control and treatment groups. In the starved group, the majority of weight was lost during the first 2 weeks. Wet weights of the starved fish were not significantly different from one another from week 2 to week 9, but significance was found between week 1 and weeks 2-9 (p < 0.0001, ANOVA). The starved group lost an average of $3.09 \mathrm{~g}$ during 8 weeks, and 1.26 $\mathrm{g}$ (greater than $40 \%$ of the total weight lost) was lost the first week followed by an average of $0.26 \mathrm{~g}$ per week (less than $12 \%$ every consecutive week) thereafter.

Bioelectrical impedance analysis slightly underestimated percent dry weight and overestimated percent water. However, the standard error was relatively high for the actual estimation of dry weight in the treatment group and general patterns in proximate composition among the treatment groups were shown by BIA estimations (Table 12).

Body composition predictions of the control and treatment groups remained similar throughout the experiment. Differences in body composition parameters emerged during the second week in the starved group (Figure 11). Differences included water weight proportions increasing in the starved group while decreasing in control and 
treatment groups. Dry mass, fat mass, fat-free mass and protein mass proportions decreased in starved fish, and ash proportions in the starved group increased during week five. The rates of water increases were inversely related to dry weight decreases in all the groups (Figure 11).

The specific consumption rates showed that the treatment group exhibited a hyperphagic response during the first days of the re-feed period that ended by the start of the next no-feed period. This is evidenced by the significant difference in specific consumption rates between the treatment and control groups on the first day of re-feed ( $p$ $<0.0001)$ and a lack of significance $(\mathrm{p}=0.6043)$ on the last day of the re-feed period (Figure 12). Parameters including GGE, AGR and CC did not differ between control and treatment groups ( $\mathrm{p}=0.929,0.9536$ and 0.4027 , respectively) (Table 1$)$. The parameters of GGE and CC were not calculated for the starved group.

\section{Discussion}

Brook trout are found to frequently adjust to various environmental conditions (Hutchings 1993) and because of this adjustment and the fact that they are indeterminate growers, brook trout proved to be a good species for compensatory growth studies. The growth response of the brook trout in the treatment group following cycles of no-feed and re-feed periods was found to be "compensatory" because of the measured hyperphagic responses and equivalent weight gains in both the treatment and control groups throughout the course of the experiment. Weekly measures of weight were not frequent enough to determine differences in treatment group growth rates because feed periods cycled more frequently than the weighing. Weight gains in both control and treatment groups were found to be energetic due to gains in fat, muscle, tissue or bone, and were 
determined by measurements of compositional values from BIA and laboratory methods.

The use of BIA was found to be precise in body composition comparisons, but not accurate when compared to laboratory results. The starved group lost the majority of its total weight during the first week and seemed to compensate for weight loss during weeks two through eight by a non-energetic compensatory response (i.e. water).

To maximize compensatory growth responses, experiments were conducted on juvenile brook trout in good condition during the spring. As brook trout grow older, more energy is allocated to reproduction than to growth of somatic tissue. By using these fish, our ability to detect changes in growth is enhanced. This is due to a larger proportion of energy allocated to growth that is more easily measured than the smaller proportion of energy allocated to reproduction. Fish condition prior to the experiment was also good. If animal condition is poor, a compensatory response may return the animal to its "poor condition" set point and furthermore, during nutrient deprivation, weight loss would be minimal if weight is already lost. Conversely, if the condition of the animal is good, response to nutrient deprivation would be measured from a "normal composition" set point and therefore would better reflect losses and eventual gains. Winick and Nobel (1966) found that nutritional stress that lasted too long or was inflicted upon animals at too young of an age reduced the number of cells in the body. Because of this reduction in growth potential realimentation is not as successful. Trout in this experiment had been fed at hatchery rations prior to the study and were in good condition.

The timing of reproduction is also important to energetic responses. By conducting experiments in the spring, allocation of consumed energy would not be 
directed toward reproductive sinks. A compensatory growth response could be masked if the animal under observation is allocating energy to spermatogenesis or oogensis, and the research presented here was done during a non-reproductive period to avoid competition from these confounding factors.

Compensatory growth determination was due to 1) detection of hyperphagia in the treatment group and 2) equivalent weight gains in treatment and control groups. Since food consumption by individual fish was measured daily and the no feed and re-feed periods cycled every 2 and 5 days, respectively, daily measures of consumption were frequent enough to detect consumption rate differences between the two groups during each feed period. Specific consumption rates of the treatment group during the first day of the re-feed period were twice that of the control group during every cycle indicating that a hyperphagic response occurred (Figure 12). This response has been identified as a prelude to compensatory growth among fishes (Dobson and Holmes 1984; Jobling and Koskela 1996; Hayward et al. 1997; Johansen et al. 2001) and it has been correlated with increases in growth rates. The hyperphagic response in the treatment group allowed cumulative consumption (total food consumed) in the treatment group to equal that of the control group. Although consumption measurements allowed detection of hyperphagia, closely associated growth rates were undetectable between the two groups.

Hyperphagia was detected in the treatment group growth rate changes. The correlation between hyperphagia and an increase in growth is well documented (Jobling and Koskela 1996; Johansen et al. 2001) but the frequency of weight measurements used in growth rate calculations must be more frequent than the periods of the no feed /re-feed cycle in order to determine changes in growth. The weekly measurements of total weight 
were not frequent enough in our study to detect these differences. This is because growth rates were based on one measurement per week while the feed cycles were based on two periods per week, and weight measures must be more frequent than feed cycles. Growth rates slow down during periods of nutrient deprivation and then increase during periods of nutrient supplementation (Hayward et al. 1997). Increasing the frequency of weight measurements to at least one measurement per period would increase the sensitivity of weight measures to detect changes. For example, if the measurements were taken at the beginning of each period, there would be three measurements per cycle: one at the start of the no-feed period, a second at the start of the feed period and a third at the end of the feed period. This would provide the sensitivity needed to follow change in weight as it pertains to the cyclic changes of feed deprivation and supplementation. Hayward et al. (1997) found differences in growth rates between groups when weights were measured weekly and fish were fed more than once per week. Not only were weigh schedules more frequent than the food cycles, but the feed cycles were variable resulting in higher growth rates.

Other re-feed schedules have resulted in higher rates of compensatory growth than those found in our study. In a study by Hayward et al. (1997) with Lepomis macrochirus, the re-feed periods ended at the cessation of hyperphagia rather than after a fixed time. This resulted in final weights of the treatment group exceeding the control group by as much as a factor of two. Hayward's no-feed period of two days was identical with ours, but the re-feed period was maintained until hyperphagia ended. Daily specific consumption rates of the control and compensatory groups were not different. In the current study, no-feed and re-feed time periods were set, and although hyperphagia had 
ceased at the onset of the no-feed period, the actual time it ceased may have been before this point. Rather than using set schedules, it may be beneficial to maintain a dynamic no-feed · re-feed schedule similar to Hayward et al. (1997). Hogg (1991) points out that to initiate compensatory growth, nutritional stress from either the quantity or quality of food should be reduced to the point of not allowing the animal to express its genetic potential for growth but not to the extent to cause permanent slow growth. The two day no-feed period in our study reduced the potential for growth, but the study by Hayward et al. (1997) maximized periods of re-feeding by initiating the no-feed period at the cessation of hyperphagia. Following methods in Hayward et al. (1997), the re-feed periods should be more dynamic allowing by initiating re-feed periods at the cessation of hyperphagia rather than using finite temporal limits. The study by Hayward et al. (1997) did not include composition data to confirm that weight changes were energetic, but because consumption and growth efficiencies were higher in their treatment group, it is assumed that weight gains were also due to energetic gains rather than water weight gains.

Energetic measures of growth should be included in compensatory growth studies. Growth and consumption rates, growth efficiencies, and final weights are common measures for determination of compensatory growth, but body composition values should also be included in weight gain responses to verify that weight gains are energetic. Several studies included energetic measures (Quinton and Blake 1990; Paul et al. 1995; Johansen et al. 2001), but most did not (Dobson and Holmes 1984; Jobling and Koskela 1996; Nicieza and Metcalfe 1997; Hayward et al. 1997; Whitledge et al. 1998; Hayward et al. 2000). To ensure that weight gains in either group are energetic and due 
to gains in muscle, tissue or bone, compositional values from either laboratory methods or from BIA should be used to determine body composition values. In this study, laboratory measurements of dry and water weights were not significantly different between the control and treatment groups indicating that the weight gains were energetically based and not due to water weight gains. Other methods of body composition analysis have been used in compensatory growth studies including body weight regressions (Johansen et al. 2001), and length per weight (Dobson and Holmes 1984), but body composition provides the best measure of energetic gains. In our study, BIA estimations indicated energetic gains and not water weight gains in the control and treatment groups and proved to be precise but not accurate compared to laboratory results in measuring compositional change. Dry weight proportions were underestimated and water weight proportions were overestimated by BIA when compared to laboratory observations. It was useful in mapping trends of relative compositional gains and losses over time, especially by tracking changes over time for each individual fish in a repeated measures design.

The study of compensatory growth is important to agricultural and ecological sciences. Agriculturally, capitalization of animal growth without adversely affecting carcass composition may depend solely on feed reduction and supplementation, but research has shown that other variables such as genotype, sex, age, age at maturity, species etc. also play important roles in compensatory growth (Wilson and Osbourn 1960; Winick and Nobel.A 1966; Zubair and Leeson 1994). Ecologically, compensatory growth may provide valuable insight into energy allocation and investment theories of organisms especially during time of nutritional depression or stress. Compensatory 
growth is not fully described or understood, but considering if and where energetic gains or losses occur within growth or metabolic compartments may provide valuable insight into the mechanisms and pathways underlying the paradoxical compensatory growth response. Allen (1951) determined that energetic inputs via invertebrate production are below levels for fish growth (the Allen paradox). One possible solution to elevate fish productivity may be a compensatory growth response. Invertebrate production rates can be periodic (high production followed by no/low production) and brook trout feeding rates may also be periodic due to them. This periodic feeding could be similar to the experiments described here, and initiate a compensatory growth response in wild trout populations. This would increase growth rates that would support life history theory of increased growth rates favoring high effort and early reproduction (Hutchings 1993). If compensatory growth is more or less prevalent among certain species of trout, the possession of a compensatory growth response may allow a competitive advantage. For example, it has been shown by De Staso and Rahel (1994) that brook trout dominate other trout species during warmer temperatures, and this may be due to compensatory growth. 


\section{References}

Allen, K.R. 1951. The New Zealand Marine Department of Fisheries Bulletin. 10: 1-231.

Craig, J.F., Kenley, M.J., and Talling, J.F. 1978. Comparative estimations of the energy content of fish tissue from bomb calorimetry, wet oxidation and proximate analysis. Fresh. Biol. 8: 585-590.

Craig, J.F., Smiley, K., and Babaluk, J.A. 1989. Changes in the body composition with age of goldeye, Hiodon alosoides. Can. J. Fish. Aq. Sci. 46: 853-858.

De Staso III, J. and Rahel, F.J. 1994. Influence of water temperature on interactions between juvenile Colorado River cutthroat trout and brook trout in a laboratory stream. Trans. Am. Fish. Soc. 123: 289-297.

Dobson, S.H. and Holmes, R.M. 1984. Compensatory growth in the rainbow trout, Salmo gairdneri Richardson. J. Fish. Biol. 25: 649-656.

Elliott, J.M. 1976a. Body composition of brown trout (Salmo trutta L.) in relation to temperature and ration size. J. Anim. Ecol. 45: 273-289.

Elliott, J.M. 1976b. The energetics of feeding, metabolism and growth of brown trout (Salmo trutta L.) in relation to body weight, water temperature and ration size. J. Anim. Ecol. 45: 923-948.

Elliott, J.M. and Hurley, M.A. 1995. The functional relationship between body size and growth rate in fish. Funct. Ecol. 9: 625-627.

Fox, D.G., Johnson, R.R., Preston, R.L., Docherty, R.R., and Klosterman, E.W. 1972. Protein and energy utilization during compensatory growth in beef cattle. J. Anim. Sci. 34: 310. 
Hartman, K.J. and Brandt, S.B. 1995a. Comparative energetics and the developmental of bioenergetics models for sympatric estuarine piscivores. Can. J. Fish. Aq. Sci. 52: $1647-1666$.

Hartman, K.J. and Brandt, S.B. 1995b. Estimating energy density of fish. Trans. Am. Fish. Soc. 124: 347-355.

Hayward, R.S., Wang, N., and Noltie, D.B. 2000. Group holding impedes compensatory growth of hybrid sunfish. Aqua. 183: 299-305.

Hayward, R.S., Noltie, D.B., and Wang, N. 1997. Use of compensatory growth to double hybrid sunfish growth rates. Trans. Am. Fish. Soc. 126: 316-322.

Hogg, B.W. 1991. Compensatory Growth in Ruminants. In Growth Regulation in Farm Animals. Edited by A.M. Pearson and T.R. Dutson. Kluwer Academic Publishers, New York, NY.

Hutchings, J.A. 1993. Adaptive life histories effected by age-specific survival and growth rate. Ecol. 74: 673-684.

Jobling, M. and Koskela, J. 1996. Interindividual variations in feeding and growth in rainbow trout during restricted feeding and in a subsequent period of compensatory growth. J. Fish. Biol. 49: 658-667.

Johansen, S.S., Ekli, M., Stangnes, B., and Jobling, M. 2001. Weight gain and lipid deposition in Atlantic salmon, Salmo salar, during compensatory growth: evidence for lipostatic regulation? Aqua. Res. 32: 963-974.

Jonsson, N., Jonsson, B., and Hansen, L.P. 1997. Changes in proximate composition and estimates of energetic costs during upstream migration and spawning in Atlantic salmon (Salmo salar). J. Anim. Ecol. 66: 425-436. 
King, J.R. and Farner, D.S. 1966. The adaptive role of winter fattening in the whitecrowned sparrow with comments on its regulation. Am. Nat. 100: 403-418.

Koskela, J., Pirhonen, J., and Jobling, M. 1997. Effect of low temperature on feed intake, growth rate and body composition of juvenile Baltic salmon. Aqua. Int. 5: 479488.

Kyriazakis, I., Stamataris, C., Emmans, G.C., and Whittemore, C.T. 1991. The effects of food protein content on the performance of pigs previously given foods with low or moderate protein content. Anim. Prod. 52: 165.

Mrosovsky, N. and Sherry, D.F. 1980. Animal Anorexias. Sci. 207: 837-842.

Nicieza, A.G. and Metcalfe, N.B. 1997. Growth compensation in juvenile Atlantic salmon: Responses to depressed temperature and food availability. Ecol. 78: $2385-2400$.

Paul, A.J., Paul, J.M., and Smith, R.L. 1995. Compensatory growth in Alaska yellowfin sole, Pleuronectes asper, following food deprivation. J. Fish. Biol. 46: 442-448.

Plavnik, I. and Hurwitz, S. 1985. The performance of broiler chicks during and following a severe feed restriction at an early age. Poult. Sci. 64: 348 .

Quinton, J.C. and Blake, R.W. 1990. The effect of feed cycling and ration level on the compensatory growth response in rainbow trout, Oncorhynchus mykiss. J. Fish. Biol. 37: 33-41.

Thomson, B.C., Thomas, B.J., Ward, L.C., and Sillence, M.N. 1997. Evaluation of multifrequency bioelectrical impedance data for predicting lean tissue mass in beef cattle. Aust. J. Exp. Agric. 37: 743-749. 
Weatherup, R.N. and McCracken, K.J. 1999. Changes in rainbow trout, Oncorhynchus mykiss (Walbaum), body composition with weight. Aqua. Res. 30: 305-307.

Whitledge, G.W., Hayward, R.S., Noltie, D.B., and Wang Ning. 1998. Testing Bioenergetics Models under Feeding Regimes that Elicit Compensatory Growth. Trans. Am. Fish. Soc. 127: 740-746.

Wilson, P.N. and Osbourn, D.F. 1960. Compensatory growth after undernutrition in mammels and birds. Biol. Rev. 35: 324.

Winick, M. and Nobel.A. 1966. Cellular response in rates during malnutition at various ages. J. Nutr. 89: 300.

Zubair, A.K. and Leeson, S. 1994. Effect of varying period of early nutrient restriction on growth compensation and carcass characteristics of male broilers. Poult. Sci. 73: 129. 
Table 14. Feeding and consumption rates for control, treatment and starved groups of brook trout (Salvelinus fontinalis) over 57 days. For each group values are given for total feed days, number of no-feed / feed cycles, initial and final live weights, average growth rate (AGR), the cumulative consumption (CC), and the gross growth efficiency (GGE). Values in parenthesis are standard deviations (SD) and asterisks $(*)$ indicate values are different (ANOVA, $\mathrm{P}<0.05)$ from controls.

\begin{tabular}{|c|c|c|c|c|c|c|c|}
\hline \multirow[b]{2}{*}{ Group } & \multicolumn{2}{|c|}{ Feeding } & \multicolumn{2}{|c|}{ Mean } & \multirow[b]{2}{*}{ AGR $(g / d)$} & \multirow[b]{2}{*}{$\mathrm{CC}(\mathrm{g})$} & \multirow[b]{2}{*}{ GGE } \\
\hline & Days & Cycles & Initial weight (g) & Final weight $(\mathrm{g})$ & & & \\
\hline Control & 57 & 0 & 15.55 & $68.43(9.33)$ & $0.94(0.16)$ & $167.37(15.20)$ & $0.33(0.08)$ \\
\hline Treatment & 40 & 8 & $15.32(1.57)$ & $67.82(9.21)$ & $0.94(0.15)$ & $151.72(9.90)$ & $0.34(0.05)$ \\
\hline Starved & 0 & 0 & $15.02(1.10)$ & $11.93(1.08)$ * & $-0.06(0.01)$ * & 0 & 0 \\
\hline
\end{tabular}




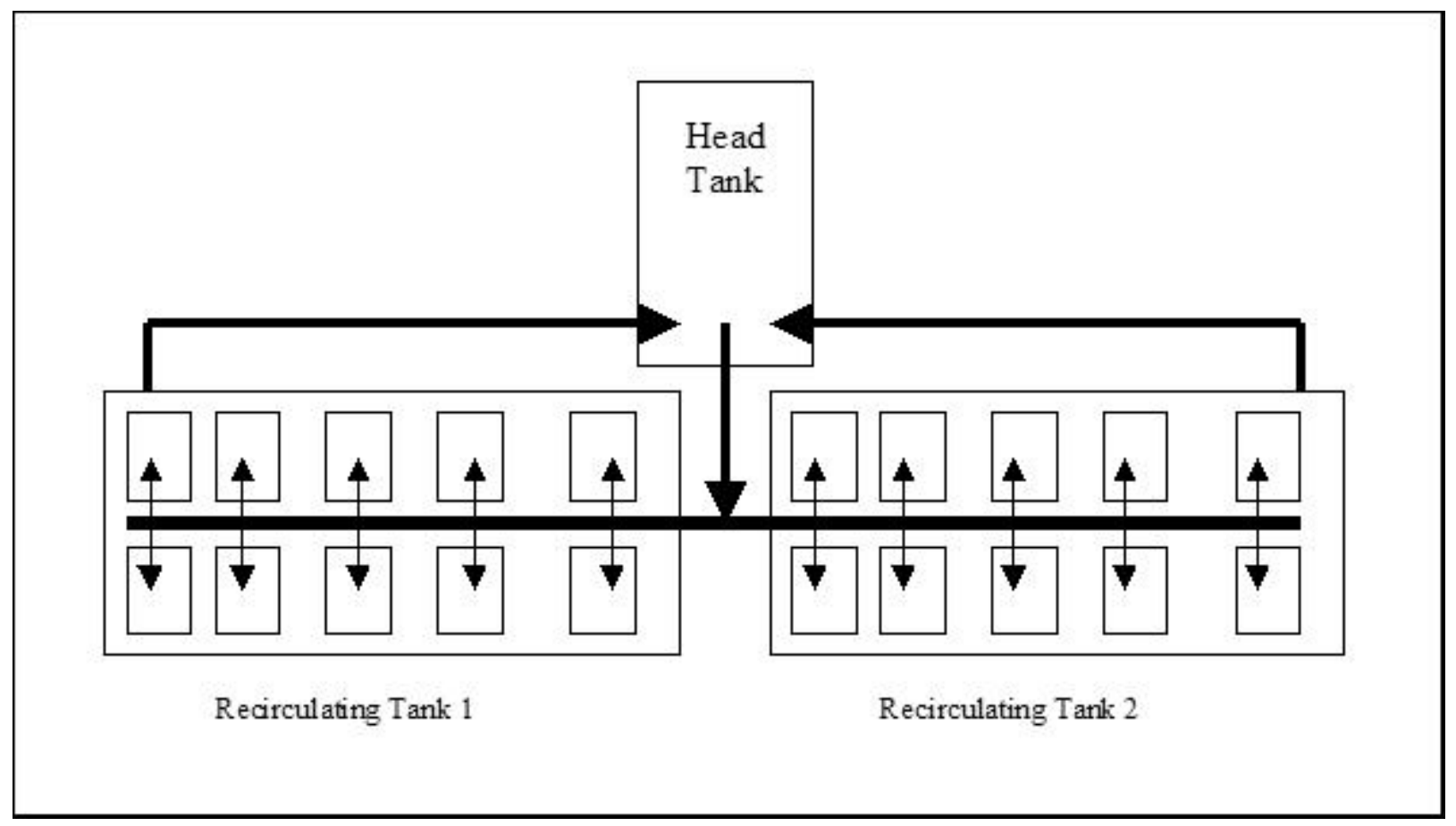

Figure 8. West Virginia University cold water re-circulating tanks used in the compensatory growth experiment. 

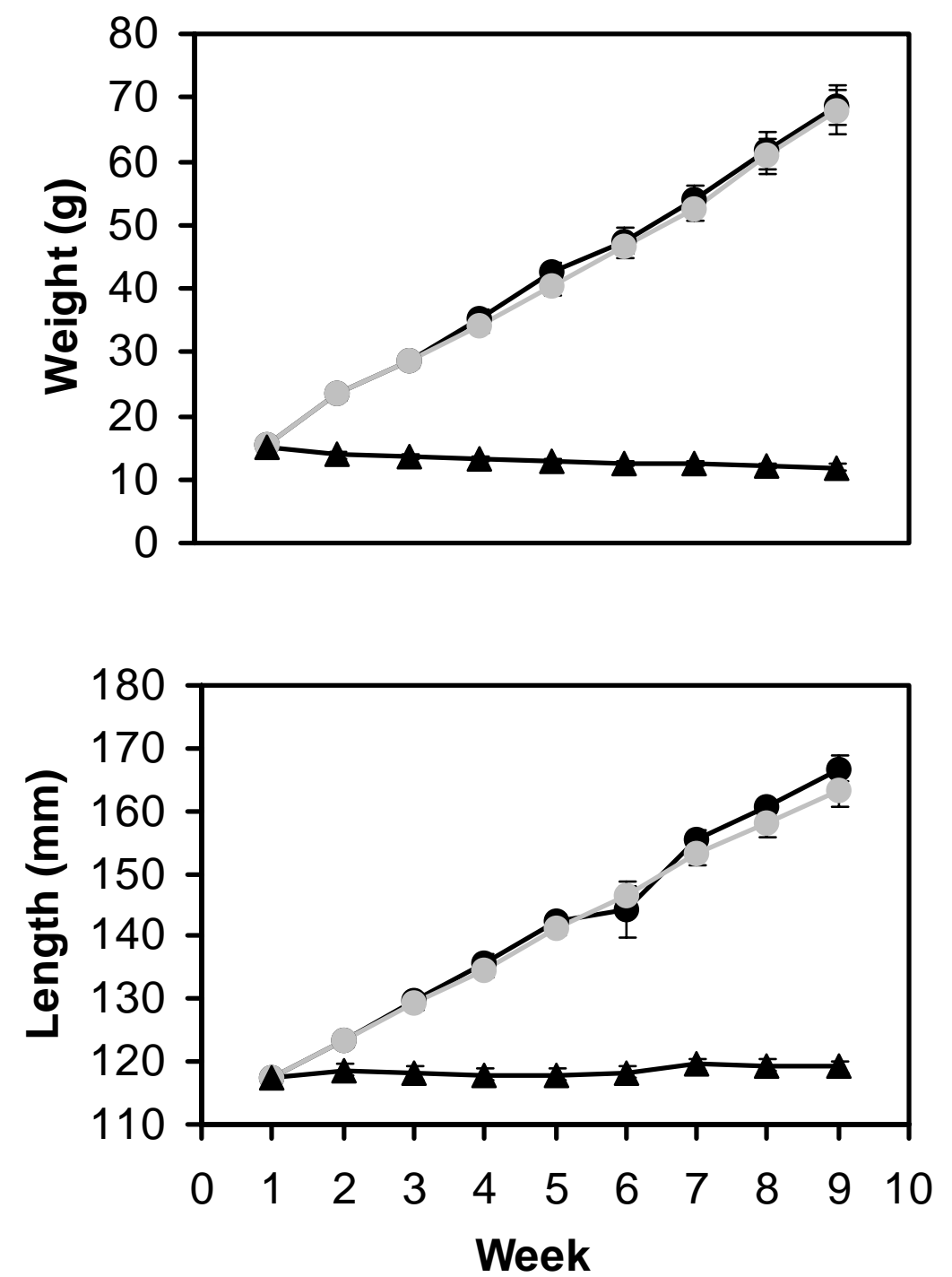

Figure 9. Weekly length and weight measurements of the starved ( $\mathbf{\Delta})$, treatment $(\bullet)$ and control $(\bullet)$ groups of brook trout over 57 days $(\mathrm{N}=8$ fish per group). 


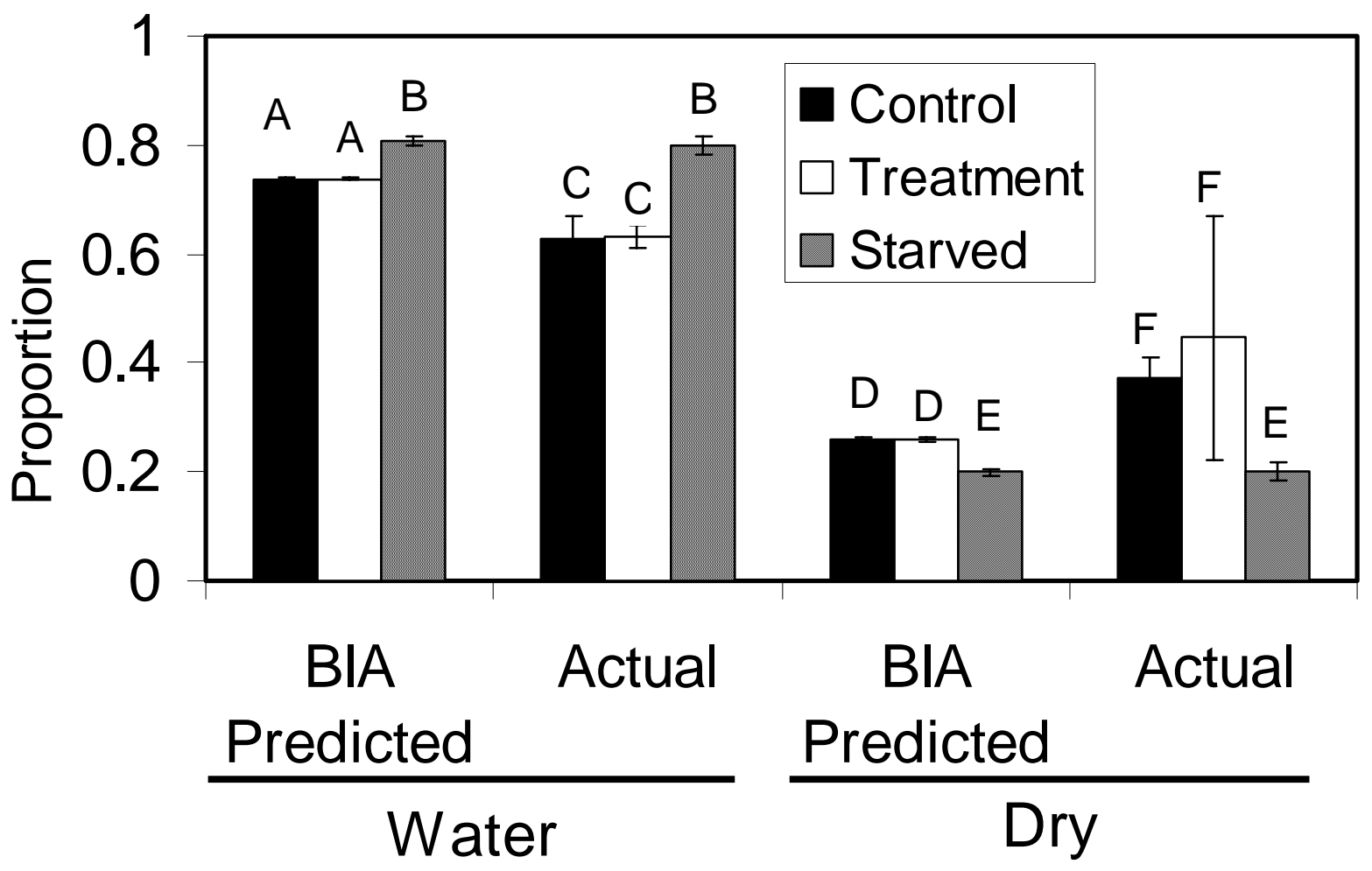

Figure 10. Mean predicted and observed energy densities obtained from calculations from bioelectrical impedance analysis (BIA) predictions and laboratory results of dry weight (DW). Dry weights (observed and predicted) were then used to estimate energy densities following methods in (Hartman and Brandt 1995b). 

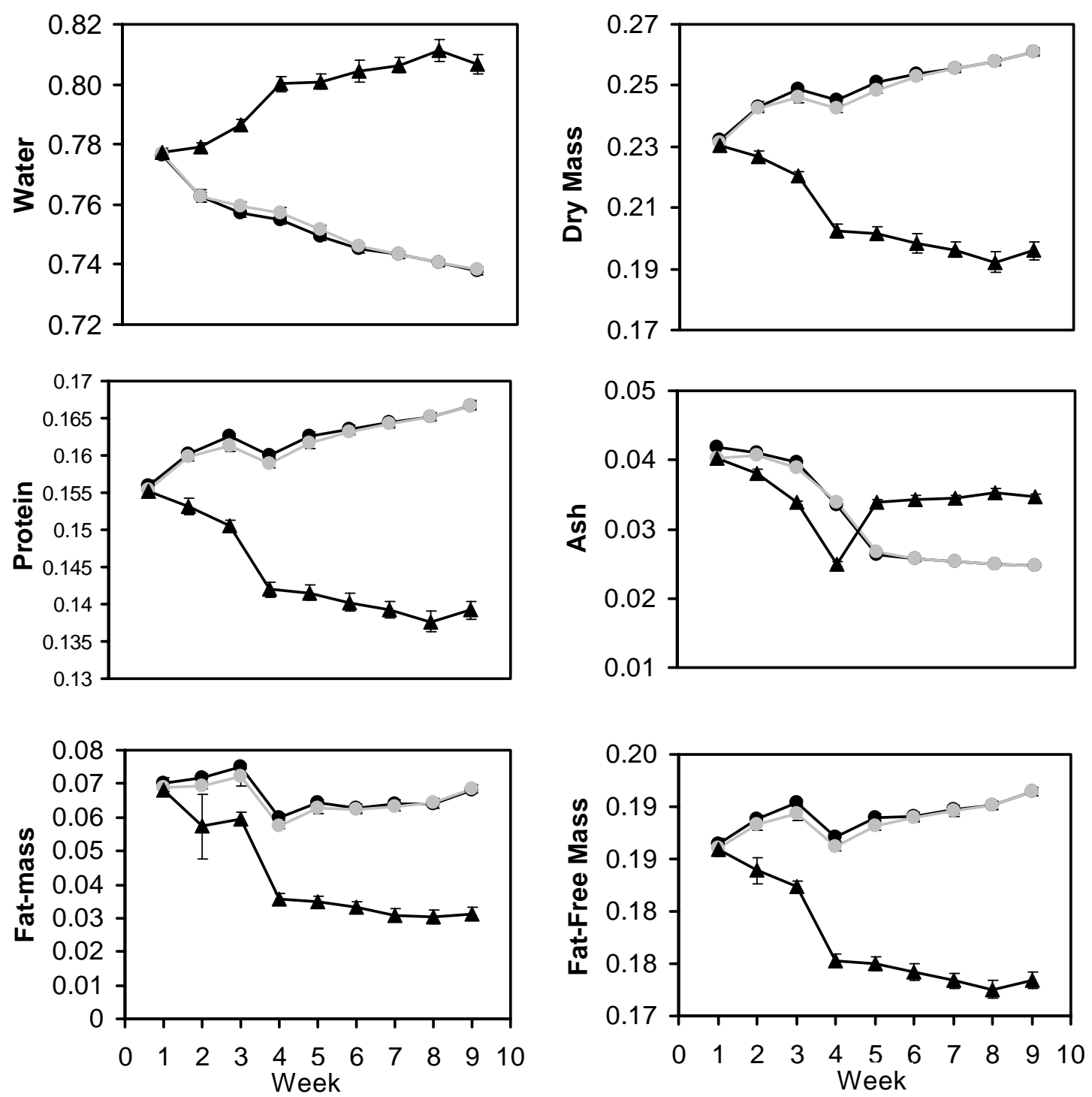

Figure 11. Weekly body composition measurements from bioelectrical

impedance analysis (BIA) starved $(\boldsymbol{\Lambda})$, treatment $(\bullet)$ and control $(\bullet)$ groups of brook trout over 57 days $(\mathrm{N}=8$ fish per group 


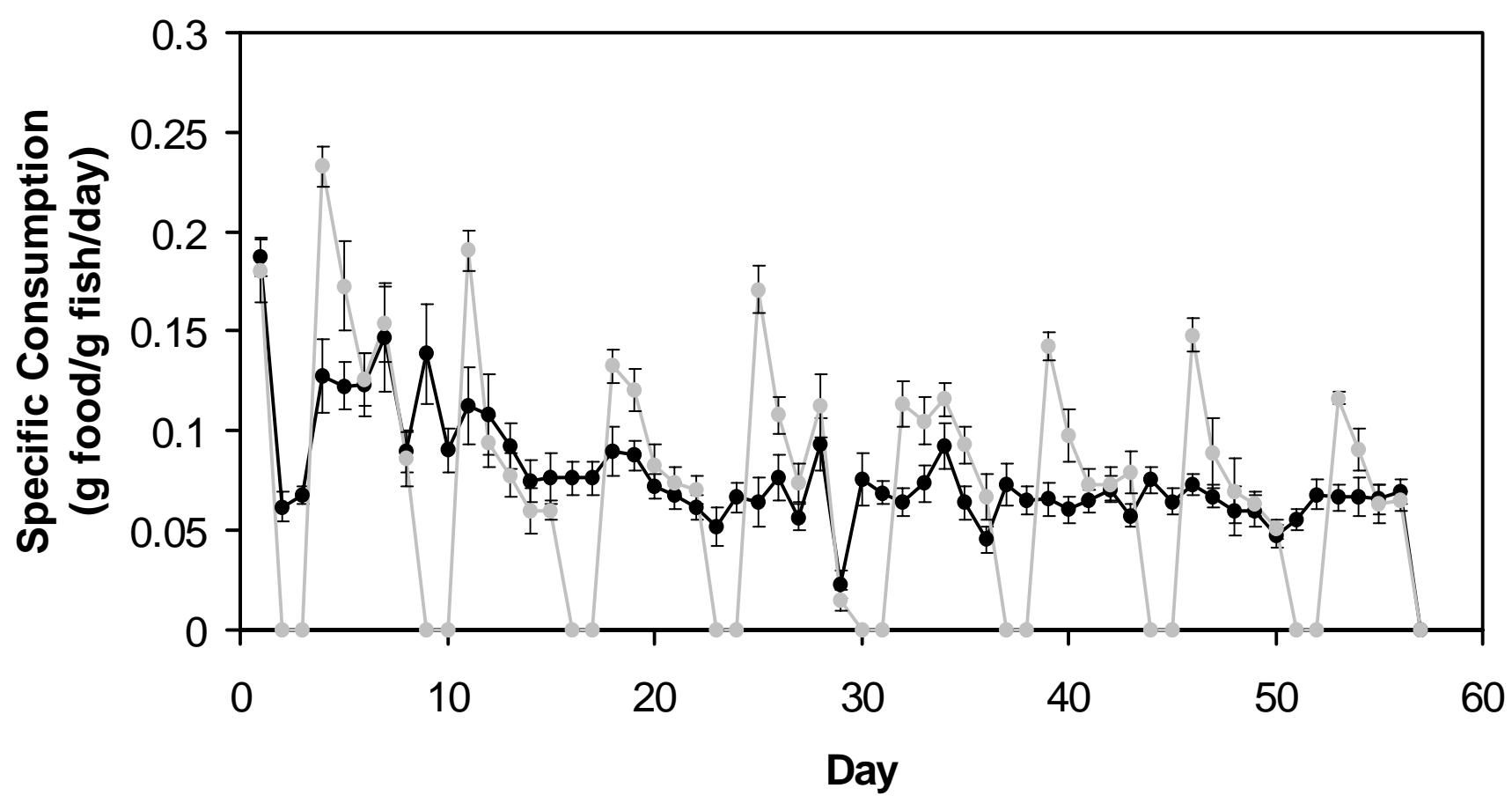

Figure 12. Daily specific consumption rates (food consumed $(\mathrm{g}) /$ weight fish $(\mathrm{g}) /$ day) of the treatment $(\bullet)$ and control $(\bullet)$ groups for the duration of the experiment $(\mathrm{N}=8$ fish per group). 


\section{Chapter 6. Conclusions}

\section{Overview}

Bioenergetics modeling is based on the first law of thermodynamics in that energy may be transferred through system boundaries with energy gains (consumption) being allocated to metabolism (respiration) and growth (somatic or reproductive), or lost through heat (SDA) and extrusion (egestion and excretion). The use of bioenergetics models is becoming an important tool in fisheries biology with fieldwork being done on a multitude of species. Prior to field testing, it has been suggested by several authors that bioenergetics models be laboratory tested under controlled environments with species specific variables (Brandt and Hartman 1993). Because bioenergetics models are based on energy transference, there is a need to accurately and precisely measure body composition in order to estimate energy content for energetic inputs (predator and prey) and outputs (predator growth). Methods to obtain body composition estimations usually require sacrificing the specimen, thus making multiple measures on the same individual over time, or measures on politically sensitive species impractical. The major areas of this work involve 1) bioenergetic model validation for brook trout and 2) exploration of a new method to non-lethally estimate body composition in fish.

\section{Bioenergetic model validation}

Brandt and Hartman (1993) suggested a three-tiered approach to bioenergetics model testing following the development of a bioenergetics model. These tiers include performing laboratory and field validations under controlled conditions prior to field work. During the development of a brook trout bioenergetics model, Hartman and Sweka 
(2001) noted an anomaly in the respiration measurements. When initial brook trout metabolic parameter measures in this study were compared, similar errors in metabolism were also noted. Errors were found when respiration rates decreased sharply at upper temperatures rather than increasing with temperature until a threshold is reached. It was thought that this may be due to the capture of some component of SDA from incomplete evacuation of stomach contents. Results from further experimentation by Sweka et al. (2004) determined that gastric evacuation rates were lower than expected. By ensuring that foodstuffs had passed through the gut at all temperatures, subsequent metabolic measures presented in Chapter 2 were found to increase as expected with temperature. Activity rates were solved for by rearranging the bioenergetics equations as Boisclair and Leggett (1989), and results demonstrated that variability was high within the group (1.3 to 2.9). Although this could have been due to differences in individual activity rates among fish, error could also have been within the other bioenergetics model parameters. Activity rates were solved for and adjusted to match observed values of growth and consumption. For this method to be valid, one must assume that the other parameters within the equation are accurate, which means that error resides only within the activity multiplier. If this is not true, and the other parameters are not accurate, all the error within each parameter are then summed into the activity multiplier. Simply solving for activity in the latter case in reality transforms the activity multiplier into a "fudge factor".

Aside from the aforementioned parameter measures, other problematic input variables are energy densities of the prey (foodstuff) and predator (fish). The energy density of the prey (i.e. consumed foodstuffs) is necessary to track energy allocations 
from consumed food into each of the various output compartments (i.e. growth, metabolism, egestion and excretion). The prey item used in this study (wax worm, Galleria mellonella) goes through 7 instars, and energy content varies with each instar (Finke 2002). Prey energy densities in most studies are obtained from published data such as Cummins and Wuycheck (1971), but the published data for wax-worms did not account for changes in energy density that may have occurred for different instars. To account for this problem, wax worm larvae were ordered in bulk and frozen, and subsamples were taken from the group and analyzed for energy density by bomb calorimetry. Energy density measures of the predator (fish) must also be obtained, but, for accuracy, these measures should be obtained at the beginning and end of the experiment. This approach accounts for energy allocated from the prey into growth of the predator. Current methods to estimate energy density include direct measures from bomb calorimetry (AOAC 1990), and indirect measures from percent water and body compositional measures (Hartman and Brandt 1995).(Craig et al. 1978) Both of these methods require sacrificing the organism. In order to obtain initial energy densities, subsamples of the validation group had to be sacrificed and measured. In Chapter 2, energy density values were measured from a sub-sampled group and were variable. The average of these values was then used to represent the validation group individuals, but because the sub-sampled group was variable, it assumed that the validation group individuals were just as variable. The final energy densities, on the other hand were obtained by sacrificing individual fish at the conclusion of the experiment and measuring energy density. This allowed final energy densities to be the actual values of each fish. 
The bioenergetics model for brook trout by Hartman and Sweka (2001) along with the refined metabolism parameters presented in Chapter 2 confirm that the model is a robust tool for estimating the consumption and growth of brook trout in a laboratory setting under controlled conditions. Problems encountered were the variability in the metabolism data and ACT multiplier, as well as determination of initial energy densities. Sacrificial energy density methods are achievable for prey and also for predators at the conclusion of the experiment, but what is needed is a method to measure individual energy density of the predators at the start of the experiment.

\section{Bioelectrical Impedance Analysis (BIA)}

Many studies use body composition in their work and must therefore employ several methods to obtain these values. A literature search of research using body compositional information resulted in a broad range of research that included human wasting disorders (Lukaski 1987; Corcoran et al. 2000), ecological fisheries research (Koskela et al. 1997; Lantry et al. 1999; Marshall et al. 1999), fisheries aquaculture (Einen et al. 1998; Hendry et al. 2000) and mammalian research (Lindstedt and Boyce 1985; Stanton et al. 1992). The methods used in each of these studies were dependent on the organism and type of study, but generally, methods could be categorized as direct or indirect. Direct methods involve sacrificing the animal and actually measuring each individual parameter of water, protein, fat and ash masses usually following methods found in the AOAC (1990). Aside from being sacrificial, these methods are lengthy, technical, time consuming and laboratory based. Indirect methods are based on mathematical relationships between initial parameter or zoometric measures and other unknown parameters. The initial parameter or zoometric measurements may be 
sacrificial such as dry and water weights used to estimate other parameters such as fat. Non-sacrificial methods include estimations for water using radioisotopes such as oxygen-18, fat-free mass using potassium-40 decay rates and zoometric measurements such as relative length weight indices (Lukaski 1987; Corcoran et al. 2000). Generally, these methods present a tradeoff of accuracy with expense and technical expertise. Other indirect methods include total body electrical conductivity (TOBEC) and bioelectrical impedance analysis (BIA) that use changes in electrical conductivity within the body to estimate body composition parameters (Lukaski 1987; Gallagher et al. 1991; Fischer et al. 1996a; Fischer et al. 1996b; Lockner et al. 1999; Corcoran et al. 2000). Lantry et al. (1999) found that the TOBEC method accurately estimates composition parameters for healthy individuals, but errors increase when subjects are undergoing weight or compositional changes, or when subjects with dissimilar body sizes are compared. Furthermore, the TOBEC unit is large and non-portable, making field studies impractical. BIA is available in an inexpensive, small, portable unit that has provided accurate and reliable estimations of water mass in humans, but as with the TOBEC, complex body geometries tend to decrease the accuracy of the composition estimations. In Chapter 3, BIA technology was applied to organisms with a more simplified body geometry (majority of the mass located in the a single volume), and if accuracy of measurements was not lost, proximate composition estimations could accurately and non-lethally be made.

To investigate BIA in fish, brook trout (Salvelinus fontinalis) were measured for bioelectrical impedance and sacrificed for analysis of total body proximate composition. Validation experiments were performed on a second group of brook trout and on 9 
species of warm water fishes. BIA estimations were derived from 3 measurements; resistance (measure of extra-cellular resistance), reactance (measurement of "celled" mass) and distance between detecting electrodes. Results showed that BIA can estimate body composition with a high degree of predictability $\left(\mathrm{R}^{2}>0.8507\right)$ in validation groups consisting of both the brook trout and warm water species. These three measurements predicted TBW, DW, FFM, TBP, TBA and TBF, and were obtained on live, anaesthetized organisms in about the time it would take to measure live weight. Additional experiments showed that BIA methods are non-lethal and appear to produce little measurable effect upon fish health or behavior. Furthermore, the strong linear relationships in the generality group portion of this study suggest that the brook trout model may predict compositional parameters for other organisms. This may be due to the similar geometric shapes found among the species of fish used in this study.

\section{BIA generality}

To test generality and usefulness of BIA, impedance values from 9 species of warm water fish were inserted into the brook trout model and predicted values were compared with actual values of dry, water and total weights of the fish. Predicted values were strongly correlated with observed values for all species, indicating that BIA models are general across different fish taxa. This is due to the similar compositional makeup of fish species as well as the similar shapes found among them. It may also be possible to take BIA generality a step further and test the generality not only with fish species, but also with amphibians, reptiles and some mammals. The brook trout models used here were tested for model generality and we conclude that general relationships observed for brook trout measured with BIA might work with other species. 


\section{BIA and field applicability}

Although BIA estimations were strongly correlated with actual values among several species of fish, the applicability of it was questioned in Chapter 4 due to possible electrical property shifts with temperature and repeated use. Hourly measurements significantly affected BIA estimations both within and between treatment and control groups of large and small fish, but differences were small (e.g. \% water range, 75.118 to 75.277\%) and largely due to the small standard errors (e.g. .00521) that were generated. Biologically these differences in \% water are not significant, but of course this depends on boundaries set by the researcher. The small standard errors of the estimates does suggest that BIA is a precise technique with a high degree of repeatability (Dowdy et al. 1991). The small differences that were found were probably due to the high frequency of punctures in the fish. Each puncture from the electrodes lyses cells and subsequently releases intra-cellular fluids that can affect impedance measurement.

In addition to puncture effects, significance differences were also found due to temperature effects. The model by Cox and Hartman (Chapter 2) was made at a controlled temperature of $15^{\circ} \mathrm{C}$, for BIA to be useful in the field, temperature effects must be considered. The electrical impedance of any homogenous substance varies almost linearly with temperature, so a change in temperature would cause an expected shift in the impedance values used in the model formation (Keller et al. 1993). This is exactly what happened with the impedance values, but interestingly, when data was normalized by weight (e.g. predicted mass / predicted wet weight), the temperature terms were canceled out resulting in similar proportion estimations over time (Chapter 4). Regardless of significance testing, mean differences due to repeated punctures and 
temperature were quite small and depending on the question at hand, may not be biologically significant.

\section{BIA and compensatory growth}

Due to the need to sacrifice animals, it has been previously impractical to use a repeated measures statistical design to compare compositional change in fish over time, but BIA can enable us to measure body composition repeatedly to study these energetic changes. A classic growth enigma is compensatory growth, and it is defined as an animal exhibiting higher growth and feeding rates when fed ad libitum following a period of no feed compared to an identical animal during normal growth (Johansen et al. 2001). Growth and consumption rates, growth efficiencies, and final weights are common measures for determination of a compensatory growth response. It would seem that body composition values should be included to verify that weight gains are energetic. To examine weight gains in fish exhibiting compensatory growth, compositional values from direct measures (AOAC 1990) and BIA predictions were used to determine body composition values. Results in Chapter 5 showed that dry and water weights were not significantly different between the control and treatment groups indicating that the weight gains in the compensatory group were energetic and not due to water weight gains. Other methods to indirectly measure energetic gains have been used in compensatory growth studies including body weight regressions (Johansen et al. 2001) and length per weight (Dobson and Holmes 1984), but body composition provides the best measure of energetic gains. In the current study, BIA proved to be a precise but inaccurate (when compared to laboratory results) method to determine compositional change. Although dry weight proportions were underestimated and water weight proportions were overestimated by 
BIA when compared to laboratory observations, BIA was useful however in mapping trends of relative compositional gains and losses over time especially by tracking changes over time for each individual fish in a repeated measures design.

\section{Summary}

Suggestions in Hartman and Brandt (1993) of a three tiered approach to bioenergetics model testing did direct our focus to parameters and external variables rather than results of the model. This approach provided some rational for reducing errors in some of the parameters and variables. Using prey items that are less energy dense than the predator could reduce error reduction in consumption. This will decrease the power of errors on model results. Prey items should also be very digestible to decrease variation in excretion/egestion rates. Metabolic responses were variable at all temperatures, and variability may be reduced by using a homogenous population of fish (i.e. all from the same hatchery brood stock) that have not been stressed or been through any type of experimental process. Ney (1993) points out that all external variables, such as energy densities used in the bioenergetics models, should be representative of the fish and prey items used in the models, and our experiments with BIA seem to hold promise in this area.

\section{References}

AOAC 1990. Official Methods of Analysis. Association of Official Analytical Chemists, Washington, DC. 
Boisclair, D. and Leggett, W.C. 1989. The importance of activity in bioenergetics models applied to actively foraging fishes. Can. J. Fish. Aq. Sci. 46: 1859-1867.

Brandt, S.B. and Hartman, K.J. 1993. Innovative approaches with bioenergetics models: Future applications to fish ecology and management. Trans. Am. Fish. Soc. 122: $731-735$.

Corcoran, C., Anderson, E.J., Burrows, B., Stanley, T., Walsh, M., Poulos, A.M., and Grinspoon, S. 2000. Comparison of total body potassium with other techniques for measuring lean body mass in men and women with AIDS wasting. Am. J. Clin. Nutr. 72: 1053-1058.

Craig, J.F., Kenley, M.J., and Talling, J.F. 1978. Comparative estimations of the energy content of fish tissue from bomb calorimetry, wet oxidation and proximate analysis. Fresh. Biol. 8: 585-590.

Cummins, K.W. and Wuycheck, J.C. 1971. Caloric equivalents for investigations in ecological energetics. Mitteilungen der Internationalen Vereinigung fur theoretische und angewandte Limnologie 18.

Dobson, S.H. and Holmes, R.M. 1984. Compensatory growth in the rainbow trout, Salmo gairdneri Richardson. J. Fish. Biol. 25: 649-656.

Dowdy, S. and S. Wearden 1991. Statistics for research. John Wiley and Sons, New York.

Einen, O., Waagan, B., and Thomassen, M.S. 1998. Starvation prior to slaughter in Atlantic salmon (Salmo salar) I. Effects on weight loss, body shape, slaughterand fillet-yield, proximate and fatty acid composition. Aqua. 166: 85-104.

Finke, M.D. 2002. Complete nutrient composition of commercially raised invertebrates 
used as food for insectivores. Zoo Biol. 21: 269-285.

Fischer, R.U., Congdon, J.D., and Brock, M. 1996a. Total body electrical conductivity (TOBEC): a tool or estimate lean mass and nonpolar lipids of an aquatic organism? Copeia. 2: 459-462.

Fischer, R.U., Congdon, J.D., and Brock, M. 1996b. Total body electrical conductivity (TOBEC): a tool to estimate lean mass and nonpolar lipids of an aquatic organism? Copeia. 2: 459-462.

Gallagher, M.R., Rutishauser, H.E., and O'Dea, K. 1991. A comparison of four methods of body composition analysis. Proc-Nutr-Soc-Aust. South Perth, WA: The Society. 16: 41 .

Hartman, K.J. and Brandt, S.B. 1995. Estimating energy density of fish. Trans. Am. Fish. Soc. 124: 347-355.

Hartman, K.J. and Sweka, J.A. 2001. Development of a bioenergetics model for Appalacian Brook Trout. Proc. Annu. Conf. S.E.A.F.W.A. 55: 38-51.

Hendry, A.P., Dittman, A.H., and Hardy, R.W. 2000. Proximate Composition, Reproductive Development, and a Test for Trade-Offs in Captive Sockeye Salmon. Trans. Am. Fish. Soc. 129: 1082-1095.

Johansen, S.S., Ekli, M., Stangnes, B., and Jobling, M. 2001. Weight gain and lipid deposition in Atlantic salmon, Salmo salar, during compensatory growth: evidence for lipostatic regulation? Aqua. Res. 32: 963-974.

Keller, F.J., E.W. Gettys, and M.J. Skove 1993. Physics. McGraw-Hill, New York. Koskela, J., Pirhonen, J., and Jobling, M. 1997. Effect of low temperature on feed intake, growth rate and body composition of juvenile Baltic salmon. Aqua. Int. 5: 479- 
488.

Lantry, B.F., Stewart, D.J., Rand, P.S., and Mills, E.L. 1999. Evaluation of total-body electrical conductivity to estimate whole-body water content of yellow perch, Perca flavescens, and alewife, Alosa pseudoharengus. Fish. Bull. 97: 71-79.

Lindstedt, S.L. and Boyce, M.S. 1985. Seasonality, fasting endurance and body size in mammals. Am. Nat. 125: 873-878.

Lockner, D.W., Heyward, V.H., Griffin, S.E., Marques, M.B., Stolarczyk, L.M., and Wagner, D.R. 1999. Cross-validation of modified fatness-specific bioelectrical impedance equations. Int. J. Sprts. Nut. 9: 48-59.

Lukaski, H.C. 1987. Methods for the assessment of human body composition: traditional and new. Am. J. Clin. Nutr. 46: 537-556.

Marshall, C.T., Yaragina, N.A., Lambert, Y., and Kjesbu, O.S. 1999. Total lipid energy as a proxy for total egg production by fish stocks. Nature. 402: 288-290.

Ney, J.J. 1993. Bioenergetics modeling today: Growing pains on the cutting edge. Trans. Am. Fish. Soc. 122: 736-748.

Stanton, C.A., Hamar, D.W., Johnson, D.E., and Fettman, M.J. 1992. Bioelectrical impedance and zoometry for body composition analysis in domestic cats. Am. J. Vet. Res. 53: 251-257.

Sweka, J.A., Cox, M.K., and Hartman, K.J. 2004. Gastric Evacuation Rates of Brook Trout. Trans. Am. Fish. Soc. 133: 204-210. 